\title{
Development and implementation of a novel voltage-free interface for capillary electrophoresis-mass spectrometry separations of proteins
}

\author{
Courtney J. Kristoff \\ West Virginia University, ck0031@mix.wvu.edu
}

Follow this and additional works at: https://researchrepository.wvu.edu/etd

Part of the Analytical Chemistry Commons

\section{Recommended Citation}

Kristoff, Courtney J., "Development and implementation of a novel voltage-free interface for capillary electrophoresis-mass spectrometry separations of proteins" (2020). Graduate Theses, Dissertations, and Problem Reports. 7853.

https://researchrepository.wvu.edu/etd/7853

This Thesis is protected by copyright and/or related rights. It has been brought to you by the The Research Repository @ WVU with permission from the rights-holder(s). You are free to use this Thesis in any way that is permitted by the copyright and related rights legislation that applies to your use. For other uses you must obtain permission from the rights-holder(s) directly, unless additional rights are indicated by a Creative Commons license in the record and/ or on the work itself. This Thesis has been accepted for inclusion in WVU Graduate Theses, Dissertations, and Problem Reports collection by an authorized administrator of The Research Repository @ WVU. For more information, please contact researchrepository@mail.wvu.edu. 
Development and implementation of a novel voltage-free interface for capillary electrophoresis-mass spectrometry separations of proteins

\author{
Courtney J. Kristoff
}

Thesis submitted to the Eberly College of Arts and Sciences at West Virginia University in partial fulfillment of the requirements for the degree of Master of Science in Chemistry

\author{
Lisa A. Holland, Ph.D., Chair \\ Stephen J. Valentine, Ph.D. \\ Peng Li, Ph.D.
}

Department of Chemistry

Morgantown, West Virginia

2020

Keywords: capillary electrophoresis, mass spectrometry, interface, ionization, $\beta$-blocker, peptide, protein

Copyright 2020 Courtney J. Kristoff 
Development and implementation of a novel voltage-free interface for capillary electrophoresis-mass spectrometry separations of proteins

\author{
Courtney J. Kristoff
}

Capillary electrophoresis-mass spectrometry is a powerful technique for high-throughput and high efficiency separations combined with structural identification. Electrospray ionization is the primary interface used to couple capillary electrophoresis to mass analyzers; however, improved designs continue to be reported. A new interfacing method based on vibrating sharp-edge spray ionization is presented in this work to overcome the challenges of decoupling applied voltages and to enhance the compatibility with separations performed at near-neutral $\mathrm{pH}$. The versatility and ease of use of this ionization source is demonstrated using $\beta$-blockers, peptides, and proteins. The cationic $\beta$-blocker pindolol was injected electrokinetically and detected at concentrations ranging from $10 \mathrm{nM}$ to $5 \mu \mathrm{M}$, with an estimated detection limit of $2 \mathrm{nM}$. The vibrating sharp-edge spray ionization functions with flow rates from 70 to $200 \mathrm{~nL} / \mathrm{min}$ and did not perturb the capillary electrophoresis separation electroosmotic flow as evidenced by the observation that most migration times differed less than $7 \%(n=3)$ across a lab-built system interfaced to mass spectrometry and a commercial system that utilizes absorbance detection. For cationic $\beta$ blockers the theoretical plates achieved in the capillary electrophoresis-mass spectrometry setup were $80 \%$ to $95 \%$ of that observed with a commercial capillary electrophoresis-UV absorbance detection system. 


\section{Acknowledgements}

Some text and figures in this work are reproduced and/or adapted with permission from Kristoff, C. J.; Li, C.; Li, P.; Holland, L. A. Anal. Chem. 2020, 92, 3006-3013. Copyright 2020 American Chemical Society.

Contributions to the work in this Thesis are as follows:

Courtney J. Kristoff: CE capillary fabrication, CE-VSSI alignment, CE-UV analyses (all), CEVSSI-MS analyses (all), data processing and interpretation, figure elements, writing/editing

Chong Li: VSSI probe fabrication, CE-VSSI alignment, CE-VSSI-MS analyses ( $\beta$ blockers/peptides)

Peng Li, Ph.D.: conceptualization, methodology, supervision, project administration, funding acquisition

Lisa A. Holland, Ph.D.: conceptualization, methodology, validation, writing/editing, figure elements, supervision, project administration, funding acquisition

I and the other contributors gratefully acknowledge Stephen J. Valentine, Ph.D. for insightful discussions on ionization.

Research reported in this report was supported by the National Institute of General Medical Sciences of the National Institutes of Health under Award Number P41GM128577. 
Table of Contents

Abstract ......................................................................................................................

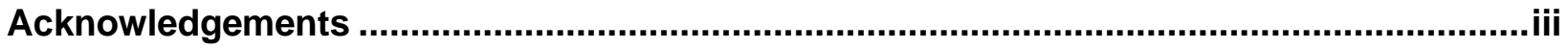

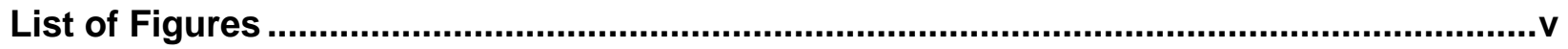

List of Tables................................................................................................................................ vii

List of Symbols and Abbreviations .....................................................................................ii

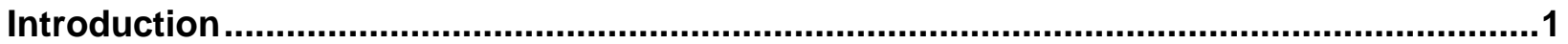

Experimental Details and Theoretical Analysis .................................................................

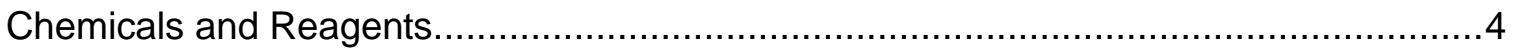

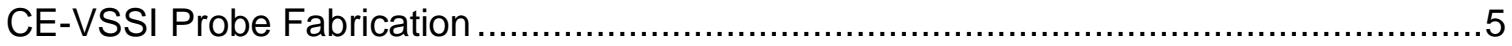

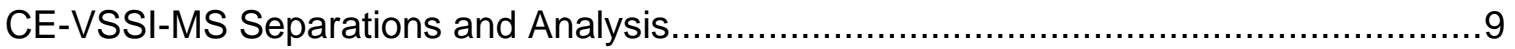

CE-UV Separations and Analysis ...................................................................... 12

Capillary Treatment and Run Conditions ........................................................ 12

Current Results and Discussion .....................................................................................12

Interface Design and Implementation ............................................................ 12

Evidence of Acoustic Driven Spray .............................................................

Separation and Detection with CE-VSSI-MS Compared to CE-UV at pH 5..................16

Separation and Detection with CE-VSSI-MS Compared to CE-UV at $\mathrm{pH} 6.5 \ldots \ldots \ldots \ldots \ldots . . . .18$

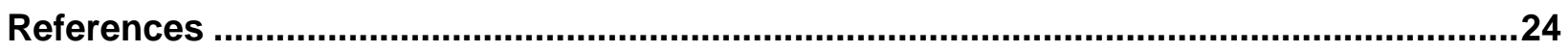

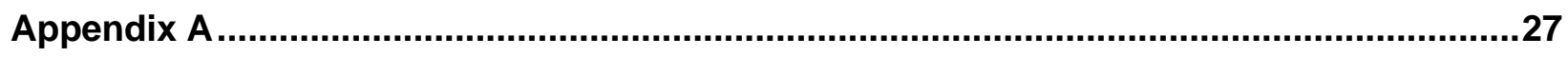

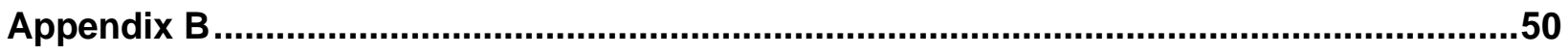

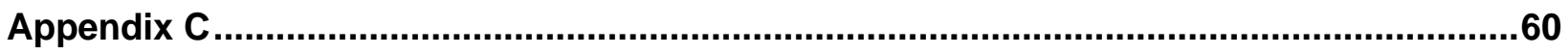




\section{List of Figures}

\section{Experimental Details and Theoretical Analysis}

Figure 1. Diagram for capillary fabrication ......................................................

Figure 2. Diagram for capillary and probe alignment.............................................. 7

Figure 3. Comparison of good and bad devices..................................................... 8

Figure 4. Image of lab-built instrument.................................................................

\section{Current Results and Discussion}

Figure 5. Concept diagram and image of CE-VSSI device.....................................13

Figure 6. Demonstration that ionization starts and stops with acoustics.....................14

Figure 7. Figures of merit and optimization studies for CE-VSSI-MS .........................15

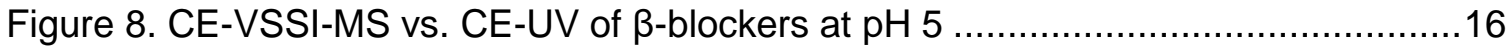

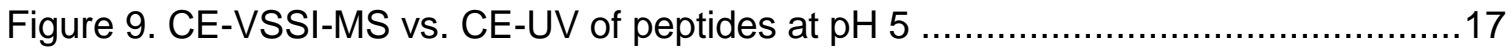

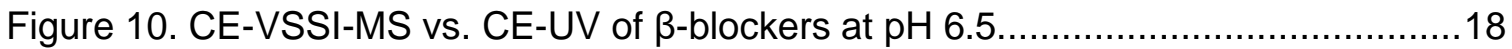

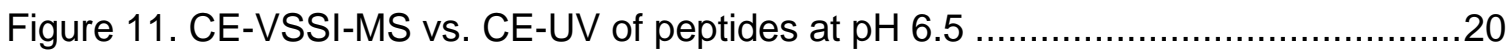

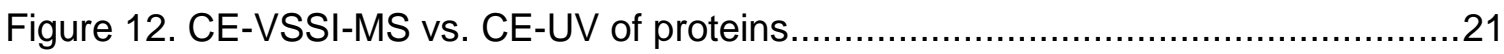

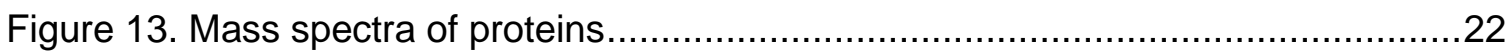

\section{Appendix A}

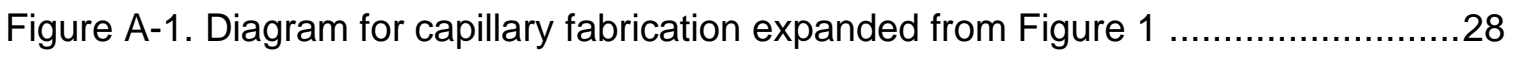

Figure A-2. Diagram for capillary and probe alignment expanded from Figure 2..........29

Figure A-3. Comparison of flow rates with pressure and voltage ...............................30

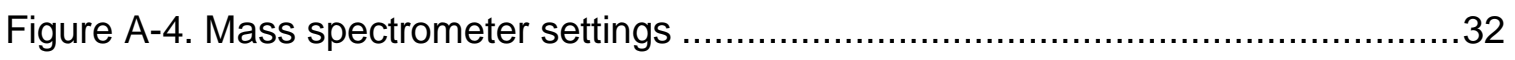

Figure A-5. Effect of siphoning on $\beta$-blockers separations ..................................... 33

Figure A-6. Example of contamination in CE-VSSI-MS analysis ..................................34

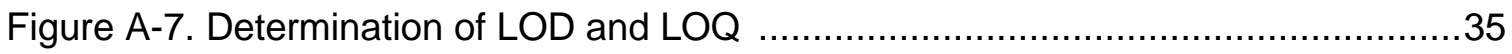

Figure A-8. Comparison of electrokinetic and hydrodynamic injections.......................36

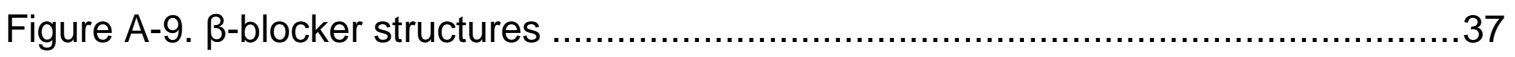

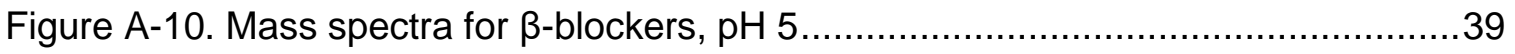

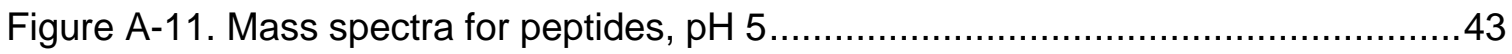

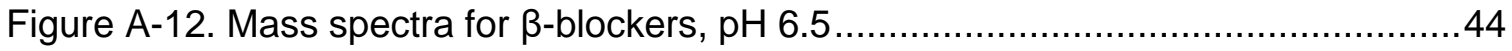

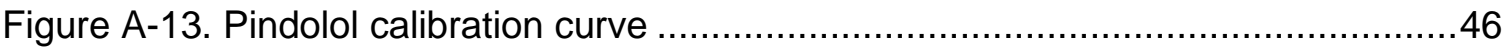

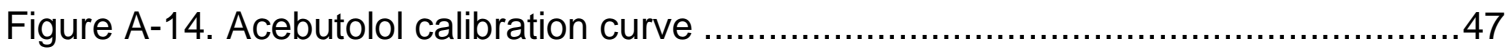

Figure A-15. Mass spectra for peptides, pH 6.5 ...................................................... 49 


\section{Appendix B}

Figure B-1. Instrumental differences of CE-UV and CE-MS .....................................51

Figure B-2. Separation of $\beta$-blockers and peptides (CE-UV) .....................................52

Figure B-3. Capillary stability after sitting in buffer ..............................................54

Figure B-4. Effect of ionic strength on trypsin inhibitor and ubiquitin adsorption.............57

Figure B-5. Effect of ionic strength on ribonuclease $A$ adsorption .............................58

Figure B-6. Mass spectra for ribonuclease A ………...........................................59 


\section{List of Tables}

\section{Appendix A}

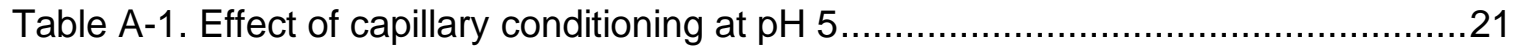

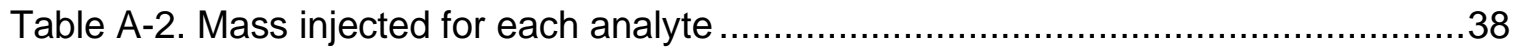

Table A-3. Migration time at pH 5 (CE-VSSI-MS vs CE-UV) .....................................40

Table A-4. Separation efficiency at pH 5 (CE-VSSI-MS vs CE-UV) .............................41

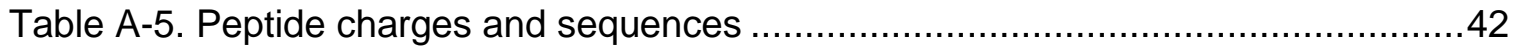

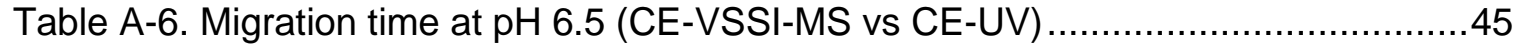

Table A-7. Separation efficiency per meter at pH 6.5 (CE-VSSI-MS vs CE-UV) ...........48

\section{Appendix B}

Table B-1. Migration time stability at $\mathrm{pH} 6.5$ .53

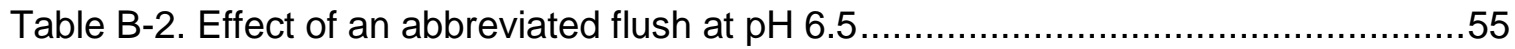

Table B-3. Effect of voltage, flow rate, and $\mathrm{pH}$ on ionization ......................................56

\section{Appendix C}

Table C-1. Raw data for capillary conditioning with normal flush ..............................61

Table C-2. Raw data for capillary conditioning with $0.1 \mathrm{~N} \mathrm{NH} 4 \mathrm{OH}$ flush ......................62

Table C-3. Raw data for capillary conditioning with $1 \mathrm{~N} \mathrm{NH} 4 \mathrm{OH}$ flush ........................63

Table C-4. Raw data for capillary conditioning with buffer flush ...............................64

Table C-5. Raw data for capillary conditioning with $\mathrm{HCl}$ flush ...................................65

Table C-6. Raw data for migration times and efficiencies with abbreviated flush ..........66

Table C-7. Raw data for migration times and efficiencies with full flush ......................67 


\section{List of Symbols and Abbreviations}

\begin{tabular}{|c|c|}
\hline CE & capillary electrophoresis \\
\hline $\mathrm{Da}$ & Dalton \\
\hline EK & electrokinetic \\
\hline EOF & electroosmotic flow \\
\hline $\mathrm{EPH}$ & electrophoretic mobility \\
\hline ESI & electrospray ionization \\
\hline i.d. & inner diameter \\
\hline $\mathrm{kDa}$ & kilodalton \\
\hline $\mathrm{kHz}$ & kilohertz \\
\hline $\mathrm{kPa}$ & kilopascal \\
\hline $\mathrm{kV}$ & kilovolt \\
\hline LOD & limit of detection \\
\hline $\mathrm{LOQ}$ & limit of quantification \\
\hline $\mathrm{m} / \mathrm{z}$ & mass-to-charge ratio \\
\hline MS & mass spectrometry \\
\hline$m V_{p p}$ & millivolt peak-to-peak \\
\hline o.d. & outer diameter \\
\hline $\mathrm{OH}^{-}$ & hydroxide \\
\hline psi & pounds per square inch \\
\hline UV & ultraviolet \\
\hline V & volt \\
\hline SSI & vibrating sharp-edge spray ionization \\
\hline$\mu \mathrm{A}$ & microampere \\
\hline
\end{tabular}




\section{INTRODUCTION}

Capillary electrophoresis (CE) is a powerful technique for chemical analyses due to its ability to achieve high-efficiency separations and high throughput analyses. ${ }^{1-3}$ Mass spectrometry (MS) coupled to CE through electrospray ionization (ESI) enhances CE separations because it provides structural identification of samples available in limited volumes. These attributes of CEMS have been leveraged for remarkable applications ${ }^{4}$ including the detection of highly complex samples, ${ }^{5-8}$ analyses of clinical samples available in limited volumes, ${ }^{9,10}$ single cell proteomics ${ }^{11}$ and metabolomics, ${ }^{12-14}$ identification of unprecedented numbers of proteins and proteoforms, ${ }^{6,15-}$ 19 and unambiguous analyses of the next generation of biological therapeutics. ${ }^{20-23}$

Since the initial configuration of CE-MS, ${ }^{24,25}$ these new instrumental approaches which have been used to achieve these CE-ESI-MS analyses include sheath flow and sheathless interfaces. Sheathless interfaces do not cause sample dilution because the background electrolyte is the only liquid in the system, ${ }^{26}$ but require an effective method of current decoupling and must deliver stable electrospray at sub-microliter flow rates. ${ }^{4}$ Sheathless designs decouple the separation and electrospray currents through a porous region fabricated at the CE capillary ${ }^{27}$ or custom-fabricated to incorporate other designs ${ }^{28}$ including tapering. ${ }^{13}$ Sheath flow interfaces address the low flow problem by augmenting the existing electroosmotic flow. ${ }^{24}$ The sheath flow system must be appropriately designed and implemented to avoid analyte dilution which diminishes the sensitivity of the measurements. ${ }^{4}$ Coaxial hydrodynamic sheath flow at low flow rates has been described to assist in electrospray and in decoupling with no observed sample dilution. ${ }^{29-32}$ An alternative approach for current decoupling utilizes an electrokinetically delivered sheath flow, in which the liquid used as the coaxial sheath is delivered from a microvial. ${ }^{33-35}$ Hybrid designs allow the interface type to be switched between nanosheath and a porous frit. ${ }^{36}$ Commercial systems are available based on microfluidic electrophoresis, ${ }^{37-41}$ sheathless capillaries with integrated porous tips, ${ }^{27}$ and microvial sheath flow interfaces that are coupled to separation capillaries. ${ }^{42}$

Though electrospray ionization has proven its value time and time again for the analysis of large biomolecules, that doesn't mean that it comes without flaws. The sheathless design of the porous frit overcomes the barrier of sample dilution but presents users with a new set of problems. They are expensive to purchase, only available in a limited number of sizes, and have a limited lifetime because it is prone to clogging. A commercial capillary costs approximately $\$ 1700$ and is typically only available in $30 \mu \mathrm{m}$ i.d. and $90 \mathrm{~cm}$ in length to fit in the commercial CEESI system ${ }^{43}$. In addition, researchers have reported a limited lifetime on the capillaries due to the small, tapered i.d. becoming clogged with analyte ${ }^{13}$. They are also not user-friendly to 
fabricate in lab as the etching process to obtain a porous region requires the use of dangerous hydrofluoric acid.

Another set of problems arises with the requirement for a conductive liquid and conductive liquid capillary. This is an important aspect of helping to maintain an electrical connection for the ESI circuit since there is no longer a sheath liquid. With this requirement, an additional capillary is necessary to hold the conductive liquid and incorporate it into the porous region of the capillary. An additional capillary also means additional flushing protocols, which are already fairly extensive $^{44}$. Another component of the hardware that complicates matters is that electrospray ionization, when coupled to capillary electrophoresis, requires two independent voltage systems. One system is employed for the separation, while the other is used to control the electrospray.

Operational disadvantages of the system include difficulty or inability to perform electrokinetic injections, breakdown of certain analytes that are sensitive to high electric fields ${ }^{45}$, and a limited range of operational $\mathrm{pH}$ and flow rates. Electrokinetic (EK) injections are the preferred method of sample introduction for capillary electrophoresis separations, but the rapid increase and decrease in applied voltages can damage the porous region of the capillary. For this reason, hydrodynamic injections are typically performed. Also, some analytes undergo unwanted and unforeseen changes when they encounter a high electric field. This can complicate analyses and make the observation of some molecules impossible with ESI. Additionally, most commercialized systems are operated at highly acidic $\mathrm{pH}$ values (i.e. $\mathrm{pH} \sim 2$ ), which leads to two additional drawbacks. At this low $\mathrm{pH}$, there is essentially no electroosmotic flow in the capillary due to charge suppression on the capillary surface, meaning longer analysis times and these super acidic $\mathrm{pH}$ values are not compatible with native state protein and biomolecule analysis.

ESI interfaces continue to evolve with the goal of simplifying CE-MS, improving performance, decreasing cost, and increasing accessibility of this powerful technique. A recent and exciting advance in ionization for MS is based on vibrating sharp-edge spray ionization (VSSI). The use of VSSI as a novel ionization source for mass spectrometry has been demonstrated for small molecules, carbohydrates, peptides, and proteins. ${ }^{46,47}$ VSSI requires no voltage application or nebulization gas making it ideal for portable applications. Thus far, this acoustic method of spray generation is compatible with flow rates ranging from $1-1000 \mu \mathrm{L} / \mathrm{min}$ and has been used for direct infusion or in combination with separation techniques such as HPLC. ${ }^{47}$ Although successfully implemented at higher flow rates, VSSI has not previously been adapted to sub-microliter flow rates that occur with capillary electrophoresis.

The technique presented in this paper, capillary electrophoresis-vibrational sharp-edge spray ionization-mass spectrometry (CE-VSSI-MS) offers a unique alternative to electrospray 
ionization that overcomes the practical barriers associated with the latter method, explained further in the following paragraphs. The VSSI source utilizes an acoustic wave to vibrate a glass coverslip to which the glass probe is affixed. When the probe vibrates against the end of the separation capillary, the background electrolyte fluid is converted into tiny droplets that are directed into the mass spectrometer.

The VSSI device addresses many of the problems associated with a sheathless porous frit design. Any regular capillary can be utilized in the device and the vibrational probe setup only requires a glass microscope slide, piezoelectric transducer, and pulled glass capillary. Because of this, the expensive commercial capillary used for ESI can be fabricated for just a few dollars in the case of VSSI. In addition to the low cost of the device, the equipment needed to generate spray-inducing vibrations (a waveform generator and amplifier) can also be purchased for a couple hundred dollars. Since the end of this capillary is not tapered like commercial capillaries for ESI, clogging is rarely an issue so capillaries can be reused several times. Another huge benefit in the fabrication of the VSSI device is that there are no major safety concerns. No etching is required so the only danger is in the applied voltage when using the device.

All of the issues related to the conductive liquid and additional capillary and voltage supply that are required for ESI are eliminated because the only capillary involved is the one used for the CE separation. This simplifies the entire set up as well as the electrical connections since there is only one power supply to operate the CE separation.

Many of the disadvantages in the operation of CE-ESI are no longer problematic because any normal CE capillary can be used. Due to the lack of a porous region, EK injections are possible and there is no need to slowly ramp up or down the voltage during an injection or separation. Additionally, no ESI voltage is used so those analytes that may be sensitive to high electric fields will not be affected by the VSSI. Finally, as many researchers are moving toward native-state protein analysis, the VSSI device is compatible with any $\mathrm{pH}$ buffer since it is affected by the flow rate of the solution, not the amount of charges present in it.

To fully understand the advantages of VSSI over ESI, a few fundamental concepts of capillary electrophoresis must be explained. In capillary electrophoresis, there are two primary methods of sample introduction: electrokinetic and hydrodynamic injections. While they both serve their purpose, EK injections are more common. A voltage is applied to the capillary, which causes analytes to move into the capillary via electroosmotic flow and electrophoretic mobility. This type of injection allows a tight band of analyte to be introduced into the capillary, increasing the plate counts once these analytes are detected. A hydrodynamic injection uses pressure to force the analyte into the capillary and this introduces another type of flow, called laminar flow. 
This parabolic flow decreases the plate counts due to widening the initial peak introduced into the capillary.

The two methods of transport within a CE capillary are electroosmotic flow (EOF) and electrophoretic mobility (EPH). The EOF is determined by the charge on the capillary surface and the electric field. The charge of the surface is largely dependent on the $\mathrm{pH}$ of the background electrolyte. At low $\mathrm{pH}$ values (i.e. $\mathrm{pH}<4$ ), the exposed silica on the surface is mostly protonated so the EOF is very slow and almost non-existent so the separation depends almost solely on the $\mathrm{EPH}$ of the analytes, making migration times fairly long. The EPH of the analyte is simply how it moves under an applied electric field and depends on the charge and the size of the analyte. Larger analytes move slower, while smaller ones move faster and those with higher charges move faster than others with less of a charge. A scenario that is often seen with CE-ESI-MS analyses that are typically done at low $\mathrm{pH}$ is that the deprotonated surface does not lend itself well to the simultaneous separation of cationic and anionic analytes because when only the EPH is at play, only one type of ion will be detected determined by the polarity of the separation.

Beyond the low cost, extraordinary portability, and flexible coupling at a wide range of flow rates, several features of VSSI offer promising advantages to future implementation of the method. In particular, the source achieves efficient ionization in deionized water and high ionic strength buffers equally well in the presence and absence of organic solvents typically required to assist in the electrospray process. ${ }^{46,47}$ Given the persistent design improvements reported for CE-MS interfacing and the advantages of VSSI, a demonstration of proof-of-principle of coupling CE-VSSI-MS is fundamental to realizing applications of separations systems that benefit from attributes of this voltage-free interfacing to CE. This work describes the implementation of a CEVSSI-MS device with a lab-built instrument and demonstrates functionality of CE-VSSI. Barefused silica separations of $\beta$-blockers were completed with different volatile background electrolytes with $\mathrm{pH}$ values ranging from $\mathrm{pH} 5$ to 10 to compare separation efficiency and migration times between a traditional UV system and the MS system. The effects of ionic strength and flow rate were investigated as well. Beyond this characterization with small cationic molecules, the interface was applied to peptide and protein separations achieved with a bare fused silica capillary and ammonium acetate background electrolyte maintained at a pH of 6.5.

\section{EXPERIMENTAL DETAILS AND THEORETICAL ANALYSIS}

Chemicals and Reagents. Ammonium acetate (73594), acetic acid (A6283), pindolol (P0778), acebutolol (A-3669), soybean trypsin inhibitor (T9128) and ubiquitin (U6253) were purchased from Millipore Sigma (Burlington, MA). Ammonium hydroxide (44273) was purchased 
from Fisher Scientific (Waltham, MA). Somatostatin and oxytocin were purchased from American Peptide (Sunnyvale, CA). Deionized water was filtered with an Elga Purelab ultra water system (Lowell, MA). Solutions were filtered using $0.45 \mu \mathrm{m}$ PTFE filters (VWR).

CE-VSSI Probe Fabrication. Fused silica capillary $(50 \mu \mathrm{m}$ i.d., $365 \mu \mathrm{m}$ o.d., Polymicro Technologies, Phoenix, AZ) was cut to a length of $40 \mathrm{~cm}$ and $0.5 \mathrm{~cm}$ of the polyimide coating was burned off the outside on both ends. The ends were checked under a microscope for clean, straight cuts. A $25 \mu \mathrm{m}$ platinum wire (PT005113, Goodfellow, Huntingdon, England) was cut to approximately $1 \mathrm{~cm}$ in length and bent at two $90^{\circ}$ angles in a "U" shape. This wire was maintained across the front orifice of the capillary using a small amount of 1-minute epoxy (1366072, Henkel, Düsseldorf, Germany). A thicker wire cut to about $5 \mathrm{~cm}$ was attached to the thinner wire via conductive epoxy (8331-14G, MG Chemicals, Ontario, Canada) to create an electrical connection (Fig 1). After the conductive epoxy cured, it was covered with an additional layer of 1-minute epoxy (1366072, Henkel) for mechanical stability and to insulate the connection. The end of the larger wire was soldered with a drop of lead solder. Capillaries were allowed to cure completely before they were aligned with the VSSI spray probe.

An important detail to successfully creating a capillary with an integrated electrode that can be used for alignment with the VSSI probe is how the electrode is positioned when it is affixed. As explained in later paragraphs, the VSSI probe should be parallel to the electrode for the best chances of success without the electrode breaking. However, making this occur can be more difficult than it seems. The best approach to ensuring a seamless alignment process is to attach the longer wire to the side of the capillary closest to the person fabricating it. If it is attached in this manner, the capillary (and electrode) can be flipped 180 when the alignment process begins and the resulting arrangement is that the electrode and spray probe are typically parallel. Also, it should be noted that the $25 \mu \mathrm{m}$ platinum wire should be flush against the front of the capillary.

Another important tip is to be mindful of the 1-minture epoxy consistency when using it to hold the platinum in place or wrap the capillary for insulation. The epoxy should be mixed until it reaches a sticky, stringy, taffylike consistency. At this point, an unfolded paper clip was used to scoop up a glob of epoxy and the thin, wispy strings were wrapped around the capillary (Fig 1, Fig A-1), being careful to not let the epoxy near or in the

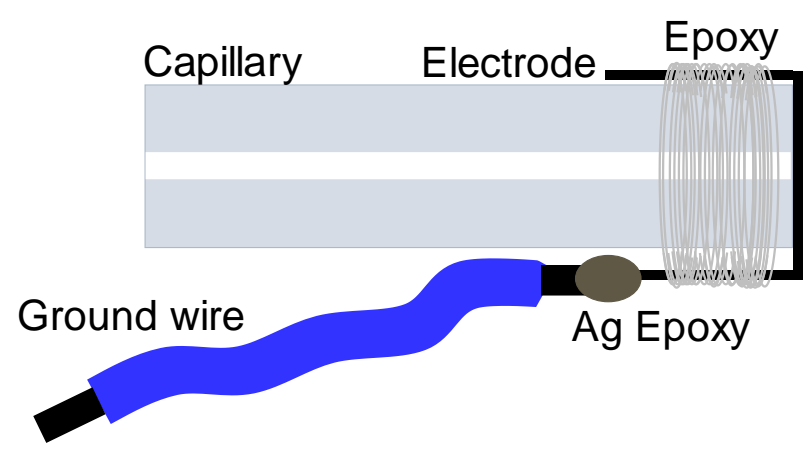

Figure 1. Diagram for capillary fabrication. Gray loops at the end of the capillary represent 1 minute epoxy while the brown oval on the ground wire is conductive silver epoxy. 
orifice of the capillary. If the epoxy is too liquid-like, it is difficult to make it stick and hold the electrode in place, while mixing it too long turns it into a solid. Once the desired consistency is reached, there is approximately a 30 second window that it can be handled before it is too hard.

To fabricate the VSSI spray probes, a P-2000 capillary puller (Sutter Instrument Company, Novato, CA) was used to pull $75 \mathrm{~mm}$ long capillaries with an i.d. of $0.4 \mathrm{~mm}(\# 1-000-800 / 12$ Drummond Scientific Company, Broomall, PA). Parameters used were: HEAT/FIL/VEL/DEL/PUL $=700 / 4 / 55 / 200 / 175$. A pulled glass capillary was attached to one end of a glass microscope slide and a piezoelectric transducer (7BB-27-4 L0, Murata). The piezoelectric transducer was glued to the other end as reported previously. ${ }^{46}$ The probe was attached to a function generator (AFG1062, Tektronix, Beaverton, OR) and amplifier (7500, Krohn-Hite, Brockton, MA) and driven with a square wave, having a frequency in the range of 92 to $96 \mathrm{kHz}$ and an amplitude in the range of 30 to $140 \mathrm{mV}_{\mathrm{pp}}$, depending upon the size and geometry of the glass probe. Each spray probe has a slightly different geometry which means that one frequency and amplitude is not applicable to all probes. In general, larger probes (i.e. > $50 \mu \mathrm{m}$ o.d. tip) require a larger amplitude than small probes (i.e. $\leq 50$ um o.d. tip). In all cases, the lowest frequency and amplitude that generates stable spray should be used. If either of these parameters are increased too much, there is a risk that the spray probe will shatter.

The capillary and spray probe were aligned on the microscope with the tip of the spray probe touching the wall of the capillary near the orifice. The glass probe was fixed on the corner of the glass coverslip with no more than $4 \mathrm{~cm}$ extending over the edge, as depicted in prior work. ${ }^{47}$ This allowed the probe to vibrate freely when the frequency and amplitude are applied. A $90^{\circ}$ angle relative to the capillary was chosen so that sufficient contact with the capillary could be made. Since the probe must touch the orifice of the capillary, this angle allowed for the most contact between the probe and the capillary tip. The spray probe was placed parallel to the platinum electrode or at a small angle relative to the platinum electrode to ensure that the probe and electrode did not come into contact. This was done because placing the probe perpendicular to the electrode often resulted in severing the platinum electrode. The integrated probe and capillary assembly was placed within $2 \mathrm{~mm}$ of the transfer line.

Other factors that contributed to the successful alignment of the capillary with the VSSI probe were the absolute and relative positions of the pieces, the size of the probe relative to the capillary, and the overall shape of the spray probe tip. It is important for the VSSI probe (and the coverslip that it's affixed to) to be angled in a manner that allows the capillary to reach it at a $90^{\circ}$ angle without overlapping the coverslip holding the VSSI probe (Fig 2, Fig A-2). If the capillary sits on the coverslip with the VSSI probe, it will be too high to properly align. On this note, if either 
the capillary or spray probe are too low, a thin glass coverslip or some clear office tape can be used to lift either piece. The relative positions are also important as a $90^{\circ}$ angle appeared to give optimal ionization efficiency and if these positions are not maintained, the device typically does not continue to spray. To ensure the most stable alignment possible, the final layer of epoxy that was placed on the capillary should overhang the edge of the slide just enough to not be lifted up. If the epoxy is on the slide, the capillary will sit at an angle that makes it impossible to align. If the capillary hangs over the edge too far, the

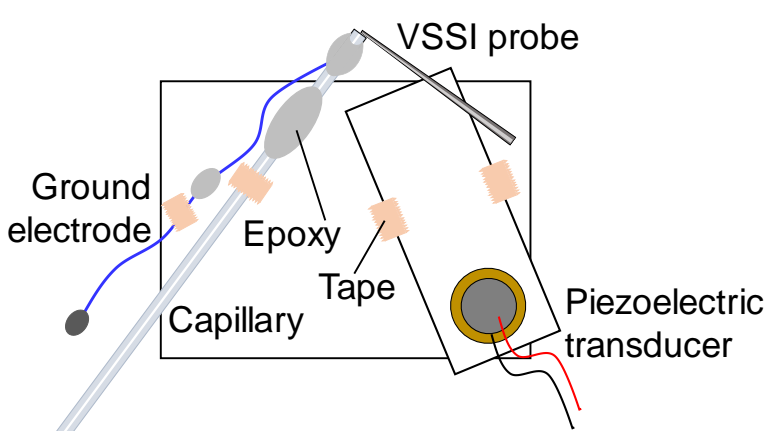

Figure 2. Diagram for capillary and probe alignment. The VSSI probe and piezoelectric transducer are attached to a 1" $x 3$ " glass coverslip with glass glue. The coverslip and capillary are attached to a large (2" x 3 ") glass microscope slide that has been cut to a final dimension of 2" x 1.5" with tape and 1-minute epoxy.

slightest movement can cause the alignment to change. The size of the probe should also be approximately $50 \mu \mathrm{m}$ at the tip, which was just estimated relative to the i.d. of the separation capillary. A very small tip had a tendency to break due its fragility, while very large ones led to stable spray, but often severed the electrode or broke the end of the capillary due to the force of the vibrations. Broken electrodes were also observed if the spray tip had jagged edges, probably due to it catching the electrode and tearing it.

Four examples of aligned CE-VSSI devices are shown in Figure 3. Figure 3A is a wellaligned device, as the electrode and VSSI probe are parallel to each other, while the capillary and spray probe are at $90^{\circ}$ angle. Also, the probe is approximately the size of the i.d. of the capillary (i.e. $~ 50 \mu \mathrm{m}$ ). The electrode is also flat against the face of the capillary so that there is optimum arrangement for a proper electrical connection to be made. Figure 3B is a poorly-aligned device, as evidenced by the large (i.e. $\sim 100 \mu \mathrm{m}$ ) spray probe that is cracked and electrode that is not across the face of the capillary. Figure $3 \mathrm{C}$ is a device that appears to be aligned correctly; however, the spray probe is too large and has a jagged tip and the electrode is no longer attached to the front of the capillary. Finally, Figure 3D depicts a device with proper hardware, but the electrode and spray probe are aligned perpendicular instead of parallel.

After capillaries are visually aligned, the alignment is tested by introducing flow into the separation capillary. Pressure-driven flow was also tested first with a pressure of $6.2 \mathrm{kPa}(0.9$ psi) being used to drive the liquid through the capillary. This pressure was chosen after performing CE-UV experiments to determine the equivalent pressure to the voltage that is used 
during the separation (Fig A-3). Since flow rate does have an effect on spray, it is necessary to test the alignment and spray at a flow rate equivalent or close to that which will be used for the analyses. It is important to make adjustments while pressure is being applied instead of voltage so that there is no risk of being shocked. Also, capillaries can appear to be aligned and still not spray so it is crucial to not skip the step of actually testing spray while liquid is moving through the capillary. It is not always possible to see the liquid being ionized under the microscope so it oftentimes helpful to look at the end of the capillary with the naked eye because a plume can usually be seen.
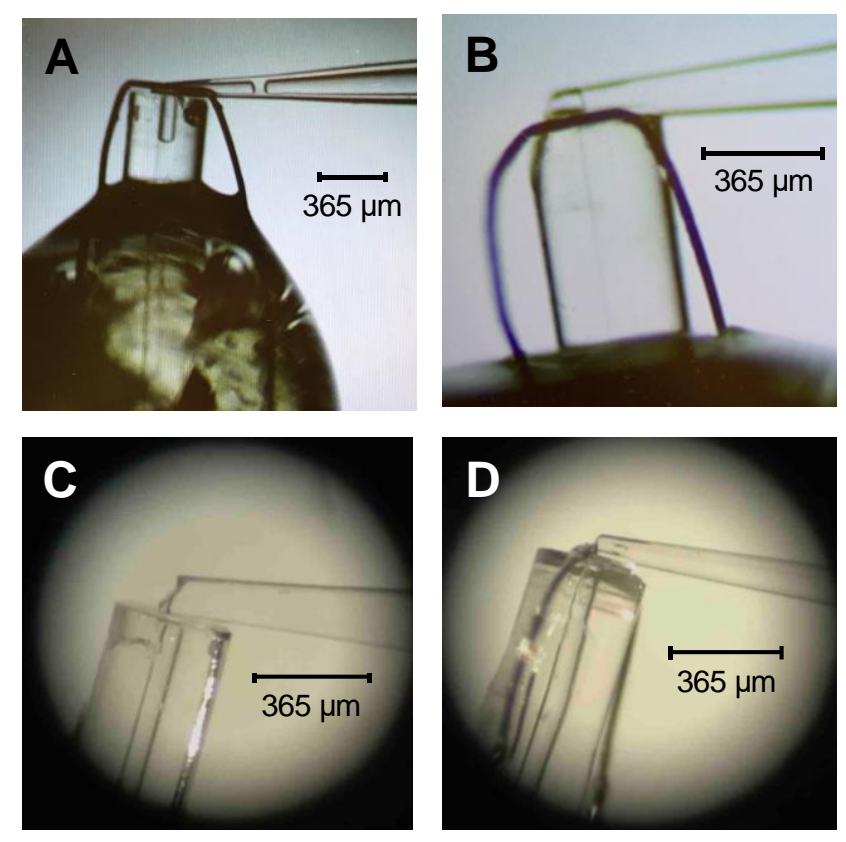

Figure 3. Comparison of good and bad devices. Microscope images of a (A) well-aligned and (BD) poorly-aligned capillaries. Scale bars are given for each image based off the o.d. of the capillary.

Once stable spray is achieved with pressure-driven flow for at least 3 minutes, the pressure should be turned off and the voltage should be applied at a value of $10 \mathrm{kV}$ (the same voltage used for the separation). The capillary should still be spraying when only voltage is applied so this is typically done as a final check to ensure that everything else is in order - nothing came out of alignment and the current is stable indicating that the electrode is intact and in the proper position. It should be noted that the current observed in this step will differ slightly (about $2 \mu \mathrm{A}$ ) from that achieved during the separation since the capillary surface has not been fully conditioned with flushes. As long as the current is stable and close to the expected separation current during this step, it is acceptable to proceed.

The final step to the alignment is to permanently affix all pieces in the device. Before liquid passed through the capillary, the probe, capillary, and electrode should have been fixed in position with tape (Fig A-2). Once the alignment is final, 1-minute epoxy can be placed on the capillary and electrode to hold them in place so that neither piece moves as the device is being transported. The epoxy should only be placed in the positions designated in Figure 2 because adding 1-minute epoxy to the spray probe or its coverslip could affect the way that it vibrates and ionizes. At this point, the electrode should also be affixed with 1-minute epoxy off the back of the slide so that attaching the alligator clips for the separation does not cause it to move. 
A few common problems that may be encountered and how to address them are described here. The first is that unstable current is observed. This could be caused by an electrode that it broken or out of place. If it has been moved out of place, it can be pushed back into its proper alignment and a small amount of 1-minute epoxy can be used to hold it. At this point, it is important to understand why this occurred. Most likely, the probe was not parallel to the electrode and it worked its way under the electrode, causing it to move. If left unfixed, this can cause the electrode to be completely severed. At this point, a new capillary must be used and caution must be taken to ensure that the probe and electrode are parallel to each other. Another common problem is that spray decreases or stops. This could be due to a change in the flow rate, which is uncommon unless something was done to the separation to cause that. Most likely, the position has changed, probably in the z-direction. The probe has probably slipped on top of or under the capillary and is no longer in contact with the liquid that is being expelled. The best solution for this is to gently push the probe back onto the face of the capillary and ensure that the pieces are not too far over the glass slide as that could cause this instability. Other factors that could have caused this problem are not being careful when moving the device or when attaching the alligator clips to the ends of the wires. Sometimes, these clips, if not properly fastened down, can move the probe or capillary out of alignment.

CE-VSSI-MS separations and analysis. A lab-built instrument composed of a nitrogen gas tank to supply pressure and a high voltage power supply (CZE1000R, Spellman, Hauppauge, NY) was constructed as previously described (Fig 4). ${ }^{48}$ Separations were carried out using bare fused silica capillaries with a total and effective length of $40 \mathrm{~cm}$, an i.d. of $50 \mu \mathrm{m}$, and an o.d. of $365 \mu \mathrm{m}$. The VSSI spray system was compatible with both $75 \mu \mathrm{m}$ and $50 \mu \mathrm{m}$ i.d. capillaries; however, the larger bore capillary was susceptible to siphoning. The $50 \mu \mathrm{m}$ i.d. capillary was chosen because it generated sufficient electroosmotic flow to sustain both electrophoresis and a visible plume of droplets, while decreasing the siphoning observed with the larger i.d. At the beginning of each day, flushes were done to condition the capillary at $41 \mathrm{kPa}(6 \mathrm{psi})$ with $0.1 \mathrm{~N}$ ammonium hydroxide for 60 minutes, water for 10 minutes, and buffer for 30 minutes with the acoustic spray off (Table A-1). In between runs, the capillary was flushed for 1 min with background electrolyte with the VSSI active during the flush. If the probe was not active during the 1-min flush applied in between the CE runs, then liquid accumulated at the capillary tip and entered the probe. When acoustic spray was restored, the additional liquid in the probe was ejected and an increase in the MS signal was observed for a few seconds. The injection was either $10 \mathrm{kV}$ for 2 or $4 \mathrm{~s}$ and the separation voltage was $10 \mathrm{kV}$ applied in normal polarity. Scanning ranges on the MS were mass-to-charge (m/z) 165 to 400 for $\beta$-blockers, 400 to 1700 for peptides, 
and 500 to 4000 for proteins. The MS capillary temperature was set to $350^{\circ} \mathrm{C}$. Using temperatures below $300^{\circ} \mathrm{C}$ seemed to cause lower ionization. Additional settings can be found in Appendix Figure A-4. An LTQ XL or Q-exactive mass spectrometer equipped with LTQ Tune Plus software (version 2.7) was used to collect the data (Thermo Fisher Scientific, San Jose, CA). Data were processed using Thermo Fisher Scientific Xcalibur (version 4.1) and Microsoft Excel (2016, Microsoft, Redmond, WA).

The CE-VSSI device was aligned in front of the mass spectrometer inlet using an open source with a sweep cone. The intersection of the capillary with the spray probe was placed approximately 1-5 $\mathrm{mm}$ from the inlet of the mass spectrometer on top of a block (for height) as shown in Figure 4. Typically, the capillary and probe were positioned level with or up to $2 \mathrm{~mm}$ below the inlet, though this was dependent upon the individual spray probe. Since each device was fabricated and aligned by hand, there were minor differences between devices which caused the spray to not always occur in the same direction. Because of this, the best method of alignment in front of the mass spectrometer was to look at the direction of spray and angle the device so that the plume was directed at the inlet.

When the final position is determined, it is crucial to ensure that both ends of the capillary are level in height to avoid siphoning issues. Since the i.d. of the separation capillary is relatively large, siphoning has a noticeable effect on the separation, causing distorted peak shapes and decreased plate counts from the superimposed laminar flow (Fig A-5). Siphoning is also dependent on the relative position of the capillary ends as well as the head pressure in the buffer vials ${ }^{49}$. Since there is only one vial in the homebuilt setup, only the volume of the anodic vial is important and should not much higher than the end of the capillary. The $3 \mathrm{~mL}$ vial was only filled to $2-2.5 \mathrm{~mL}$ for experiments so that the capillary and electrode were no more than $0.5 \mathrm{~cm}$ below the liquid surface. It is important

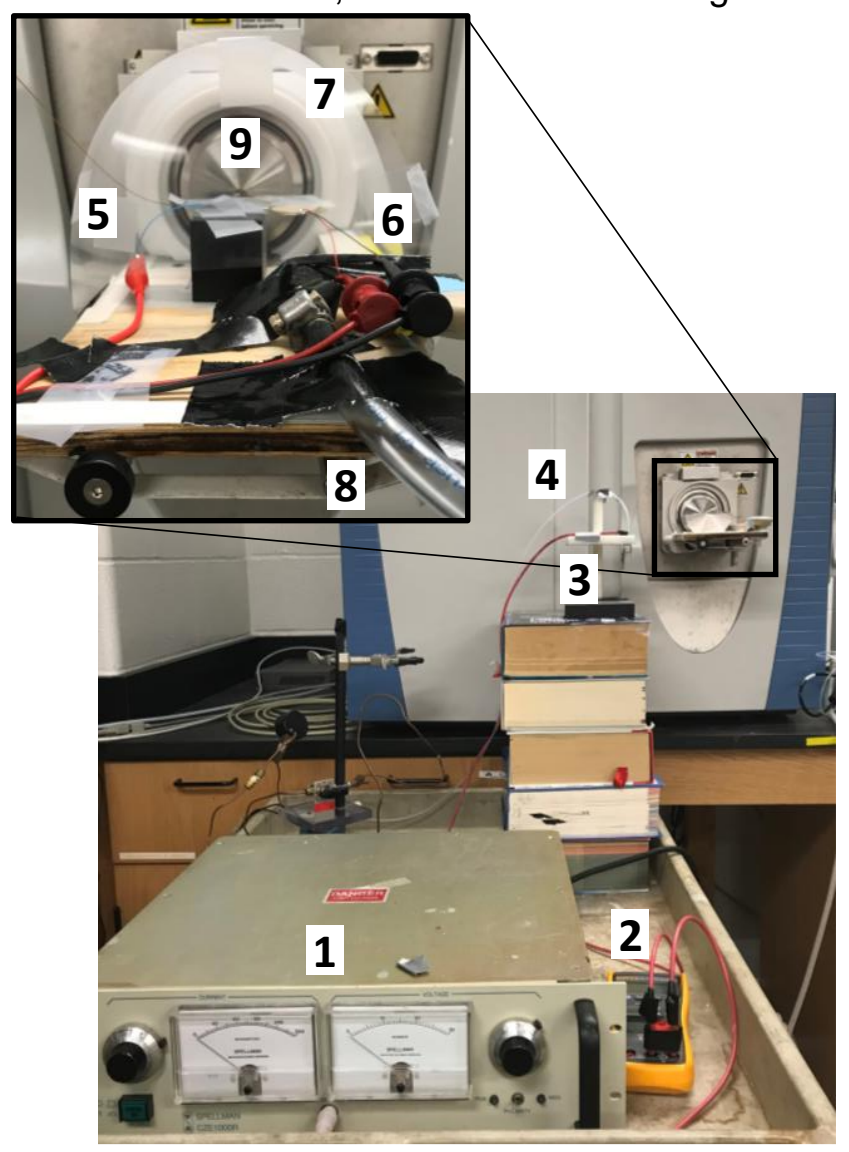

Figure 4. Image of lab-built instrument with parts labeled as follows: (1) high voltage power supply, (2) multimeter, (3) anodic electrode, (4) pressure supply, (5) separation capillary, (6) acoustic connection, (7) nitrogen chamber, (8) nitrogen inlet, (9) MS inlet. 
to ensure that both of these stay below the liquid level for the duration of the experiments so that air does not get injected into the capillary. For this reason, a buffer vial was replaced after approximately 10-20 runs with freshly degassed buffer. The more difficult place to control siphoning is keeping both ends of the capillary level since the homebuilt instrument is mobile. A specific stack of textbooks and a lab-jack marked with tape were used to ensure a level setup every time (Fig 4). In addition, before experiments were started, a level was used to ensure that both ends of the capillary were the same height.

A good check to ensure that CE-VSSI device is still spraying and in proper alignment to the source inlet is to turn on data acquisition while using pressure of $6.2 \mathrm{kPa}(0.9 \mathrm{psi})$ to push liquid through the capillary while the probe is vibrating. The scanning range of the mass spectrometer should be set to that which is used for the analysis of $\beta$-blockers ( $\mathrm{m} / \mathrm{z}$ of 165 to 400 ). On the Q-exactive mass spectrometer that was used in these studies, the total ion count should in the range of $10^{3}$ to $10^{5}$ with just buffer being pushed through the capillary with pressure. Once this value is reached with pressure, the pressure can be turned off and voltage can be applied at $10 \mathrm{kV}$. With this voltage, the total ion count should increase to $10^{4}$ to $10^{6}$ using only the background electrolyte. It is not recommended to start experiments if these values are not reached because it is usually an indicator that the device is not aligned or there is an issue with the transfer line of the mass spectrometer. At this time, the position of the device can be moved around as long as the voltage is turned off.

If the signals are still lower than expected after moving the device, the problem is most likely arising from the transfer line. Contamination or clogging of the transfer line can cause signals to be lower than what is required. Contamination can usually also be determined by looking at the ions present when only BGE is being sprayed. If there are 1 or 2 ions that are consistently dominating the mass spectrum at high signal intensities, there is a high chance there is carryover from a previous experiment (Fig A-6). It is important to clean or replace the transfer line before beginning analyses because these ions will be present in the current data as well.

The limit of detection (LOD) and limit of quantification (LOQ) were determined using LOD $=\mathrm{ks}(\mathrm{C} /(\mathrm{H}-\mathrm{h}))$, where $\mathrm{k}$ is the confidence factor (i.e. 3 for LOD and 10 for LOQ), $\mathrm{s}$ is the standard deviation of the noise, $\mathrm{C}$ is the sample concentration, $\mathrm{H}$ is the average signal of the analyte, and $h$ is the average signal of the noise (Fig A-7). The standard deviation of the noise was determined using the same number of points that comprised the analyte peak, but from a portion of the baseline just before the analyte peak eluted.

CE-UV separations and analysis. Bare-fused silica separations were conducted using a ProteomeLab PA800 capillary electrophoresis system (Sciex, Redwood City, CA). Capillaries 
had a total length of $50 \mathrm{~cm}$, an effective length of $40 \mathrm{~cm}$, an inner diameter of $50 \mu \mathrm{m}$. The capillary preparation and separation were the same as those used for the VSSI-MS analyses. To maintain the same electric field strength used on the CE-VSSI-MS system, the separation voltage was $+12.5 \mathrm{kV}$. The analyses were performed using UV absorbance detection at a wavelength of 200 $\mathrm{nm}$. The cartridge temperature was set to $19^{\circ} \mathrm{C}$ for flushes and $25^{\circ} \mathrm{C}$ for separations. Data were collected and analyzed using 32 Karat software (version 7.0, Sciex).

Capillary treatment and run conditions. As stated previously, capillaries in both the CE-MS and CE-UV systems were conditioned the beginning of each day at a pressure of 41 $\mathrm{kPa}(6 \mathrm{psi}$ ) using $0.1 \mathrm{~N}$ ammonium hydroxide for 60 minutes, water for 10 minutes, and buffer for 30 minutes. This was to ensure that any residual analyte from prior analyses was flushed out and the surface was re-equilibrated for that day's experiments. Solutions used for flushes or runs should be degassed for at least 3 minutes (for $1.25 \mathrm{~mL}$ volumes in CE-UV) or at least 5 minutes (for 2-2.5 mL volumes in CE-MS). In between runs, the capillary was flushed with background electrolyte for 1 minute at $41 \mathrm{kPa}(6 \mathrm{psi})$. The short flush was usually sufficient to clean out any leftover analyte. However, when proteins were analyzed, it was sometimes necessary to do a longer flush of about 5 minutes to remove leftover protein that was stuck to the surface. Injections on both systems were done electrokinetically at $10 \mathrm{kV}$ for 2 or 4 seconds, unless specifically stated that a hydrodynamic injection was done. In the case of hydrodynamic injections, a pressure of $2.1 \mathrm{kPa}(0.3 \mathrm{psi})$ was applied for 3s on CE-UV (Fig A-8) and a pressure of $14 \mathrm{kPa}$ (2 psi) was applied for $5 \mathrm{~s}$ on CE-MS.

\section{CURRENT RESULTS AND DISCUSSION}

Interface Design and Implementation. The elements of the CE-VSSI interface are the probe, grounding electrode, blunt capillary tip, and acoustic generator. The arrangement of each component is shown in Figure 5A (top view), Figure 5B (side view), and Figure 5C (expanded view of the interface). A fused silica capillary of $50 \mu \mathrm{m}$ i.d. and $360 \mu \mathrm{m}$ o.d. was used for the separation. The separation current was grounded through a $25 \mu \mathrm{m}$ o.d. platinum wire. A glass probe pulled to approximately $50 \mu \mathrm{m}$ tip was used to efficiently transfer vibrations from the piezoelectric source to the liquid. Both the cathodic electrode and vibrating probe were placed near the capillary orifice to maintain contact with the liquid expelled from the capillary. While the probe was in direct contact with the capillary surface to transfer energy, the electrode was offset just below the capillary orifice. This was done to prevent hydrogen gas bubbles generated from electrolysis of water from disrupting the electrical circuit of the separation and causing unstable separation current. 
Evidence of Acoustic Driven Spray. Application of the device demonstrated the significance of the VSSI probe in droplet formation and sample transfer to the mass spectrometer rather than direct electrospray at low flow rates generated by capillary electrophoresis. Capillary electrophoresis was initiated using a background electrolyte of $25 \mathrm{mM}$ acetic acid buffered to $\mathrm{pH}$ of 5 that also contained $10 \mu \mathrm{M}$ pindolol. Under these conditions, the pindolol is cationic and easily ionized. The approximate electroosmotic flow rate at this $\mathrm{pH}$ was $70 \mathrm{~nL} / \mathrm{min}$ at a field strength of $250 \mathrm{~V} / \mathrm{cm}$. The acoustic source was manually cycled on and off with no interruption of the CE voltage (Fig 6). Turning the acoustics off coincided with a drop in the ionization intensity. The average duration of near zero intensity during the off-cycle was $4.3 \pm 0.3$ s for the 4 off-cycles. Assuming no error in manually turning off the acoustics, these data indicate that the response to acoustics is as little as $0.35 \mathrm{~s}$ per on-off cycling. The average signal intensity during the three on-cycles was $37,000,29,000$, and 32,000 respectively. During the off-cycle the plume was no longer visible and fluid accumulated the end of the capillary because the electrophoresis separation continued to eject running buffer. The device was switched to pressure driven flow to deliver $200 \mathrm{~nL} / \mathrm{min}$. However, switching from voltage to pressure yielded between 10 and 100-fold lower ion intensity.

The nebulized droplets are generally, but not always, ejected at a right angle to the vibrating probe for different probes and capillaries coupled to create CE-VSSI. This is attributed to subtle differences in the probe geometry and alignment. Although the mechanism of droplet formation is different, a similar observation was reported with $\mathrm{CE}$ $\mathrm{ESI},{ }^{12}$ which was rectified through the use of a nitrogen chamber. A less sophisticated nitrogen chamber was constructed and used with VSSI with a goal of directing more

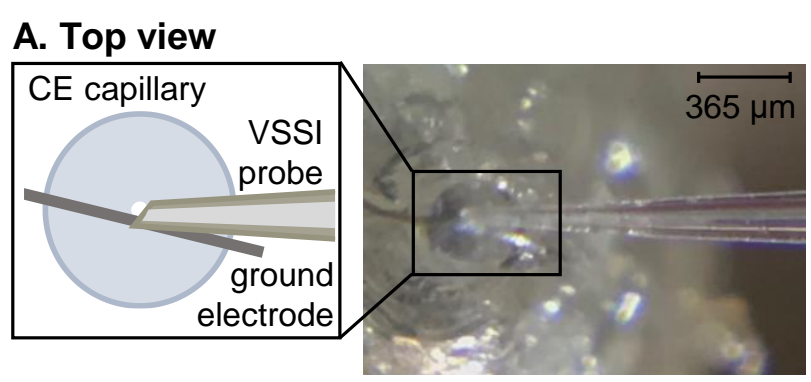

\section{B. Side view}

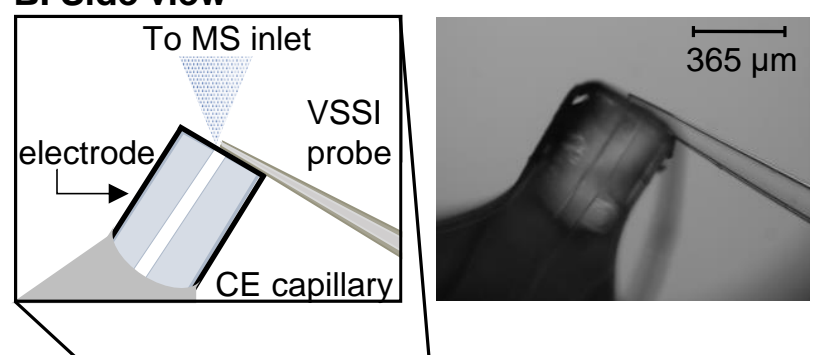

\section{Expanded view}

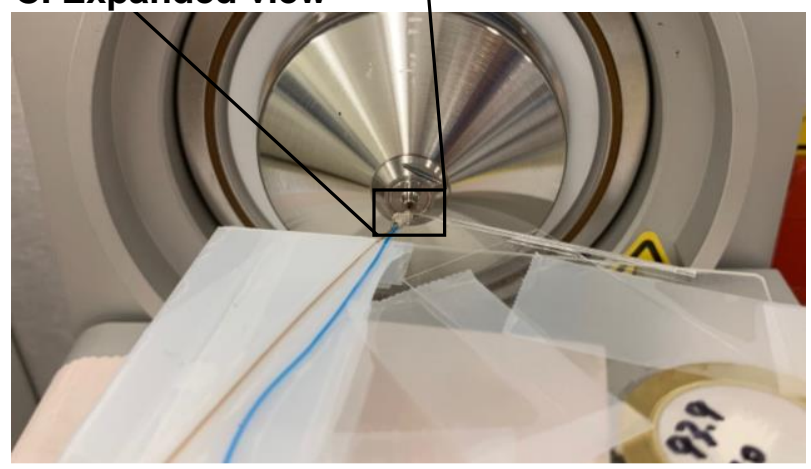

Figure 5. Concept diagram and image of the spray probe, capillary, and electrode alignment in the (A) z-direction and the (B) xy-direction. (C) Image of the CE-VSSI interface in front of the linear trap mass spectrometer. 
droplets into the MS and making a more uniform environment for ionization since the VSSI interface requires an open ion source. The peak areas obtained for the separation and detection of a sample of $1 \mu \mathrm{M}$ pindolol in the presence and absence of the nitrogen chamber, which were $300,000 \pm 100,000$ and $180,000 \pm 80,000$, respectively, were not significantly different. Improvements in the design as well as optimization of the nitrogen flow may dramatically improve the performance. Additional studies are needed to define the factors that orient the direction of the plume in order to maintain efficient ion

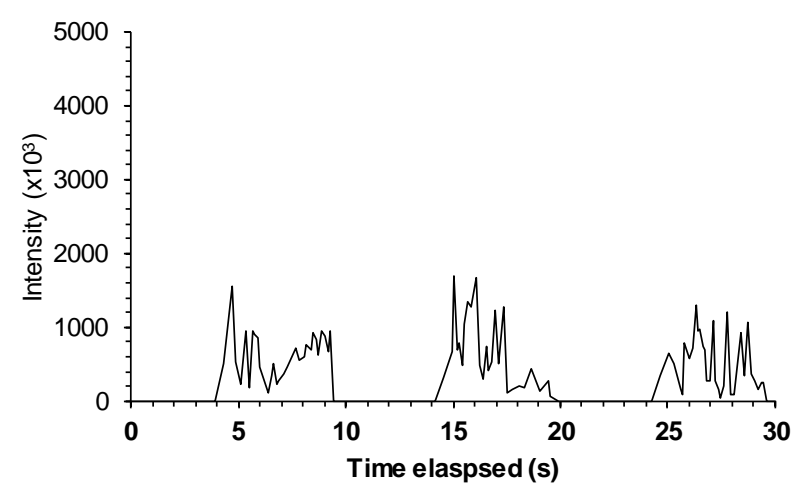

Figure 6. Demonstration that ionization starts and stops with acoustics. A voltage of $10 \mathrm{kV}$ was applied to the CE capillary during the experiment. The acoustics were pulsed on and off in 5-sec increments starting with an off period of $0-5 \mathrm{sec}$ elapsed. The extracted ion electropherogram depicts ionization intensity for pindolol which is plotted as the extracted base peak of 249.3 with a mass tolerance of $500 \mathrm{mmu}$. transfer.

To test the effects of flow rate on signal, pindolol was separated at different applied voltages and the migration velocity used as a measure of flow rate (Fig 7A). The relationship between migration velocity and peak area was linear $\left(R^{2}=0.94\right)$. This study was performed using two different CE-VSSI devices with each capillary spanning 3 points (i.e. $0.15,0.23$, and 0.41 $\mathrm{cm} / \mathrm{s}$ or $0.23,0.54$, and $0.74 \mathrm{~cm} / \mathrm{s}$ ). Each point was measured at $n=3$ replicates, except 0.23 $\mathrm{cm} / \mathrm{s}$ which was measured at $n=6$ replicates -3 from the first capillary and 3 from the second. At higher pindolol velocity a higher peak area was obtained as more analyte was delivered to the MS. Flow rates below the minimum velocity of $0.15 \mathrm{~cm} / \mathrm{s}$ could not be evaluated because the spray was unstable at these low flow rates. Conversely, rates above the maximum velocity were not tested because the separation currents approached levels that lead to Joule heating $(i=39$ $\mu A)$.

The ionic strength of the background electrolyte affects the rate of electroosmotic flow as well as ionization (Fig 7B). The impact of 4 different concentrations (ranging from 10 to $75 \mathrm{mM}$ ) of ammonium acetate were tested. As ionic strength was increased successively, the peak area of pindolol decreased. At ammonium acetate concentrations of $10,18,25$, and $75 \mathrm{mM}$, peak areas were 9,400,000 $\pm 800,000,3,300,000 \pm 300,000,1,400,000 \pm 100,000$, and 1,100,000 \pm 100,000 , respectively. The same trend was observed for acebutolol, which at ammonium acetate concentrations of $10,18,25$, and $75 \mathrm{mM}$, had peak areas of 5,200,000 $\pm 400,000,1,600,000 \pm$ $200,000,510,000 \pm 10,000$, and 490,000 $\pm 60,000$, respectively. While these data suggest that 
lower ionic strengths should be used to achieve better signal, other aspects of the background electrolyte concentration must also be considered. For example, the concentration of the background electrolyte may affect the separation through non-specific adsorption to the capillary surface.

As further support that the capillary surface changes as ionic strength changes, the migration times vary for the different concentrations. The migration times for pindolol are 1.91 (1\%), $1.93(2 \%), 2.05(2 \%)$, and $2.11(0.5 \%)$ minutes, which correspond to $10,18,25$, and $75 \mathrm{mM}$ ammonium acetate, respectively. The general trend is that an increase in ionic strength causes a decrease in the electroosmotic flow. Because of this, it can be inferred that the difference in peak area is either due to less sample being detected due to the decreased flow rate or a different charge on the capillary surface. All samples for this study were dissolved in their respective background electrolyte and injected via a hydrodynamic injection so no stacking should have occurred.

The compatibility of VSSI with different volatile background electrolytes was evaluated (Fig 7C). Pindolol was separated and detected with three different electrolytes systems at near neutral or basic $\mathrm{pH}$ values each at a concentration of $25 \mathrm{mM}$. Ammonium acetate and ammonium bicarbonate both had a measured $\mathrm{pH}$ value of 6.5. Bicarbonate is an effective buffer at this $\mathrm{pH}$ value; whereas acetate does not serve as a buffer at $\mathrm{pH}$ 6.5. Peak areas resulting from the near-neutral background electrolytes, which were 280,000 $\pm 10,000$ for ammonium acetate and $360,000 \pm 60,000$ for ammonium

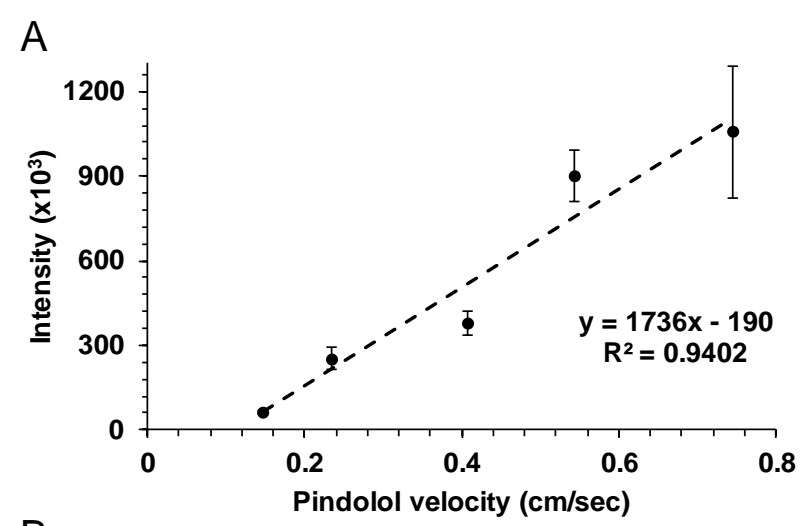

B
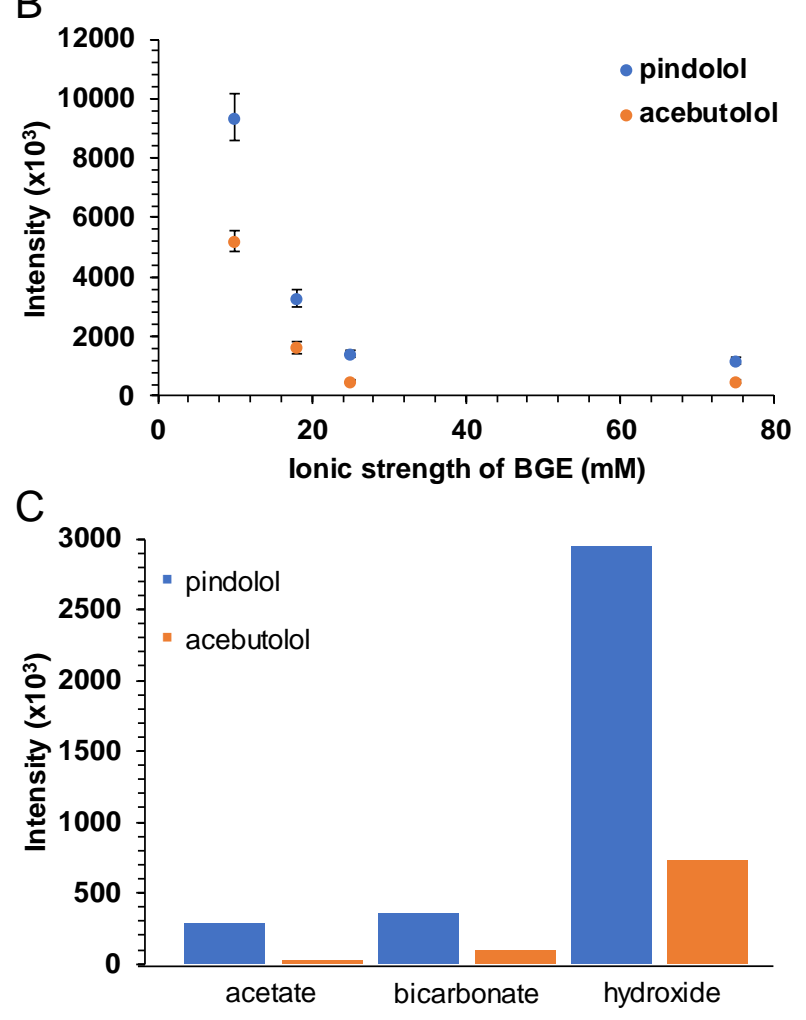

Figure 7. Figures of merit and optimization studies for CE-VSSI-MS including (A) effect of flow rate on pindolol area, $(B)$ effect of ionic strength of BGE on pindolol and acebutolol area, and (C) effect of BGE composition on pindolol and acebutolol area. 
bicarbonate, were similar. However, ammonium hydroxide buffered at $\mathrm{pH} 10$ yielded a 10-fold higher signal with an area of 2,900,000 $\pm 200,000$. This increase of positive ions at highly basic $\mathrm{pH}$ values has previously been reported in literature as the "wrong-way round" principle. ${ }^{50}$

Separation and Detection with CE-VSSI-MS Compared to CE-UV at pH 5. The CEVSSI spray probe was used to separate and detect two different $\beta$-blockers using a running buffer of $25 \mathrm{mM}$ acetic acid adjusted to $\mathrm{pH}$ of 5 . The approximate electroosmotic flow rate at this $\mathrm{pH}$ was $70 \mathrm{~nL} / \mathrm{min}$. The separation was operated at $\mathrm{pH} 5$ because at values below 4.5 the rate of electroosmotic flow is suppressed significantly due to the protonation of the silica surface. A $\beta$ blocker mixture composed of $10 \mu \mathrm{M}(2.5 \mu \mathrm{g} / \mathrm{mL})$ pindolol and $10 \mu \mathrm{M}(3.4 \mu \mathrm{g} / \mathrm{mL})$ acebutolol was used to characterize the separation and device performance (Fig 8A). Under these conditions the $\beta$-blockers are cationic (i.e. pKa values greater than 9) (Fig A-9). ${ }^{51,52}$ Sample was introduced with an electrokinetic injection. The mass of analyte injected in the capillary (Q) can be estimated as $\left(Q=\pi r^{2} \mu_{\text {app }} V_{\text {injtinj }} C / L\right)^{50}$ given the capillary radius $(r)$, capillary length $(L)$, injection voltage $\left(V_{\text {inj }}\right)$, injection time $\left(t_{\text {inj }}\right)$, and analyte concentration (C) (Table A-2). The $10 \mathrm{kV} 2 \mathrm{~s}$ injection of analyte corresponds to $13 \mathrm{pg}$ pindolol and $16 \mathrm{pg}$ acebutolol in the capillary. The mass spectra for the base peak of the +1 charge state of each $\beta$-blocker are included in the Appendix (Fig A-10).

Separation figures of merit were comparable to those obtained with UV detection (Fig 8B, Table A-3, Table A-4) and migration times were not significantly different. For capillary electrophoresiselectrospray methods performed at low $\mathrm{pH}$, flow is superimposed to stabilize the electrospray; however, this reduces the efficiency of the electrophoresis. In other instances, it has also been noted that the process of electrospray itself superimposes

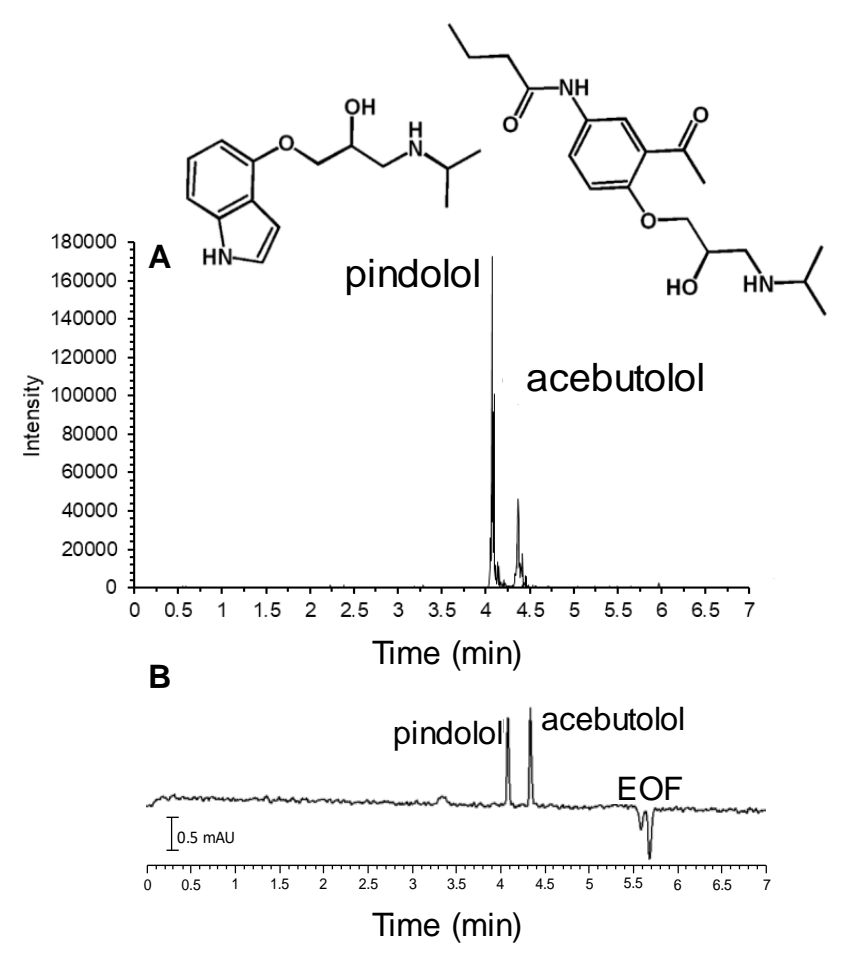

Figure 8. (A) CE-VSSI-MS separation of $10 \mu \mathrm{M}$ pindolol and acebutolol. The extracted ion electropherograms were created using the mass range of $249.25-250.25$ and $337.25-338.25$ for pindolol and acebutolol, respectively. Separation was achieved with a $40 \mathrm{~cm}$ (total and effective length), $50 \mu \mathrm{m}$ i.d. capillary at an applied voltage of $+10 \mathrm{kV}$. (B) CE-UV separation. Separation was achieved with a $50 \mathrm{~cm}$ (total length), $40 \mathrm{~cm}$ (effective length), $50 \mu \mathrm{m}$ i.d. capillary at an applied voltage of $+12.5 \mathrm{kV}$. All separations were achieved with a background electrolyte of $25 \mathrm{mM}$ acetic acid at pH 5. 
laminar flow in capillary electrophoresis. ${ }^{53,54}$ These data indicate that VSSI does not alter the capillary electrophoresis flow rate. The theoretical plate counts obtained with the CE-VSSI system were $35 \%$ to $75 \%$ of the values obtained with the automated UV-absorbance system (Table A-4). The precision in migration time and plate count obtained with the CE-VSSI was worse than that obtained with the automated UV absorbance detection (Table A-3, Table A-4); however, this was attributed to manual control of the voltage to perform injections or to coordinate the application of the separation voltage with the start of data acquisition.

The CE-VSSI interface was also applied to the separation of a sample containing $50 \mu \mathrm{M}$ (82 $\mu \mathrm{g} / \mathrm{mL})$ somatostatin and $50 \mu \mathrm{M}(50$ $\mu \mathrm{g} / \mathrm{mL}$ ) oxytocin (Fig 9A). At the $\mathrm{pH}$ used, somatostatin was cationic and oxytocin was neutral (Table A-5). Peptides were injected electrokinetically (10 kV, $2 \mathrm{~s})$, corresponding to a mass of $370 \mathrm{pg}$ somatostatin and $210 \mathrm{pg}$ oxytocin loaded into the capillary. It should be noted no effort was made to desalt the peptides prior to analysis and subsequently sodium adducts were observed for oxytocin. The mass spectra for the base peak of the +2 charge state of each peptide are included in the Appendix (Fig A-11). The migration times for the peptides varied by only $5 \%$ from expected values based on UV measurements (Fig 9B, Table A-3). The theoretical plate counts for somatostatin and oxytocin were $55 \%$ to $75 \%$ of that obtained with the automated method (Table A-4). Although these runs demonstrate the compatibility of CE-VSSI with lower pH buffers used in mass spectrometry, the resolution of the peptides was worse with CE-VSSI as compared to UV, and further studies are underway to determine the source of peak broadening and differing migration times.

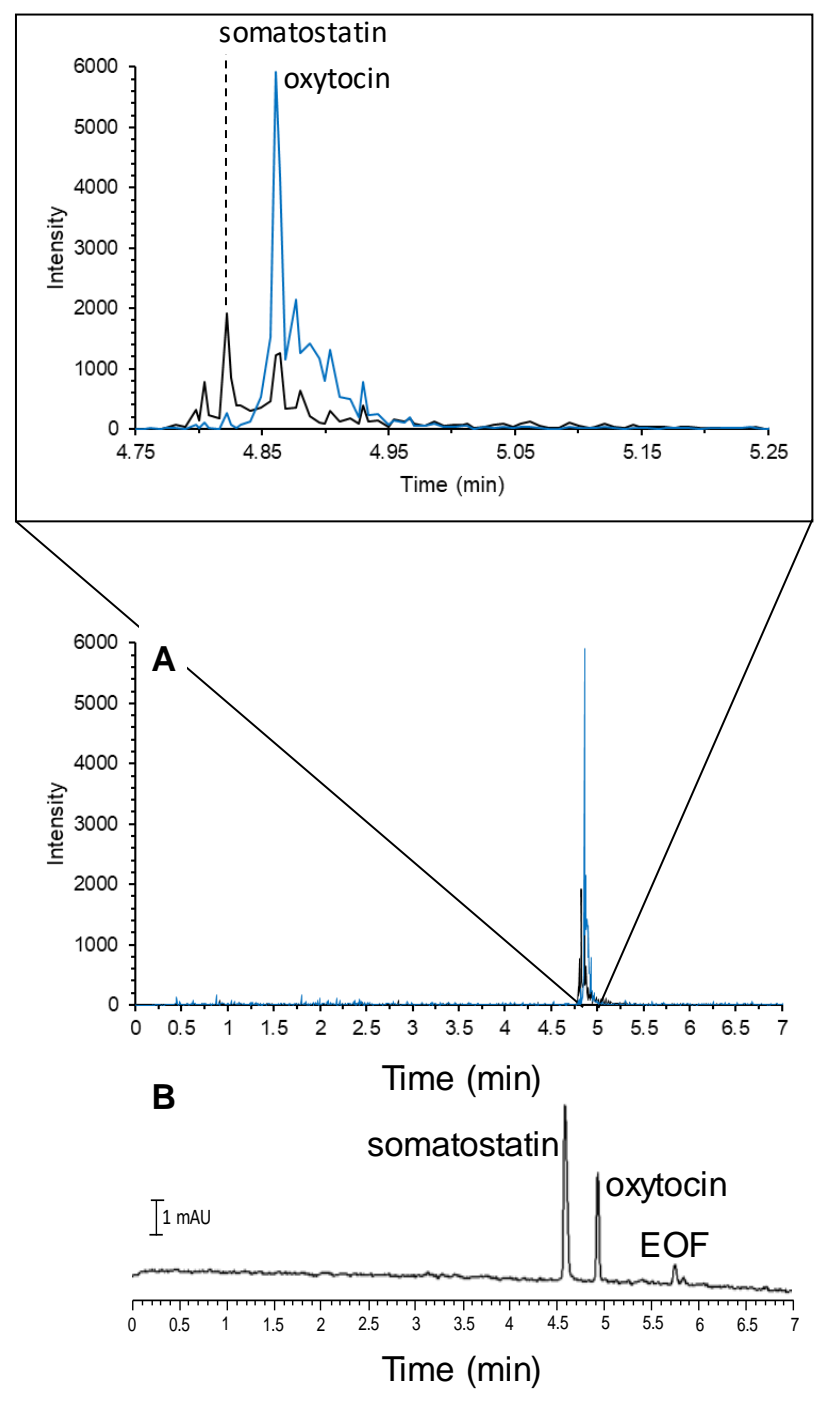

Figure 9. (A) CE-VSSI-MS separation of somatostatin and oxytocin with an extracted ion electropherogram of $\mathrm{m} / \mathrm{z} 819$ and 504 for somatostatin and oxytocin, respectively. (B) CEUV separation. The EOF marker is dimethylformamide. Separation conditions are as in Figure 8. 
Separation and Detection with CE-VSSI-MS Compared to CE-UV at pH 6.5. The CEVSSI-MS system was used to separate two $\beta$-blockers at a near neutral $\mathrm{pH}$ in order to compare the separation with CE-UV. A background electrolyte of $25 \mathrm{mM}$ ammonium acetate at pH 6.5 was used, which generated an electroosmotic flow of approximately $110 \mathrm{~nL} / \mathrm{min}$. A $\beta$-blocker mixture composed of $1 \mu \mathrm{M}(0.25 \mu \mathrm{g} / \mathrm{mL})$ pindolol and $1 \mu \mathrm{M}(0.34 \mu \mathrm{g} / \mathrm{mL})$ acebutolol was used to characterize the separation and device performance (Fig 10A). The $10 \mathrm{kV} 2 \mathrm{~s}$ injection of analyte corresponds to $1.4 \mathrm{pg}$ pindolol and $1.7 \mathrm{pg}$ acebutolol in the capillary. The mass spectra for the base peak of the +1 charge state of each $\beta$-blocker are included in the Appendix (Fig A-12). Migration times were comparable across the two systems (Fig 10B, Table A-6).

CE-VSSI-MS was compatible with hydrodynamic injections. Similar peak areas and plate counts were obtained with a $10 \mathrm{kV} 4$ s electrokinetic injection and $14 \mathrm{kPa}$ (2 psi) 5 s hydrodynamic injection. A 5-fold smaller hydrodynamic injection was used on the commercial CE-UV instrument as compared to the lab-built CE-MS instrument, which was likely due to differences in the delivery and regulation of pressure with these two different systems.

With electrokinetic injections of the sample diluted in the $\mathrm{pH} 6.5$ ammonium acetate background electrolyte, the LOD and LOQ for pindolol were calculated to be 0.002 and $0.007 \mu \mathrm{M}$, respectively (Fig A-7). This LOD can be improved further if stacking techniques are employed. However, in the absence of stacking, the pindolol LOD is comparable to values reported for CE-ESI-MS analyses achieved with acidic background electrolytes of similar small cationic molecules with sheath-flow ${ }^{12,29,55}$ and sheathless ${ }^{28,56}$ interfaces. Pindolol standards were detected by CE-VSSI-MS at concentrations ranging from 0.01 to $5 \mu \mathrm{M}$ (Fig A-13). Although the use of internal standards is recognized as the appropriate strategy for MS quantification, in the absence of an internal standard, a linear relationship was observed between

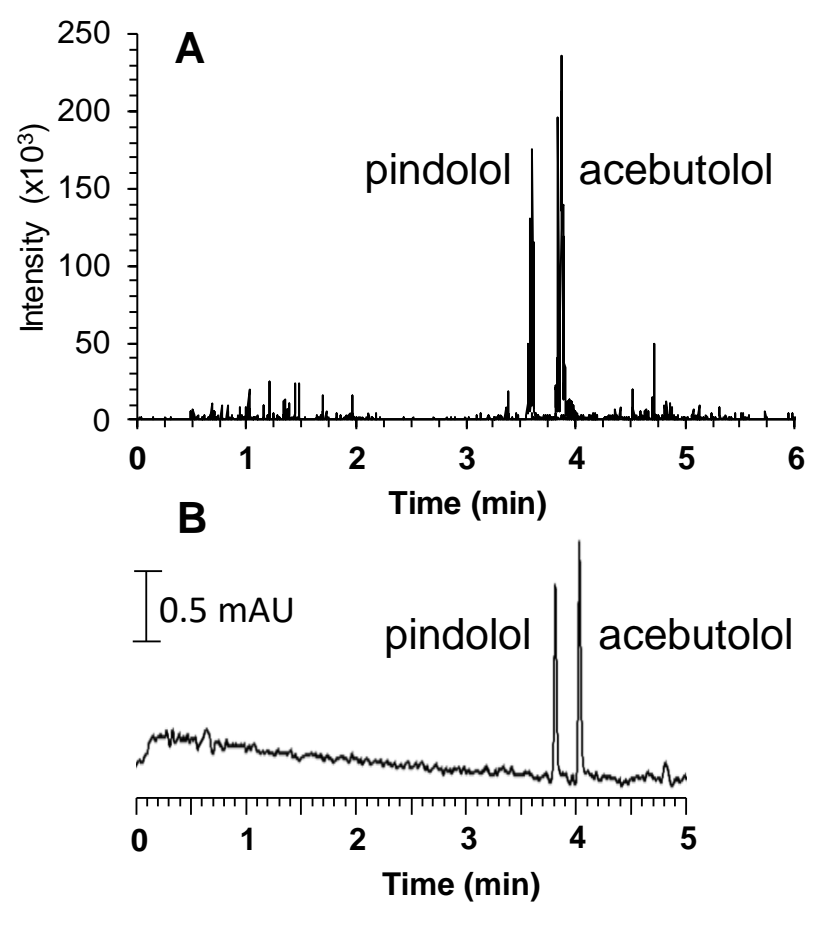

Figure 10. (A) CE-VSSI-MS separation of $1 \mu \mathrm{M}$ pindolol and acebutolol. The extracted ion electropherograms were created using masses of 249.1554 and 337.2061 for pindolol and acebutolol, respectively, with a mass tolerance of 10 ppm. Separation conditions are as in Figure 8, except a background electrolyte of $25 \mathrm{mM}$ ammonium acetate at $\mathrm{pH} 6.5(\mathrm{i}=12 \mu \mathrm{A})$ was used. 
concentration and peak area $\left(R^{2}=0.98\right)$ as determined using 5 different concentrations of pindolol (i.e. $0.01,0.01,0.1,1,5 \mu \mathrm{M}$ ). A linear relationship was also observed for acebutolol (Fig A-14).

The separation efficiency of 80,000 plates $/ \mathrm{m}$ was comparable to that obtained with the UV detection (Fig 10B, Table A-7). The theoretical plates are $80 \%$ to $95 \%$ of those observed with the capillary electrophoresis UV system and migration times vary by no more than $7 \%$ with either $\beta$ blocker. While most CE-ESI-MS separations are performed at acidic conditions to eliminate surface adsorption and facilitate ionization, these data indicate that CE-VSSI is compatible with capillary electrophoresis operated under near-neutral conditions that generate electroosmotic flow. The plate counts obtained with VSSI using a background electrolyte at pH 6.5 approach plate counts reported in the literature of 170,000 plates $/ \mathrm{m}$ for cationic metabolites, ${ }^{12}$ which was achieved under conditions of low pH. With acidic background electrolyte in bare fused silica capillary, the analyte migration is based solely on electrophoretic mobility resulting in longer run times. If flow is superimposed to stabilize the electrospray and speed the separation, the efficiency of the electrophoresis will be reduced.

While the plate counts were comparable between the two systems, the relative standard deviation (RSD) was higher than anticipated, especially in the CE-MS system. For example, the theoretical plates for pindolol were 70,000 (40\%) for CE-MS compared to 80,000 (10\%) for CEUV. The increased RSDs for plate counts are a result of having too few significant figures in the calculations. All values for peak widths of the CE-MS data had to be determined manually and only had 2 significant figures as a result. The peak widths for the CE-UV data were calculated by the 32 Karat software and had 4 significant figures. All plate counts were calculated using the formula $\mathrm{N}=16 \mathrm{t}^{2} / \mathrm{w}^{2}$, where $\mathrm{t}$ is the migration time and $\mathrm{w}$ is the width at the base of the peak.

The CE-VSSI interface was also applied to the separation of a sample containing $50 \mu \mathrm{M}$ $(82 \mu \mathrm{g} / \mathrm{mL})$ somatostatin and $50 \mu \mathrm{M}(50 \mu \mathrm{g} / \mathrm{mL})$ oxytocin (Fig 11A). The mass spectra for the base peak of the +2 charge state of each peptide are included in the Appendix (Fig A-15). Peptides were injected electrokinetically (10 kV 2 s), corresponding to a mass of $370 \mathrm{pg}$ somatostatin and $210 \mathrm{pg}$ oxytocin loaded into the capillary. It should be noted no effort was made to desalt the peptides prior to analysis and subsequently sodium adducts were observed for oxytocin. Peptide separations had similar performance relative to CE-UV data (Fig 11B). The migration times and theoretical plate counts were similar for somatostatin and oxytocin for CEVSSI and CE-UV (Table A-6, Table A-7). 
The utility of CE-VSSI-MS for protein analysis was evaluated by injecting and separating ubiquitin mixed with a commercial soybean preparation that primarily contained trypsin inhibitor. The benefit of the VSSI interface is depicted in Figure 12. With the CE-UV trace, the presence of other molecules is evident as noted by the asterisk in Figure 12B. However, the CE-VSSI-MS trace (Fig 12A) sheds light on the composition. The dominant charge state of +6 was detected for ubiquitin and was calculated to have a mass of $8,567 \mathrm{Da}$ (Fig 12C) which is within $0.02 \%$ of the average mass reported by the vendor. The $\mathrm{m} / \mathrm{z}$ differences between adjacent isotopic envelopes reveal the presence of some adducts.

The extracted ion electropherogram of the peaks associated with trypsin inhibitor reveal the presence of peptide fragments isolated from soybean with masses of 7746 $\mathrm{Da}$ and $7860 \mathrm{Da}$, as well as other fragments

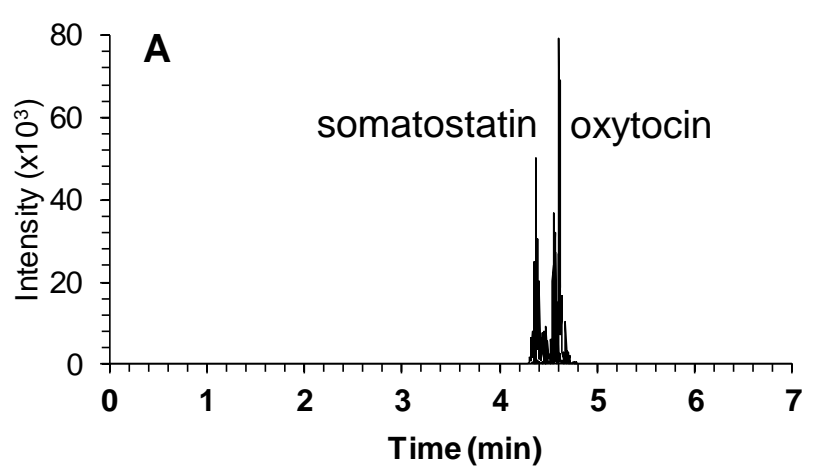

B

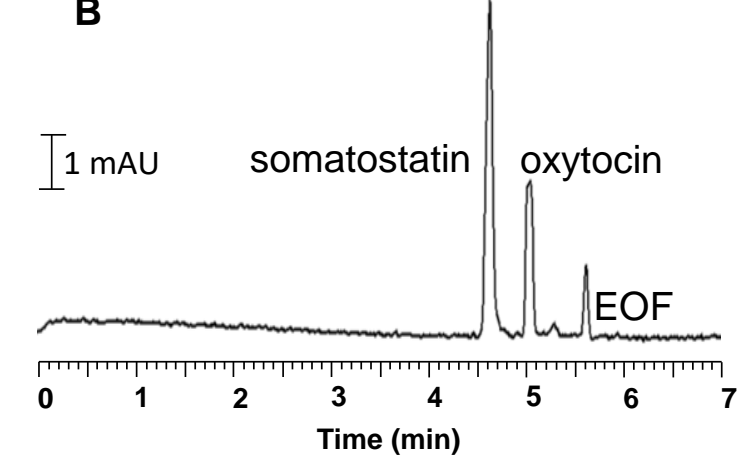

Figure 11. (A) CE-VSSI-MS separation of somatostatin and oxytocin with an extracted ion electropherogram of $\mathrm{m} / \mathrm{z} 820.1$ and 504.3 for somatostatin and oxytocin, respectively, with a mass tolerance of $500 \mathrm{mmu}$. (B) CE-UV separation. The EOF marker is dimethylformamide. Separation conditions are as in Figure 8, except a background electrolyte of 25 $\mathrm{mM}$ ammonium acetate at $\mathrm{pH} 6.5(\mathrm{i}=12 \mu \mathrm{A})$ was used.

(i.e. at 8.75 minutes) with masses ranging from 8016 to $8316 \mathrm{Da}$ (Fig 13). In addition to trypsin inhibitor, soybeans contain Bowman-Birk inhibitors which are peptides with molecular weights reported in the literature range from 6941 to $9475^{57,58}$ and have pKa values ranging from 3.9 to 6.3..$^{59,60}$ The peaks migrating faster than the peak attributed to trypsin inhibitor protein are less negative (i.e., have higher isoelectric points). These peptide fragments had nominal response in CE-UV but had higher ionization intensity in MS than the main protein peak observed in the UV separation. The dominant peak for trypsin inhibitor corresponds to +11 ions with a calculated mass of $19,979 \mathrm{Da}$ (Fig 12D). Although the trypsin inhibitor is reported to contain three variants, 
the vendor reports that the mass of trypsin inhibitor can be approximated to be $20,100 \mathrm{Da}$, which is within $0.6 \%$ of the mass observed with the CE-VSSI-MS interface. Masses for all peaks were calculated based upon the average $\mathrm{m} / \mathrm{z}$ of the three dominant charge states. The capillary electrophoresis system separated the trypsin inhibitor protein fragments from the intact protein, which enabled discrimination of the protein and protein fragments, rendering the mass identification more straight-forward.

While the concentrations of the proteins and peptides in the soybean trypsin inhibitor standard is not known, the $10 \mathrm{kV} 4 \mathrm{~s}$ injection of proteins corresponds to $580 \mathrm{pg}$ ubiquitin. The peak areas for ubiquitin and trypsin inhibitor were 33,000,000 \pm 9,000,000 and 400,000 $\pm 400,000$, respectively. The worse precision of trypsin inhibitor relative to ubiquitin is attributed to the presence of the peptides and protein variants in the stock. These factors adversely impact the ionization efficiency of this anionic protein, leading to a substantially lower signal. A future experiment will be to quantify the amount of actual trypsin inhibitor protein in the soybean preparation. The plate counts for ubiquitin and trypsin inhibitor are lower or the same with CE-VSSI-MS as compared to CE-UV. The trace in Figure 6B indicates tailing for the ubiquitin peak. The migration times obtained with CE-VSSI-MS for ubiquitin and trypsin inhibitor are 1.8 and 3.4 minutes slower. The slower migration times and tailing may be due to nonspecific surface adsorption from prior
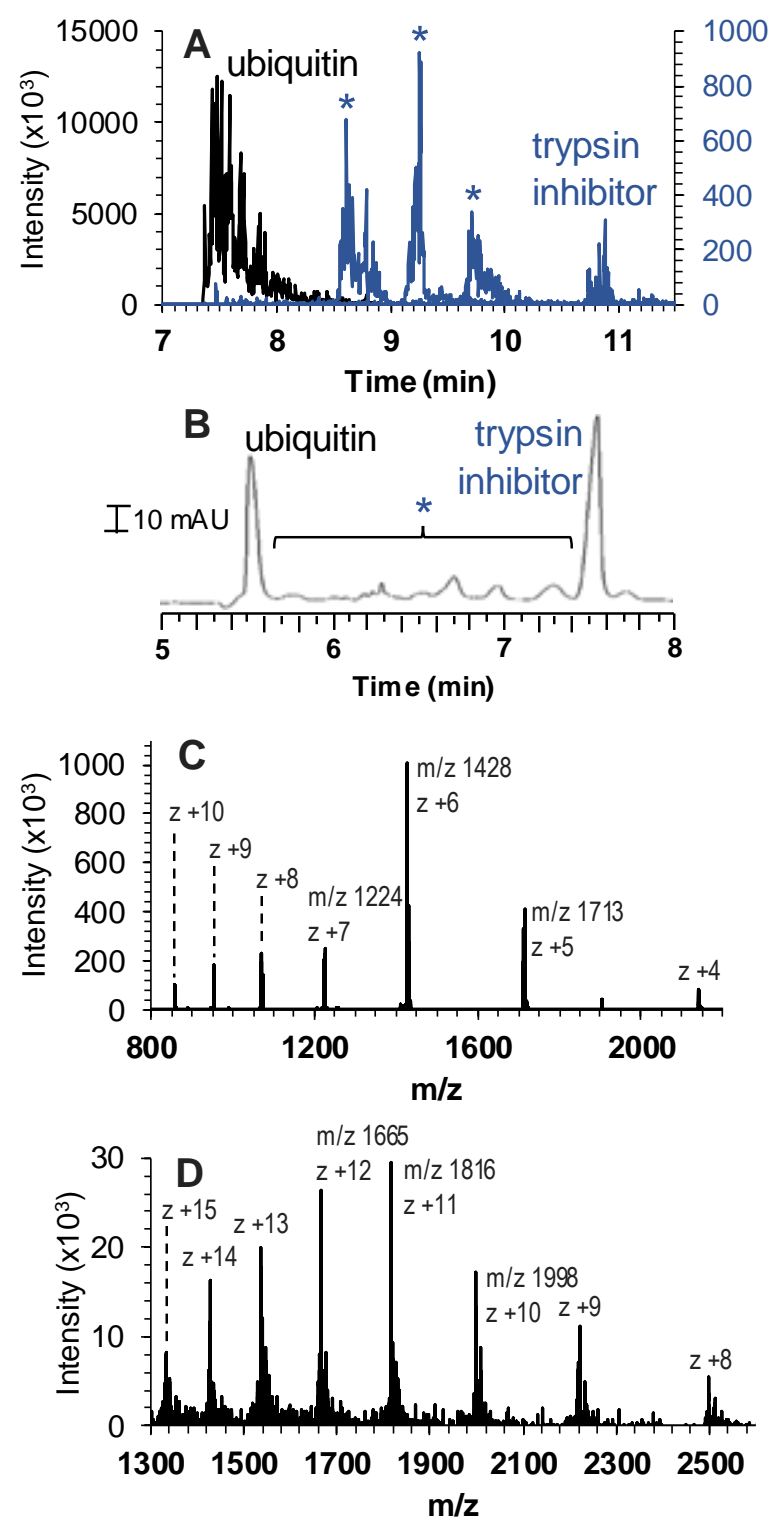

Figure 12. (A) CE-VSSI-MS separation of ubiquitin and trypsin inhibitor with an extracted ion electropherogram of $\mathrm{m} / \mathrm{z} 1428.2765$ and 1817.0015 for ubiquitin (black) and trypsin inhibitor (blue), respectively, with a mass tolerance of $10 \mathrm{ppm}$. (B) CE-UV separation. Mass spectrum of (C) ubiquitin and (D) trypsin inhibitor display the most abundant charge states for the width of the peaks in $(A)$ at half the maximum intensity. Separation conditions are as in Figure 8, except a background electrolyte of $50 \mathrm{mM}$ ammonium acetate at $\mathrm{pH} 6.5(\mathrm{i}=22 \mu \mathrm{A})$ was used. 
analyses. Although strategies were used to minimize laminar flow, it is possible the configuration of the lab-built instrument may have been subject to siphoning toward the site of injection.

The ubiquitin and trypsin inhibitor proteins were selected because, with neutral or basic separation buffers, most other proteins adsorb to the bare fused silica surface and produce broad peaks. Further optimization of the electrophoretic separation is underway to reduce surface adsorption of the protein to achieve the high efficiency separations observed with peptides. Additionally, it should be noted that the proteins have been slightly denatured based off of comparison of dominant charge states with those obtained from traditional electrospray ionization.
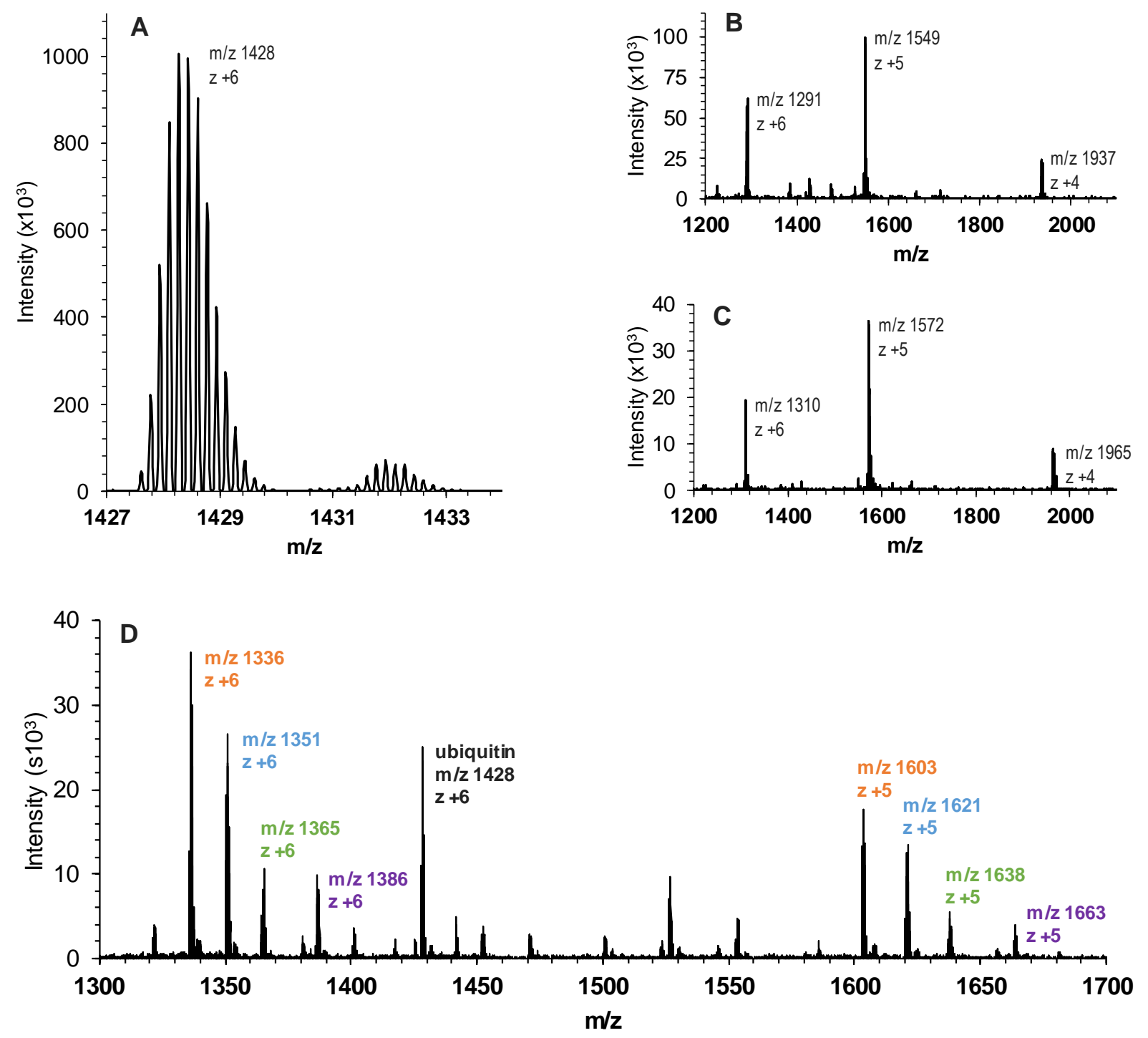

Figure 13. (A) Mass spectra containing the dominant charge state of ubiquitin. (B) Mass spectrum of the peptides in the trypsin inhibitor with masses of 7746, (C) 7860, (D) 8016 in orange, 8106 in blue, 8190 in green, and 8316 in purple. Separation conditions are as in Figure 8, except a background electrolyte of $50 \mathrm{mM}$ ammonium acetate at $\mathrm{pH} 6.5(\mathrm{i}=22 \mu \mathrm{A})$ was used. 
It is believed that the preparation and storage of the trypsin inhibitor could have led to some denaturation, as it was stored in a low ionic strength solution at $4^{\circ} \mathrm{C}$ overnight following the molecular weight cut-off. However, ubiquitin was prepared in $25 \mathrm{mM}$ ammonium acetate and stored at $4^{\circ} \mathrm{C}$ so the VSSI cannot be ruled out as a potential cause of the observed denaturing. This is something that will be investigated further in the future. Finally, although the trypsin inhibitor was desalted through buffer exchange with a $10 \mathrm{kDa}$ molecular weight cut-off filter (Merck Millipore UFC501024, Burlington, MA), sodium adducts were observed in the extracted ion electropherogram. Applying in-source ion activation will improve the technique further by declustering the protein adducts. 


\section{REFERENCES}

(1) Kristoff, C. J.; Li, C.; Li, P.; Holland, L. A. Anal. Chem. 2020, 92, 3006-3013.

(2) Voeten, R. L. C.; Ventouri, I. K.; Haselberg, R.; Somsen, G. W. Anal. Chem. 2018, 90, 14641481.

(3) Kristoff, C. J.; Bwanali, L.; Veltri, L. M.; Gautam, G. P.; Rutto, P. K.; Newton, E. O.; Holland, L. A. Anal. Chem. 2020, 92, 49-66.

(4) Stolz, A.; Jooß, K.; Höcker, O.; Römer, J.; Schlecht, J.; Neusüß, C. Electrophoresis 2019, 40, 79-112.

(5) McCool, E. N.; Lubeckyj, R. A.; Shen, X.; Chen, D.; Kou, Q.; Liu, X.; Sun, L. Anal. Chem. 2018, 90, 5529-5533.

(6) Shen, X.; Kou, Q.; Guo, R.; Yang, Z.; Chen, D.; Liu, X.; Hong, H.; Sun, L. Anal. Chem. 2018, 90, 10095-10099.

(7) Lageveen-Kammeijer, G. S. M.; de Haan, N.; Mohaupt, P.; Wagt, S.; Filius, M.; Nouta, J.; Falck, D.; Wuhrer, M. Nature Commun. 2019, 10:2137, 1-8.

(8) Sanderson, P.; Stickney, M.; Leach, F. E.; Xia, Q.; Yu, Y.; Zhang, F.; Linhardt, R. J.; Amster, I. J. J. Chromatogr. A 2018, 1545, 75-83.

(9) DiBattista, A.; Mclntosh, N.; Lamoureux, M.; Al-Dirbashi, O. Y.; Chakraborty, P.;

BritzMcKibbin, P. J. Proteome Res. 2019, 18, 841-854.

(10) Azab, S.; Ly, R.; Britz-McKibbin, P. Anal. Chem. 2019, 91, 2329-2336.

(11) Lombard-Banek, C.; Moody, S. A.; Manzini, M. C.; Nemes, P. Anal. Chem. 2019, 91, 47974805.

(12) Portero, E. P.; Nemes, P. Analyst 2019, 144, 892-900.

(13) Kawai, T.; Ota, N.; Okada, K.; Imasato, A.; Owa, Y.; Morita, M.; Tada, M.; Tanaka, Y. Anal. Chem. 2019, 91, 10564-10572.

(14) Kawai, T.; Ota, N.; Imasato, A.; Shirasaki, Y.; Otsuka, K.; Tanaka, Y. J. Chromatogr. A 2018, 1565, 138-144.

(15) Chen, D.; Shen, X.; Sun, L. Anal. Chim. Acta 2018, 1012, 1-9.

(16) Yang, Z.; Shen, X.; Chen, D.; Sun, L. Anal. Chem. 2018, 90, 10479-10486.

(17) Faserl, K.; Sarg, B.; Gruber, P.; Lindner, H. H. Electrophoresis 2018, 39, 1208-1215.

(18) Qu, Y.; Sun, L.; Zhang, Z.; Dovichi, N. J. Anal. Chem. 2018, 90, 1223-1233.

(19) Zhang, Z.; Dovichi, N. J. Anal. Chim. Acta 2018, 1001, 93-99.

(20) Wang, L.; Bo, T.; Zhang, Z.; Wang, G.; Tong, W.; Da Yong Chen, D. Anal. Chem. 2018, 90, 9495-9503.

(21) Montealegre, C.; Neusüß, C. Electrophoresis 2018, 39, 1151-1154. 
(22) Dai, J.; Zhang, Y. Anal. Chem. 2018, 90, 14527-14534.

(23) Belov, A. M.; Zang, L.; Sebastiano, R.; Santos, M. R.; Bush, D. R.; Karger, B. L.; Ivanov, A. R. Electrophoresis 2018, 39, 2069-2082.

(24) Smith, R. D.; Barinaga, C. J.; Udseth, H. R. Anal. Chem. 1988, 60, 1948-1952.

(25) Smith, R. D.; Olivares, J. A.; Nguyen, N. T.; Udseth, H. R. Anal. Chem. 1988, 60, 436-441.

(26) Guo, X.; Fillmore, T. L.; Gao, Y.; Tang, K. Anal. Chem. 2016, 88, 4418-4425.

(27) Moini, M. Anal. Chem. 2007, 79, 4241-4246.

(28) Hirayama, A.; Abe, H.; Yamaguchi, N.; Tabata, S.; Tomita, M.; Soga, T. Electrophoresis 2018, 39, 1382-1389.

(29) Lapainis, T.; Rubakhin, S. S.; Sweedler, J. V. Anal. Chem. 2009, 81, 5858-5864.

(30) Nemes, P.; Knolhoff, A. M.; Rubakhin, S. S.; Sweedler, J. V. Anal. Chem. 2011, 83, 68106817.

(31) Onjiko, R. M.; Moody, S. A.; Nemes, P. Proc. Natl. Acad. Sci. U S A 2015, 112, 6545-6550.

(32) Onjiko, R. M.; Portero, E. P.; Moody, S. A.; Nemes, P. Anal. Chem. 2017, 89, 7069-7076.

(33) Wojcik, R.; Dada, O. O.; Sadilek, M.; Dovichi, N. J. Rapid Commun. Mass Spectrom. 2010, 24, 2554-2560.

(34) Zhong, X.; Maxwell, E. J.; Chen, D. D. Y. Anal. Chem. 2011, 83, 4916-4923.

(35) Sun, L.; Zhu, G.; Zhang, Z.; Mou, S.; Dovichi, N. J. J. Proteome Res. 2015, 14, 2312-2321.

(36) Höcker, O.; Montealegre, C.; Neusüß, C. Anal. Bioanal. Chem. 2018, 410, 5265-5275.

(37) Mellors, J. S.; Gorbounov, V.; Ramsey, R. S.; Ramsey, J. M. Anal. Chem. 2008, 80, 68816887.

(38) Gilliland, W. M.; Ramsey, J. M. Anal. Chem. 2018, 90, 13000-13006.

(39) Redman, E. A.; Batz, N. G.; Mellors, J. S.; Ramsey, J. M. Anal. Chem. 2015, 87, 22642272.

(40) Redman, E. A.; Ramos-Payan, M.; Mellors, J. S.; Ramsey, J. M. Anal. Chem. 2016, 88, 53245330.

(41) Redman, E. A.; Mellors, J. S.; Starkey, J. A.; Ramsey, J. M. Anal. Chem. 2016, 88, 22202226.

(42) Peuchen, E. H.; Zhu, G.; Sun, L.; Dovichi, N. J. Anal. Bioanal. Chem. 2017, 409, 17891795.

(43) Silica Surface OptiMS Cartridge: https://us-store.sciex.com/USD/capillaryelectrophoresis/capillaries-and-cartridges/cartridges/Silica-Surface-OptiMS-CartridgezidB07367, accessed November 12, 2020. 
(44) CESI 8000 Plus High Performance Separation-ESI Module:

https://sciex.com/Documents/manuals/cesi-8000-plus-high-performance-separation-ESImodule-user-manual.pdf, accessed November 12, 2020.

(45) Jansson, E. T.; Dulay, M. T.; Zare, R. N. Anal. Chem. 2016, 88, 6195-6198.

(46) Li, X.; Attanayake, K.; Valentine, S. J.; Li, P. Rapid Commun. Mass Spectrom., 0.

(47) Ranganathan, N.; Li, C.; Suder, T.; Karanji, A. K.; Li, X.; He, Z.; Valentine, S. J.; Li, P. J. Am. Soc. Mass Spectrom. 2019.

(48) White, C. M.; Hanson, K. M.; Holland, L. A. Analytical Sciences Digital Library: http://www.asdlib.org/ 2005, ASDL Entry 10031, available at https://collection.asdlib.org/micro-separations-distance-ce/ with instructions for constructing a custom instrument available at https://www.asdlib.org/onlineArticles/elabware/holland_research/sop.htmaccessed accessed August 27, 2019.

(49) Jussila, M.; Palonen, S.; Porras, S. P.; Riekkola, M.-L. Electrophoresis 2000, 21, 586-592.

(50) Mansoori, B. A.; Volmer, D. A.; Boyd, R. K. Rapid Commun. Mass Spectrom. 1997, 11, 11201130.

(51) Zhou, C.; Jin, Y.; Kenseth, J. R.; Stella, M.; Wehmeyer, K. R.; Heineman, W. R. J. Pharm. Sci. 2005, 94, 576-589.

(52) Shalaeva, M.; Kenseth, J.; Lombardo, F.; Bastin, A. J. Pharm. Sci. 2008, 97, 2581-2606.

(53) Oda, R. P.; Landers, J. P. In Handbook of capillary electrophoresis, 2nd edition, Landers, J. P., Ed.; Taylor \& Francis: Boca Raton, 1997, p page 869.

(54) do Lago, C. L.; Vidal, D. T. R.; Francisco, K. J. M.; dos Santos, V. B. Electrophoresis 2014, 35, 2412-2416.

(55) Busnel, J.-M.; Schoenmaker, B.; Ramautar, R.; Carrasco-Pancorbo, A.; Ratnayake, C.; Feitelson, J. S.; Chapman, J. D.; Deelder, A. M.; Mayboroda, O. A. Anal. Chem. 2010, 82, 9476-9483.

(56) Lindenburg, P. W.; Ramautar, R.; Jayo, R. G.; Chen, D. D. Y.; Hankemeier, T.

Electrophoresis 2014, 35, 1308-1314.

(57) Zhang, W.; Guled, F.; Hankemeier, T.; Ramautar, R. J. Chromatogr. B 2019, 1105, 10-14.

(58) Hwang, D. L. R.; Davis Lin, K. T.; Yang, W.-K.; Foard, D. E. Biochim. Biophys. Acta, Protein Struct. 1977, 495, 369-382.

(59) Hammond, R. W.; Foard, D. E.; Larkins, B. A. J. Biol. Chem. 1984, 259, 9883-9890.

(60) Odani, S.; Ikenaka, T. The Journal of Biochemistry 1977, 82, 1513-1522. 


\section{APPENDIX A}

This section includes all figures that are directly referenced in the main text of the thesis. 


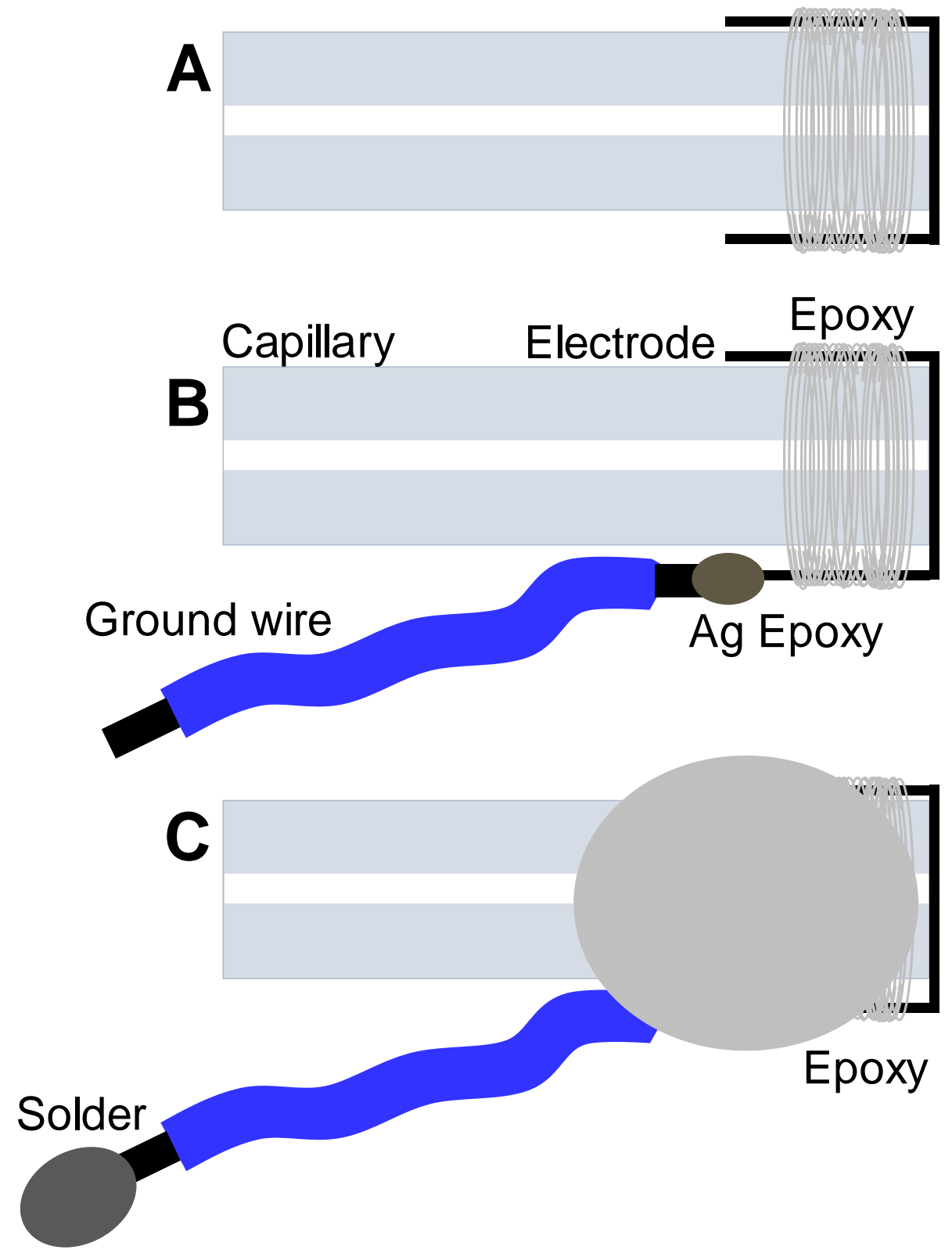

Figure A-1. Diagram for capillary fabrication expanded from Figure 1. (A) Wrap the platinum wire around the front of the capillary and secure with 1-minute epoxy. (B) Attach a longer thicker wire to the platinum wire with conductive silver epoxy. (C) Place a drop of solder on the end of the longer thicker wire so that the alligator clips can be attached. Cover the silver epoxy with 1-minute epoxy for insulation and stability. 

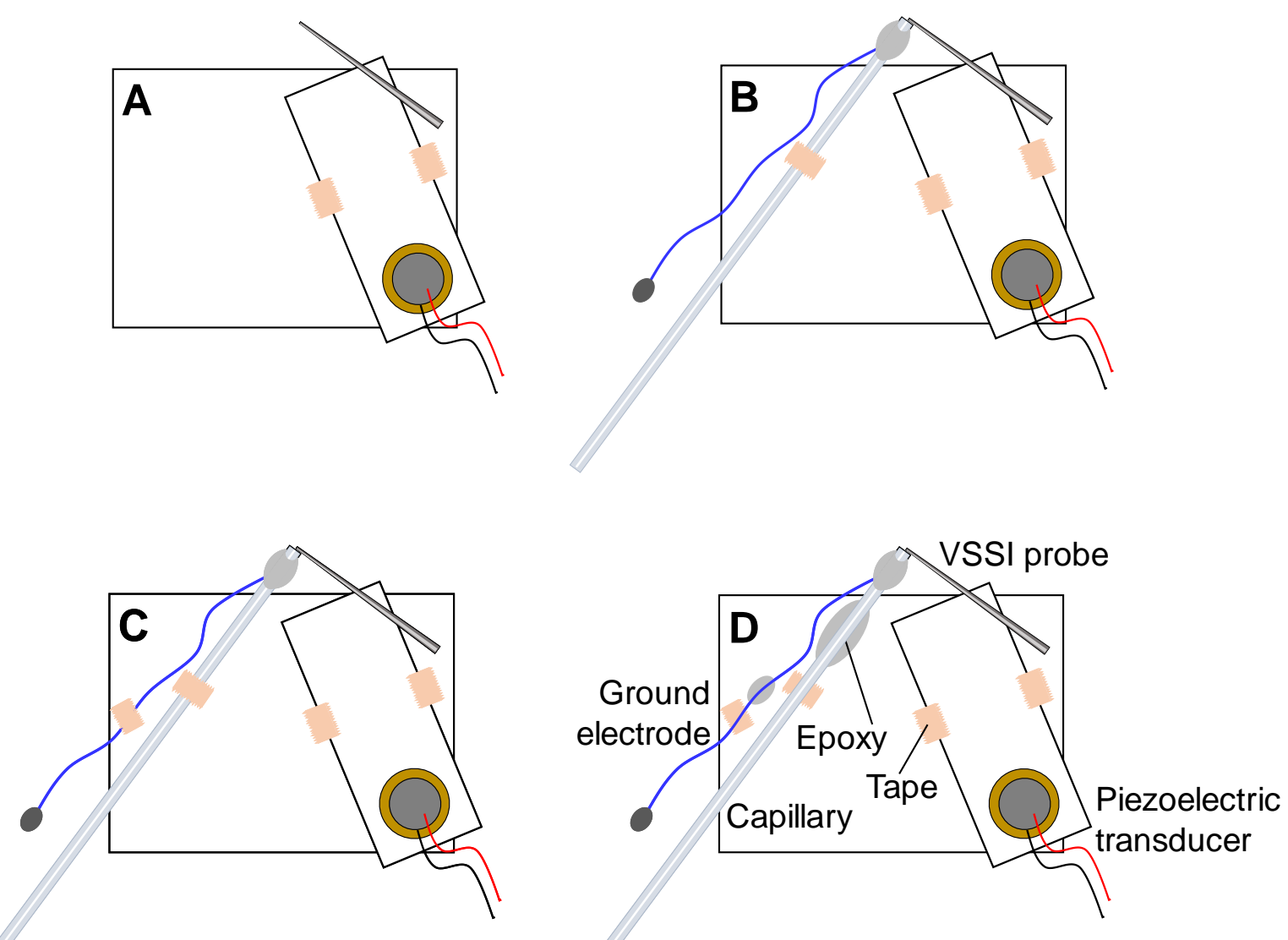

Figure A-2. Diagram for capillary and probe alignment expanded from Figure 2. (A) The glass coverslip with the piezoelectric transducer and spray probe is attached to the glass slide with tape keeping as much of the piezoelectric transducer over the glass slide as possible. (B) The capillary is positioned on the glass slide at a $90^{\circ}$ angle relative to the spray probe keeping the electrode parallel to the spray probe. It is held in place with tape. (C) Capillary and/or glass probe are adjusted until the desired alignment positions are achieved. Tape may be placed under the capillary or spray probe to lift either piece in the z-direction if necessary. Electrode is attached with tape to the glass slide. The electrode should not overlap the capillary and separate pieces of tape should be used to hold these two pieces in position. (D) A final drop of 1 -minute epoxy is placed on the capillary and electrode (should be 2 separate drops of epoxy) to hold them in place. 


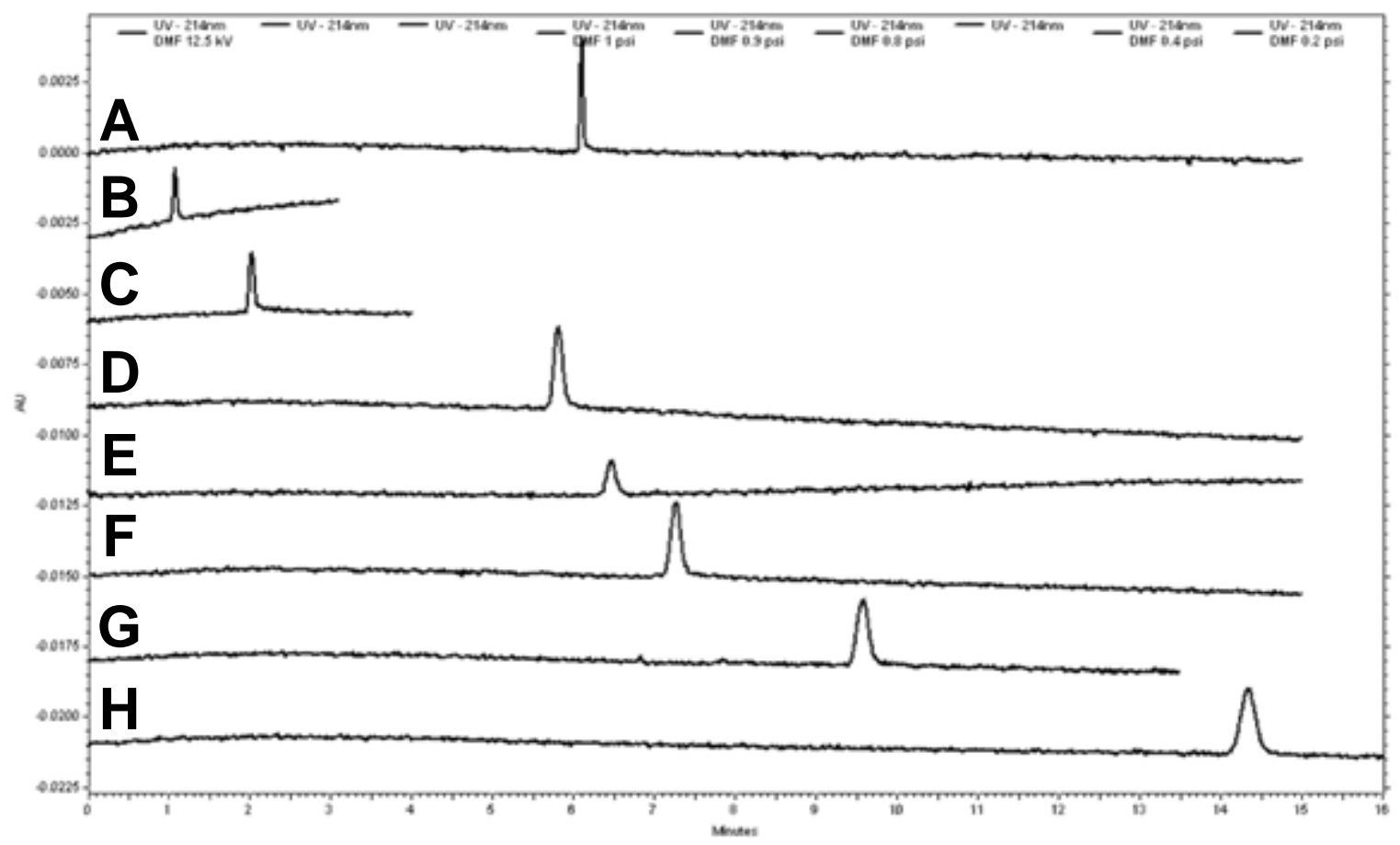

Figure A-3. Comparison of flow rates with pressure and voltage. CE-UV separation of dimethylformamide (neutral species). Separations occurred at $(A) 12.5 \mathrm{kV}(\mathrm{i}=10 \mu \mathrm{A}) \approx 130$ $\mathrm{nL} / \mathrm{min},(\mathrm{B}) 41 \mathrm{kPa}(6 \mathrm{psi}) \approx 730 \mathrm{~nL} / \mathrm{min},(\mathrm{C}) 21 \mathrm{kPa}(3 \mathrm{psi}) \approx 390 \mathrm{~nL} / \mathrm{min},(\mathrm{D}) 6.9 \mathrm{kPa}(1 \mathrm{psi}) \approx$ $135 \mathrm{~nL} / \mathrm{min}$, (E) $6.2 \mathrm{kPa}(0.9 \mathrm{psi}) \approx 120 \mathrm{~nL} / \mathrm{min},(\mathrm{F}) 5.5 \mathrm{kPa}(0.8 \mathrm{psi}) \approx 110 \mathrm{~nL} / \mathrm{min},(\mathrm{G}) 4.1 \mathrm{kPa}$ $(0.6 \mathrm{psi}) \approx 80 \mathrm{~nL} / \mathrm{min}$, and $(\mathrm{H}) 2.8 \mathrm{kPa}(0.4 \mathrm{psi}) \approx 55 \mathrm{~nL} / \mathrm{min}$. Separation was achieved with a $50 \mathrm{~cm}$ (total length), $40 \mathrm{~cm}$ (effective length), $50 \mu \mathrm{m}$ i.d. capillary with a background electrolyte of $25 \mathrm{mM}$ ammonium acetate, $\mathrm{pH} 6.5$.

Finding: An applied pressure between 6.2 and $6.9 \mathrm{kPa}(0.9$ and $1 \mathrm{psi})$ yields a similar flow rate to the applied electric field that is used in the separations. 


\section{Table A-1. Effect of capillary conditioning at pH 5}

\section{Time (RSD, $n=3$ )}

\begin{tabular}{lccccc}
\cline { 2 - 6 } & Normal $^{\mathrm{a}}$ & $\mathbf{0 . 1} \mathbf{~ N ~ N H} \mathbf{0 H}$ & $\mathbf{1 ~ N ~ N H} \mathbf{O H}^{\mathbf{c}}$ & Buffer $^{\mathrm{d}}$ & $\mathbf{H C l}^{\mathbf{e}}$ \\
Pindolol & $5.40(0.9)$ & $4.65(0.8)$ & $4.23(0.2)$ & $8.58(4)$ & $8.37(5)$ \\
Oxprenolol & $5.49(0.8)$ & $4.74(0.8)$ & $4.32(0.2)$ & $8.87(4)$ & $8.64(5)$ \\
Metoprolol & $5.61(0.9)$ & $4.83(0.8)$ & $4.40(0.3)$ & $9.20(4)$ & $8.95(5)$ \\
Acebutolol & $5.85(0.9)$ & $5.05(0.8)$ & $4.60(0.3)$ & $9.96(4)$ & $9.65(5)$ \\
\hline
\end{tabular}

${ }^{\mathrm{a}}$ Flush sequence: $60 \min 1 \mathrm{~N} \mathrm{NaOH}, 10 \min \mathrm{H}_{2} \mathrm{O}, 30$ min buffer all at $41 \mathrm{kPa}(6 \mathrm{psi})$.

${ }^{\mathrm{b}}$ Flush sequence: $60 \min 0.1 \mathrm{~N} \mathrm{NH}_{4} \mathrm{OH}, 10 \min \mathrm{H}_{2} \mathrm{O}, 30$ min buffer all at $41 \mathrm{kPa}(6 \mathrm{psi})$.

${ }^{c}$ Flush sequence: 60 min $1 \mathrm{~N} \mathrm{NH}_{4} \mathrm{OH}, 10 \mathrm{~min} \mathrm{H}_{2} \mathrm{O}, 30$ min buffer all at $41 \mathrm{kPa}$ (6 psi).

${ }^{\mathrm{d}}$ Flush sequence: $30 \mathrm{~min}$ buffer at $41 \mathrm{kPa}(6 \mathrm{psi})$.

${ }^{\mathrm{e}}$ Flush sequence: $60 \min 1 \mathrm{M} \mathrm{HCl}, 10 \mathrm{~min} \mathrm{H}_{2} \mathrm{O}, 30 \mathrm{~min}$ buffer all at $41 \mathrm{kPa}$ (6 psi).

Finding: The flush sequence than behaves most similar to the normal flush is replacing $1 \mathrm{~N}$ sodium hydroxide with $0.1 \mathrm{M}$ ammonium hydroxide. A normal flush could not be used with the CE-VSSI-MS system because the sodium hydroxide etched the tip of the spray probe and left residual sodium that was observed in the mass spectra. 
$===$ Tune Data: $===$ :

$\begin{array}{ll}\text { Spray Voltage }(+): & 0.00 \\ \text { Spray Voltage }(-): & 1500.00 \\ \text { Capillary Temperature }(+ \text { or }+-): & 350.00 \\ \text { Capillary Temperature }(-): & 250.00 \\ \text { Sheath Gas }(+ \text { or }+-): & 0.00 \\ \text { Sheath Gas }(-): & 10.00 \\ \text { Aux Gas (+ or +-): } & 10.00 \\ \text { Aux Gas (-): } & 11.00 \\ \text { Spare Gas (+ or +-) : } & 2.00 \\ \text { Spare Gas (-): } & 0.00 \\ \text { Max Spray Current (+): } & 100.00 \\ \text { Max Spray Current (-): } & 100.00 \\ \text { Probe Heater Temp. (+ or +-): } & 250.00 \\ \text { Probe Heater Temp. (-): } & 300.00 \\ \text { S-Lens RF Level: } & 50.00\end{array}$

Figure A-4. Mass spectrometer settings. These settings were used for data collection on the $\mathrm{Q}$-exactive mass spectrometer. Those highlighted in green are the conditions that were most important to pay attention to and keep that same for every experiment. 

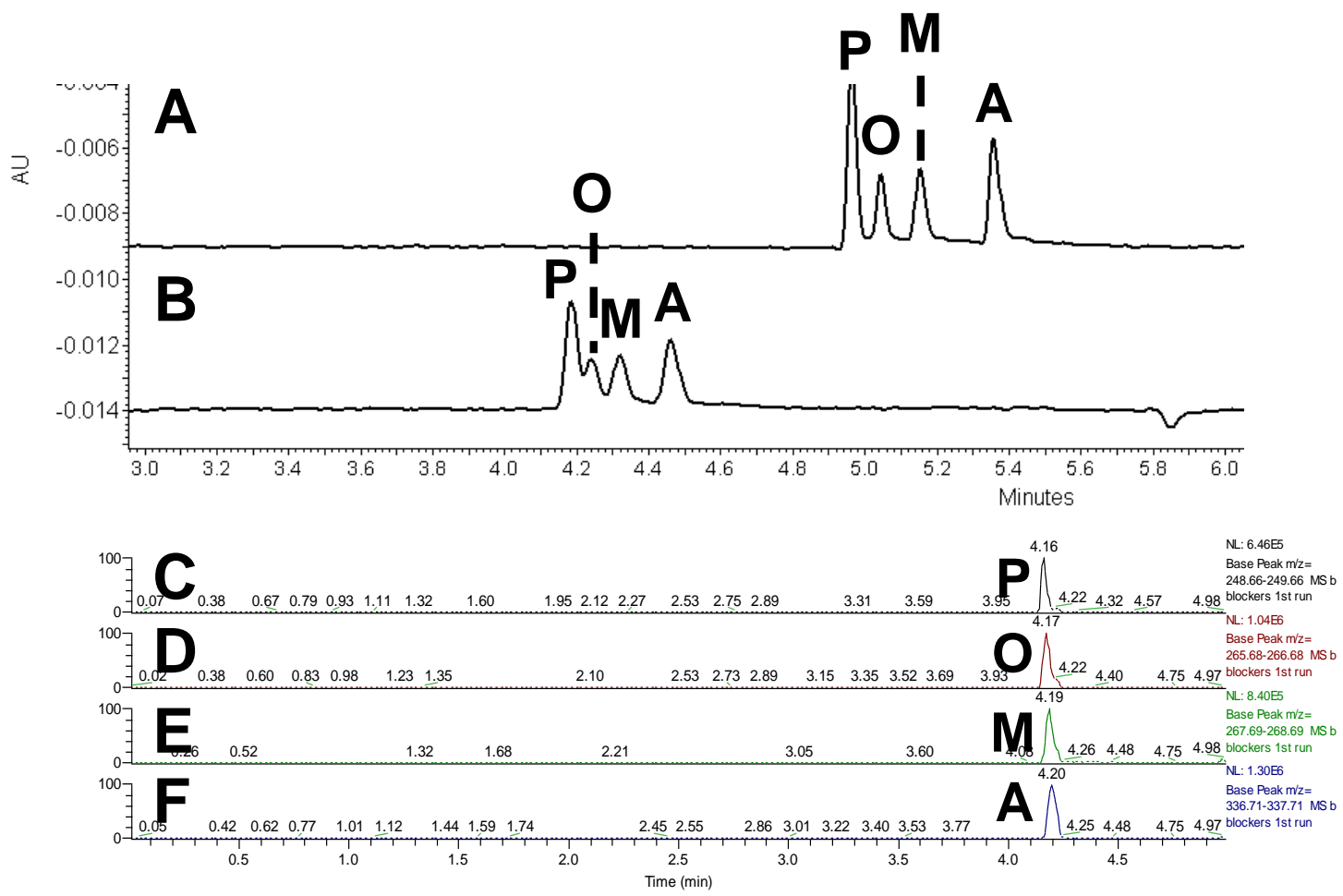

Figure A-5. Effect of siphoning on $\beta$-blocker separations. CE-UV separation of pindolol, oxprenolol, metoprolol, and acebutolol with (A) no pressure assist and (B) $0.69 \mathrm{kPa}(0.1 \mathrm{psi})$ pressure assist. Without a pressure assist, plate counts are 182,000,160,000,157,000, and 163,000 for $\mathrm{P}, \mathrm{O}, \mathrm{M}$, and $\mathrm{A}$, respectively. With the pressure assist, plate counts are 66,000 , 49,000 , and 50,000 for $P, M$, and A, respectively. No plate counts could be calculated for $O$ with the pressure assist applied because there was not enough resolution from $P$ to obtain an accurate peak width. Extracted ion electropherograms of (C) pindolol, (D) oxprenolol, (E) metoprolol, and (F) acebutolol from the CE-VSSI-MS separation. The CE-UV separation was achieved with a $50 \mathrm{~cm}$ (total length), $40 \mathrm{~cm}$ (effective length), $50 \mu \mathrm{m}$ i.d. capillary at an applied voltage of $+12.5 \mathrm{kV}(\mathrm{i}=10 \mu \mathrm{A})$ with a background electrolyte of $25 \mathrm{mM}$ ammonium acetate, $\mathrm{pH}$ 6.5. The CE-VSSI-MS separation was achieved with a $40 \mathrm{~cm}$ (total and effective length), $50 \mu \mathrm{m}$ i.d. capillary at an applied voltage of $+10 \mathrm{kV}(\mathrm{i}=10 \mu \mathrm{A})$ with a background electrolyte of $25 \mathrm{mM}$ ammonium acetate, $\mathrm{pH}$ 6.5. Note: Time scales on the two pieces of data are different.

Abbreviations: pindolol $(\mathrm{P})$, oxprenolol $(\mathrm{O})$, metoprolol $(\mathrm{M})$, acebutolol $(\mathrm{A})$

Finding 1: Adding a pressure assist of $0.69 \mathrm{kPa}(0.1 \mathrm{psi})$ causes the theoretical plate counts of the $\beta$-blockers to decrease at least 2-fold.

Finding 2: The $\beta$-blockers migrate faster with CE-VSSI-MS than CE-UV because there is siphoning present. Note: This problem was resolved by leveling the system with textbooks and a labjack. 

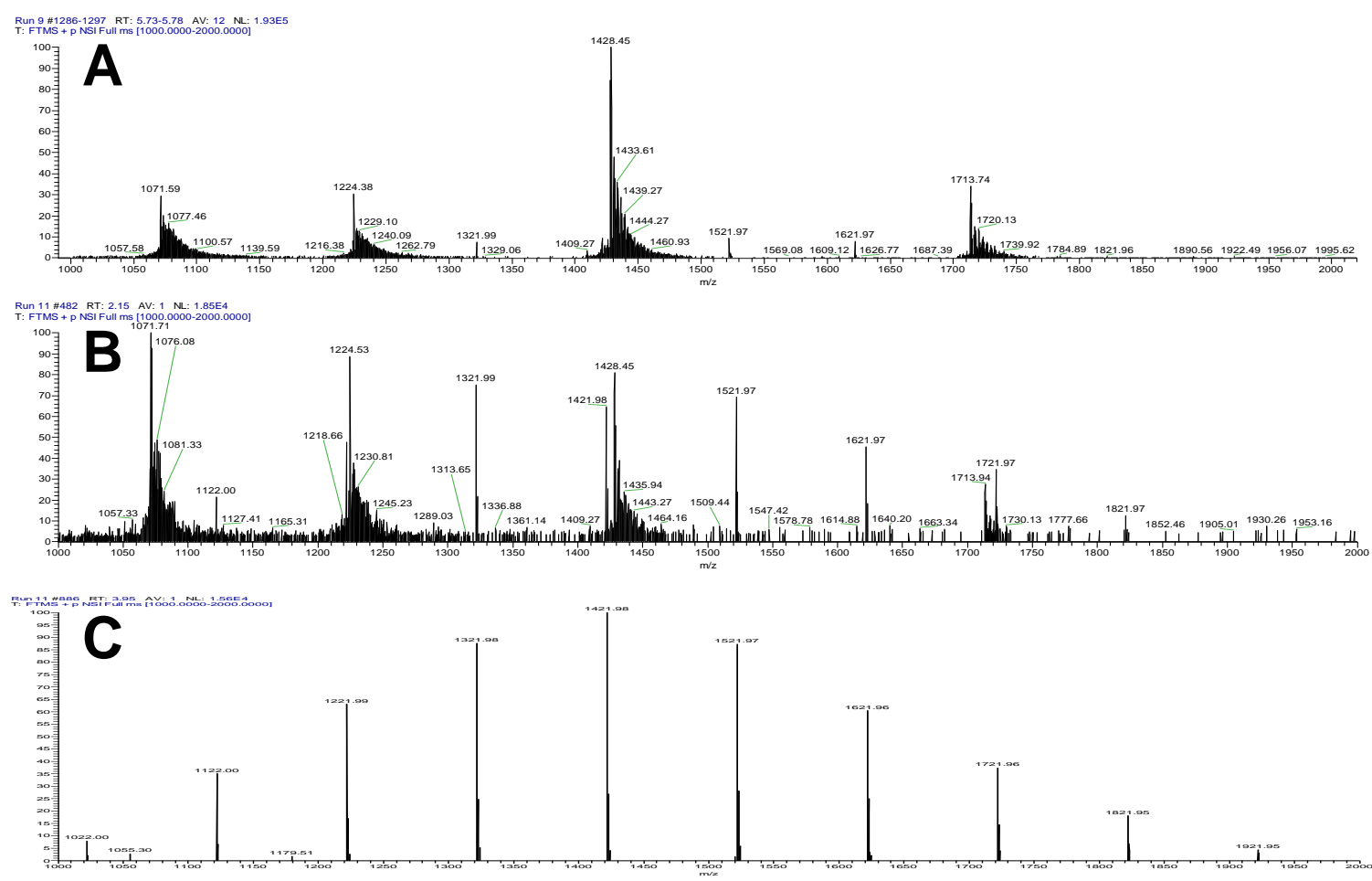

Figure A-6. Example of contamination in CE-VSSI-MS analysis. The mass spectra of the dominant charge states of $(A)$ ubiquitin, $(B)$ ubiquitin with contamination, and $(C)$ contamination is shown. The contamination observed in (B) and $(C)$ is carryover from the calibration mix that was used to calibrate the instrument. Separation was achieved with a 40 $\mathrm{cm}$ (total and effective length), $50 \mu \mathrm{m}$ i.d. capillary at an applied voltage of $+10 \mathrm{kV}(\mathrm{i}=22 \mu \mathrm{A})$ with a background electrolyte of $50 \mathrm{mM}$ ammonium acetate, $\mathrm{pH}$ 6.5. 


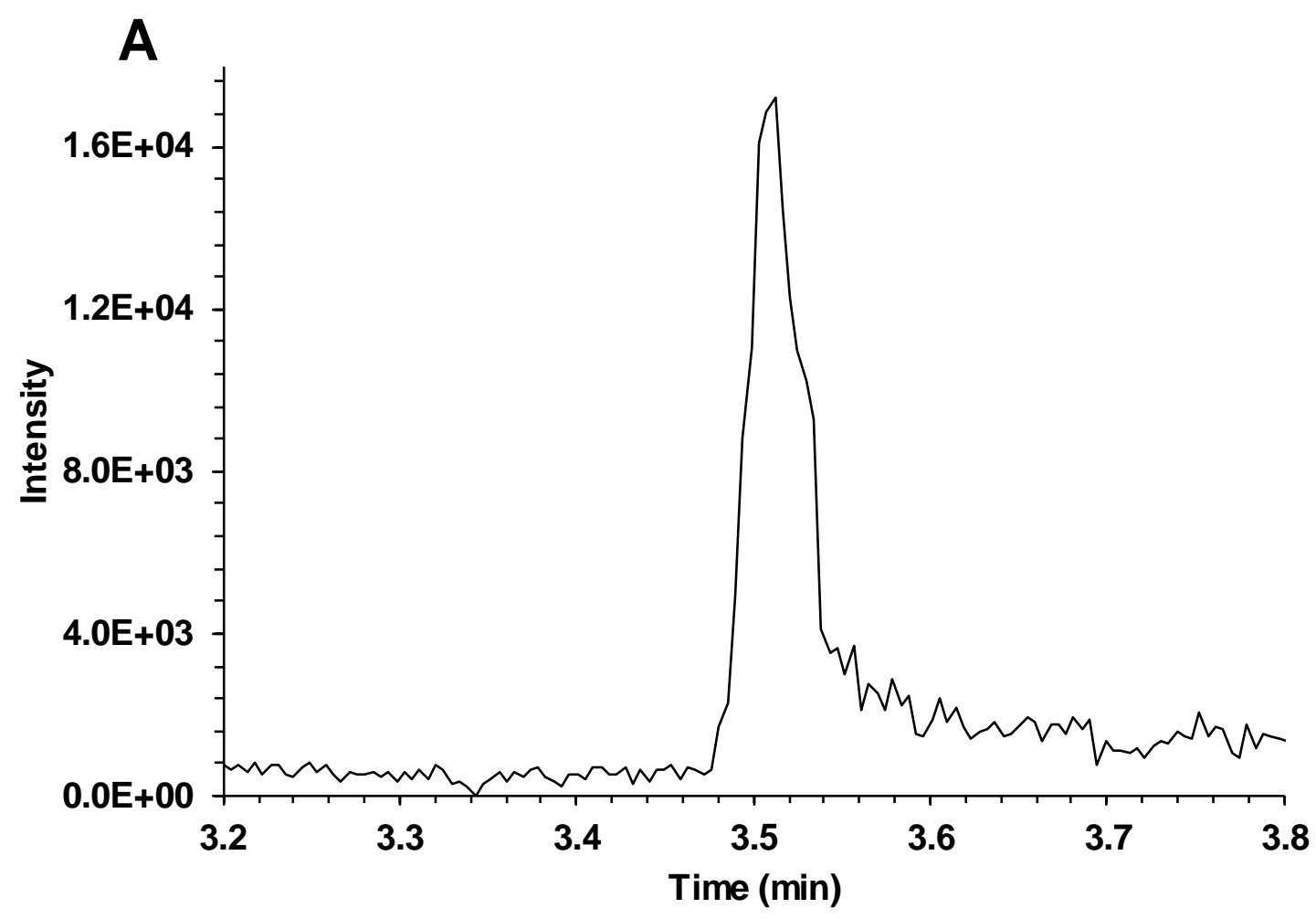

$\begin{array}{llr}\text { B } & \text { peak } & \\ \text { start } & 3.480751 \\ \text { stop } & 3.59664 \\ \text { width } & 0.11589 \\ \text { points } & 27\end{array}$

max intensity $\quad 17232.66$ average intensity 3.538696

\begin{tabular}{lr} 
noise & \\
\hline start & 3.302461 \\
stop & 3.418348 \\
width & 0.115888 \\
points & 27
\end{tabular}

average intensity 3.360405

SD intensity $\quad 0.035378$

RSD intensity $\quad 1.052798$

$\mathrm{S} / \mathrm{N}=(\operatorname{Imax}) /($ SDnoise $)$ $\mathrm{S} / \mathrm{N}$ 487097.1

Figure A-7. Determination of LOD and LOQ. (A) Extracted ion electropherogram from the CEVSSI-MS separation of pindolol. (B) Raw data imported from Excel used to calculate the LOD and LOQ for pindolol. The calculated values (in $\mu \mathrm{M}$ ) are highlighted in green. The CE-VSSIMS separation was achieved with a $40 \mathrm{~cm}$ (total and effective length), $50 \mu \mathrm{m}$ i.d. capillary at an applied voltage of $+10 \mathrm{kV}(\mathrm{i}=10 \mu \mathrm{A})$ with a background electrolyte of $25 \mathrm{mM}$ ammonium acetate, $\mathrm{pH} 6.5$. 

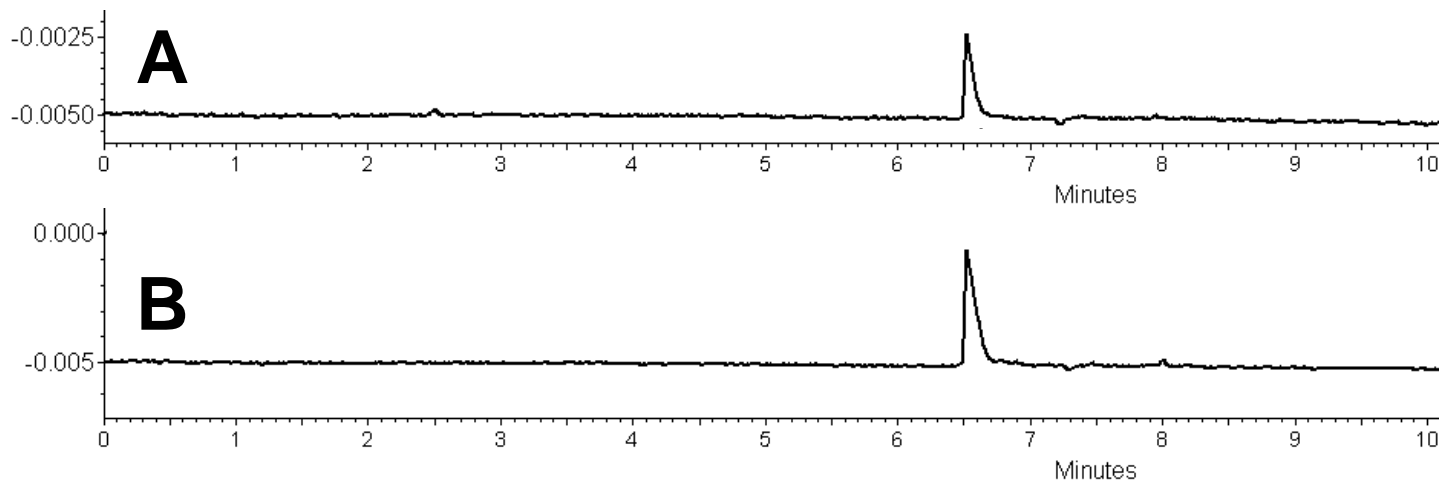

Figure A-8. Comparison of electrokinetic and hydrodynamic injections. CE-UV separation of $100 \mu \mathrm{M}$ angiotensin with a (A) $5 \mathrm{kV}, 2 \mathrm{~s}$ and (B) $2.1 \mathrm{kPa}(0.3 \mathrm{psi}), 3 \mathrm{~s}$ injection. Separation was achieved with a $50 \mathrm{~cm}$ (total length), $40 \mathrm{~cm}$ (effective length), $50 \mu \mathrm{m}$ i.d. capillary at an applied voltage of $+12.5 \mathrm{kV}(\mathrm{i}=10 \mu \mathrm{A})$ with a background electrolyte of $25 \mathrm{mM}$ ammonium acetate, $\mathrm{pH} 6.5$.

Finding: Since the electrokinetic injection had about half the area as the hydrodynamic injection, it can be concluded that a $10 \mathrm{kV}, 2 \mathrm{~s}$ injection is equivalent to a $2.1 \mathrm{kPa}(0.3 \mathrm{psi}), 3 \mathrm{~s}$ injection. 
<smiles>CC(C)NCC(O)COc1cccc2[nH]ccc12</smiles><smiles>C=CCOc1ccccc1OCC(O)CNC(C)C</smiles><smiles>COCCc1ccc(OCC(O)CNC(C)C)cc1</smiles><smiles>CCCC(=O)Nc1ccc(OCC(O)CNC(C)C)c(C(C)=O)c1</smiles>

Figure A-9. $\beta$-blocker structures: (A) pindolol, (B) oxprenolol, (C) metoprolol, and (D) acebutolol. 
Table A-2. Mass injected for each analyte

\begin{tabular}{lcccc}
\hline & \multicolumn{2}{c}{$\mathrm{pH} \mathrm{5}^{\mathrm{a}}$} & \multicolumn{2}{c}{$\mathrm{pH} \mathrm{6.5}^{\mathrm{b}}$} \\
\cline { 2 - 5 } & {$[\mu \mathrm{M}]$} & $\begin{array}{c}\text { mass injected } \\
(\mathrm{pg})\end{array}$ & {$[\mu \mathrm{M}]$} & $\begin{array}{c}\text { mass injected } \\
(\mathbf{p g})\end{array}$ \\
Pindolol & 10 & 13 & 1 & 1.4 \\
Acebutolol & 10 & 16 & 1 & 1.7 \\
Somatostatin & 50 & 370 & 50 & 370 \\
Oxytocin & 50 & 210 & 50 & 210 \\
Ubiquitin & $\mathrm{N} / \mathrm{A}$ & $\mathrm{N} / \mathrm{A}$ & $10^{\mathrm{a}}$ & $290^{\mathrm{C}}$ \\
\hline
\end{tabular}

${ }^{\mathrm{a}} \mathrm{pH}$ 5, $25 \mathrm{mM}$ acetic acid

${ }^{\mathrm{b}} \mathrm{pH}$ 6.5, $25 \mathrm{mM}$ ammonium acetate

${ }^{\mathrm{c}} \mathrm{pH}$ 6.5, $50 \mathrm{mM}$ ammonium acetate 

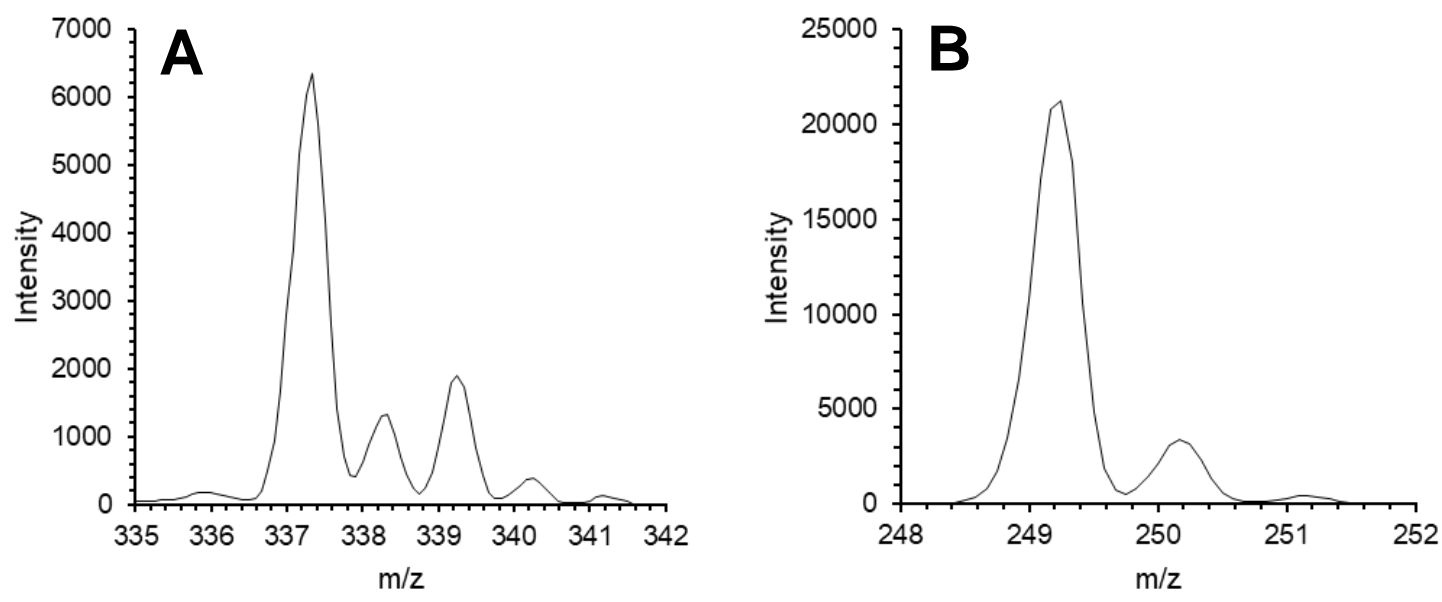

Figure A-10. Mass spectra for $\beta$-blockers, $\mathrm{pH}$ 5. The mass spectra of the isotopic envelope for the +1 charge state for $(A)$ pindolol and $(B)$ acebutolol is shown. Separation was achieved with a $40 \mathrm{~cm}$ (total and effective length), $50 \mu \mathrm{m}$ i.d. capillary at an applied voltage of $+10 \mathrm{kV}$ with a background electrolyte of $25 \mathrm{mM}$ acetic acid, $\mathrm{pH}$ 5. This corresponds to the data in Figure $8 \mathrm{a}$. 
Table A-3. Migration time at pH 5 (CE-VSSI-MS vs CE-UV)

\begin{tabular}{lcc}
\hline & CE-VSSI-MS & CE-UV \\
\cline { 2 - 3 } & Time (RSD, $\boldsymbol{n}=3)$ & Time (RSD, $\boldsymbol{n}=3$ ) \\
Pindolol $^{\mathrm{a}}$ & $3.9(5)$ & $4.101(0.1)$ \\
Acebutolol $^{\mathrm{b}}$ & $4.2(5)$ & $4.354(0.09)$ \\
Somatostatin $^{\mathrm{c}}$ & $4.84(0.7)$ & $4.62(0.4)$ \\
Oxytocin $^{\mathrm{d}}$ & $4.86(0.3)$ & $4.97(0.4)$ \\
\hline
\end{tabular}

${ }^{a}$ Statistically similar based on a Student $t$ test for the comparison of two means (t value $1.613<4.303$ ).

${ }^{b}$ Statistically similar based on a Student $t$ test for the comparison of two means (t value $1.062<4.303$ ).

${ }^{\mathrm{c}}$ Statistically different based on a Student $t$ test for the comparison of two means (t value $9.664>2.776$ ).

${ }^{d}$ Statistically different based on a Student $t$ test for the comparison of two means (t value $7.116>2.776$ ). 
Table A-4. Separation efficiency at pH 5 (CE-VSSI-MS vs CE-UV)

\begin{tabular}{lcc}
\hline & CE-VSSI-MS $^{\mathrm{a}}$ & CE-UV $^{\mathrm{b}}$ \\
\cline { 2 - 3 } & ${\text { Plates (RSD, } \boldsymbol{n}=\mathbf{3}^{\mathrm{c}}}^{\mathrm{c}}$ & ${\text { Plates (RSD, } \boldsymbol{n}=\mathbf{3})^{\mathrm{c}}}^{\text {Pindolol }}$ \\
Acebutolol & $14,000(30)$ & $39,000(10)$ \\
Somatostatin & $20,000(50)$ & $26,000(30)$ \\
Oxytocin & $5000(30)$ & $9000(30)$ \\
\hline
\end{tabular}

${ }^{\mathrm{a}}$ Values for peak width were obtained with 2 significant figures.

${ }^{b}$ Values for peak width were obtained with 4 significant figures.

${ }^{\mathrm{C}}$ Calculated by determining the width at base $(\mathrm{w})$ as $\mathrm{N}=16 \mathrm{t}^{2} / \mathrm{w}^{2}$ 
Table A-5. Peptide charges and sequences

\begin{tabular}{|c|c|c|}
\hline & Net Charge & Sequence $^{a}$ \\
\hline Somatostatin & $2+$ & $\mathrm{AGCK}^{+} \mathrm{NFFWK}{ }^{+} \mathrm{TFTSC}^{-}$ \\
\hline Oxytocin & 0 & CYIQNCPLG \\
\hline Angiotensin & $\sim 2+$ & $\mathrm{D}^{-} \mathrm{R}^{+} \mathrm{VYIH}{ }^{-+} \mathrm{PFH}{ }^{\sim+} \mathrm{L}^{\mathrm{b}}$ \\
\hline REDV & $1-$ & $R^{+} E^{-} D^{-} V$ \\
\hline
\end{tabular}

${ }^{a}$ Charges of each amino acid are given as a superscript following the single letter abbreviation.

${ }^{b}$ Histidine was considered to have $a+1 / 2$ charge. 

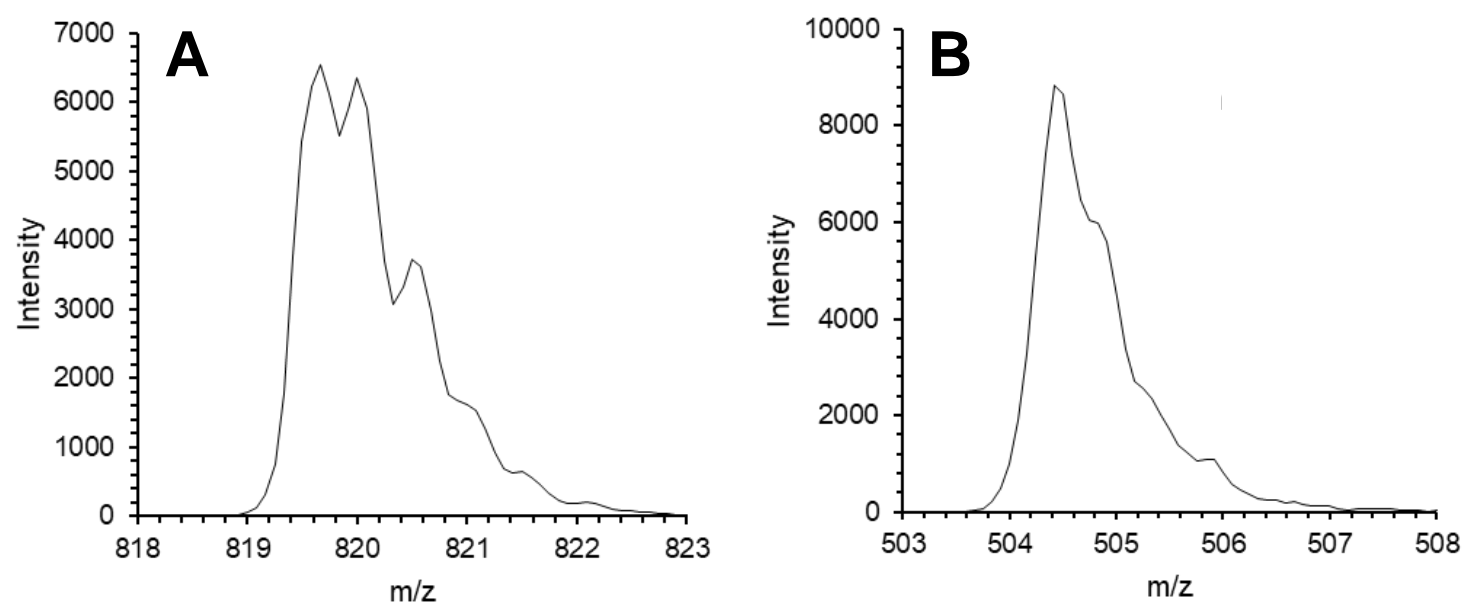

Figure A-11. Mass spectra for peptides, $\mathrm{pH}$ 5. The mass spectra of the isotopic envelope for the +2 charge state for (A) somatostatin and (B) oxytocin is shown. Separation was achieved with a $40 \mathrm{~cm}$ (total and effective length), $50 \mu \mathrm{m}$ i.d. capillary at an applied voltage of $+10 \mathrm{kV}$ with a background electrolyte of $25 \mathrm{mM}$ acetic acid, $\mathrm{pH}$ 5. This corresponds to the data in Figure 9a. 

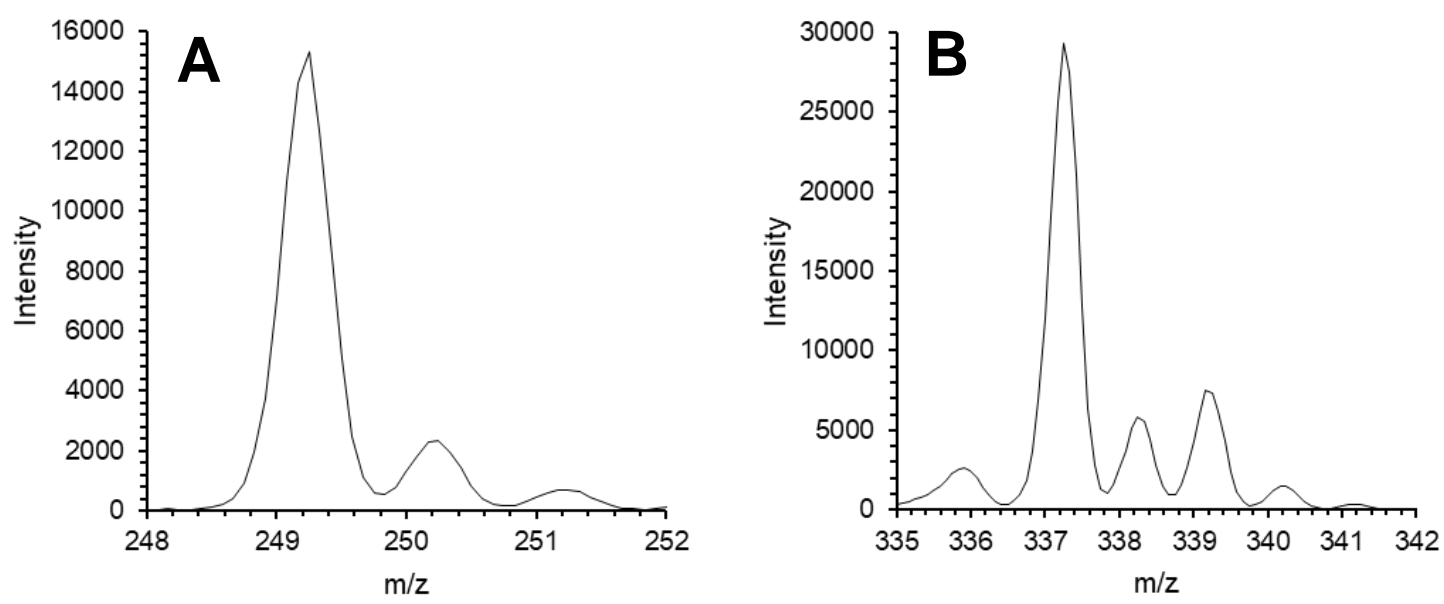

Figure A-12. Mass spectra for $\beta$-blockers, $\mathrm{pH}$ 6.5. The mass spectra of the isotopic envelope for the +1 charge state for $(A)$ pindolol and $(B)$ acebutolol is shown. Separation was achieved with a $40 \mathrm{~cm}$ (total and effective length), $50 \mu \mathrm{m}$ i.d. capillary at an applied voltage of $+10 \mathrm{kV}$ ( $\mathrm{i}$ $=10 \mu \mathrm{A}$ ) with a background electrolyte of $25 \mathrm{mM}$ ammonium acetate, $\mathrm{pH}$ 6.5. This corresponds to the data in Figure 10a. 
Table A-6. Migration time at pH 6.5 (CE-VSSI-MS vs CE-UV)

\begin{tabular}{lcc}
\hline & CE-VSSI-MS & CE-UV \\
\cline { 2 - 3 } Pindolol & Time (RSD, $\boldsymbol{n = 3 )}$ & Time (RSD, $\boldsymbol{n = 3 )}$ \\
Acebutolol & $3.59(0.5)$ & $3.84(1)$ \\
Somatostatin & $3.85(0.7)$ & $4.06(1)$ \\
Oxytocin & $4.7(10)$ & $4.6(3)$ \\
Ubiquitin & $4.9(10)$ & $5.06(0.7)$ \\
Trypsin inhibitor & $7.5(2)$ & $5.60(1)$ \\
\hline
\end{tabular}




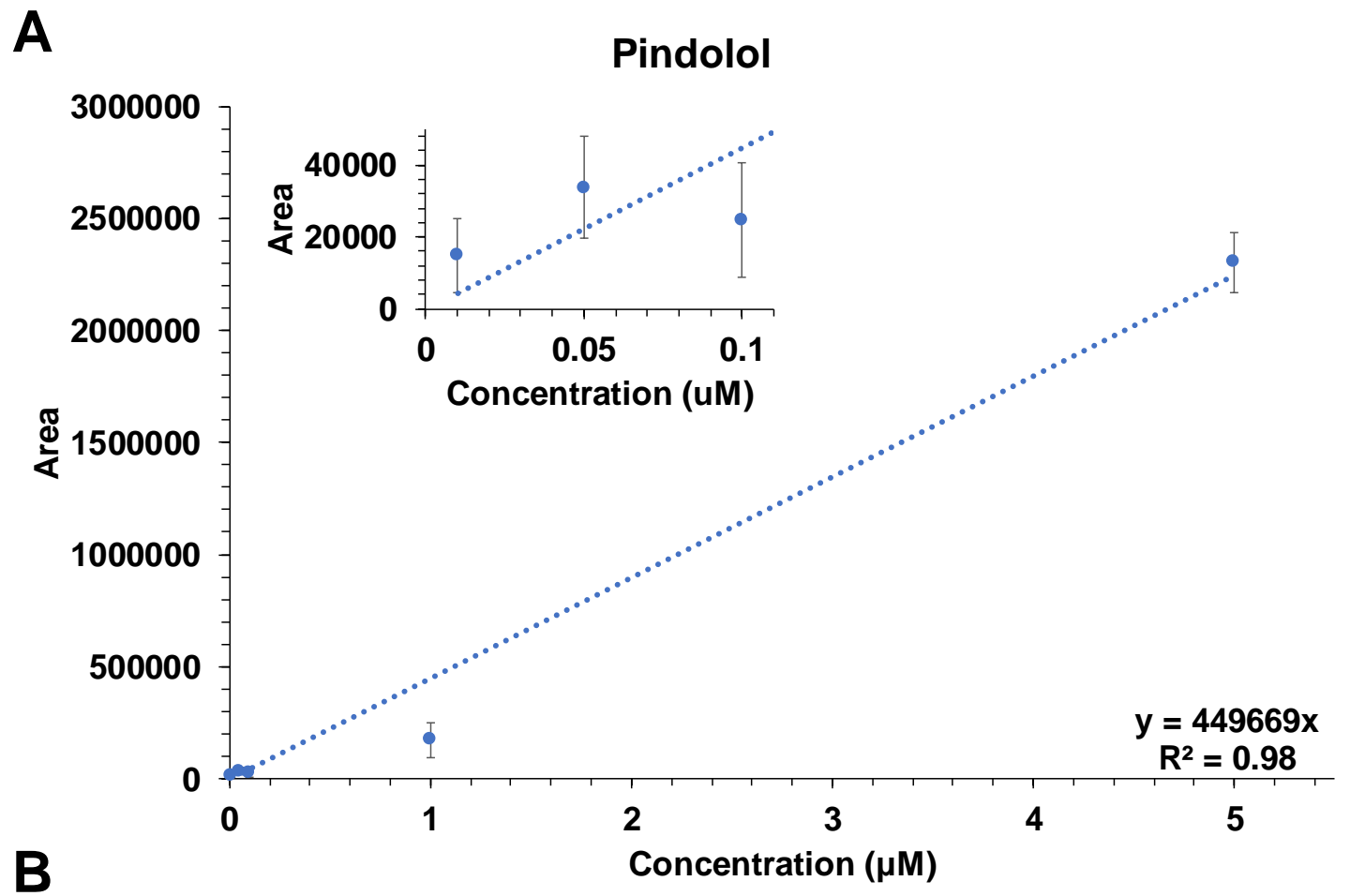

Concentration Avg. area (auto) Avg. area (manual)

\begin{tabular}{lcc}
\hline $\mathbf{0 . 0 1}$ & 14834.33333 & 14834 \\
$\mathbf{0 . 0 5}$ & 34521.66667 & 33689 \\
$\mathbf{0 . 1}$ & 25521.66667 & 24747 \\
$\mathbf{1}$ & 181041 & 171985 \\
$\mathbf{5}$ & 2425057.5 & 2304152 \\
$\mathbf{1 0}$ & 2240771.333 & 2102112
\end{tabular}

\begin{tabular}{lcccc} 
Concentration & auto SD & manual SD & auto RSD manual RSD \\
\hline $\mathbf{0 . 0 1}$ & 10248.66066 & 10248.66066 & 69 & 69 \\
$\mathbf{0 . 0 5}$ & 13768.04301 & 14154.05106 & 40 & 42 \\
$\mathbf{0 . 1}$ & 17358.88733 & 16078.85861 & 68 & 65 \\
$\mathbf{1}$ & 78457.84575 & 76396.84406 & 43 & 44 \\
$\mathbf{5}$ & 185679.8768 & 133862.3847 & 8 & 6 \\
$\mathbf{1 0}$ & 1542594.098 & 1423839.139 & 69 & 68
\end{tabular}

Figure A-13. Pindolol calibration curve. (A) Calibration curve for pindolol with error bars representing \pm standard deviation. (B) Raw data imported from Excel used to generate the calibration curve for pindolol. The plotted area values are highlighted in green. Values with "auto" next to them were based off the areas that the Xcalibur software generated during integration, while values with "manual" next to them were based off the areas that were manually selected for integration. Manual values were selected to start and stop at the beginning and end of the analyte peak, respectively. The CE-VSSI-MS separation was achieved with a $40 \mathrm{~cm}$ (total and effective length), $50 \mu \mathrm{m}$ i.d. capillary at an applied voltage of $+10 \mathrm{kV}(\mathrm{i}=10 \mu \mathrm{A})$ with a background electrolyte of $25 \mathrm{mM}$ ammonium acetate, $\mathrm{pH}$ 6.5. 


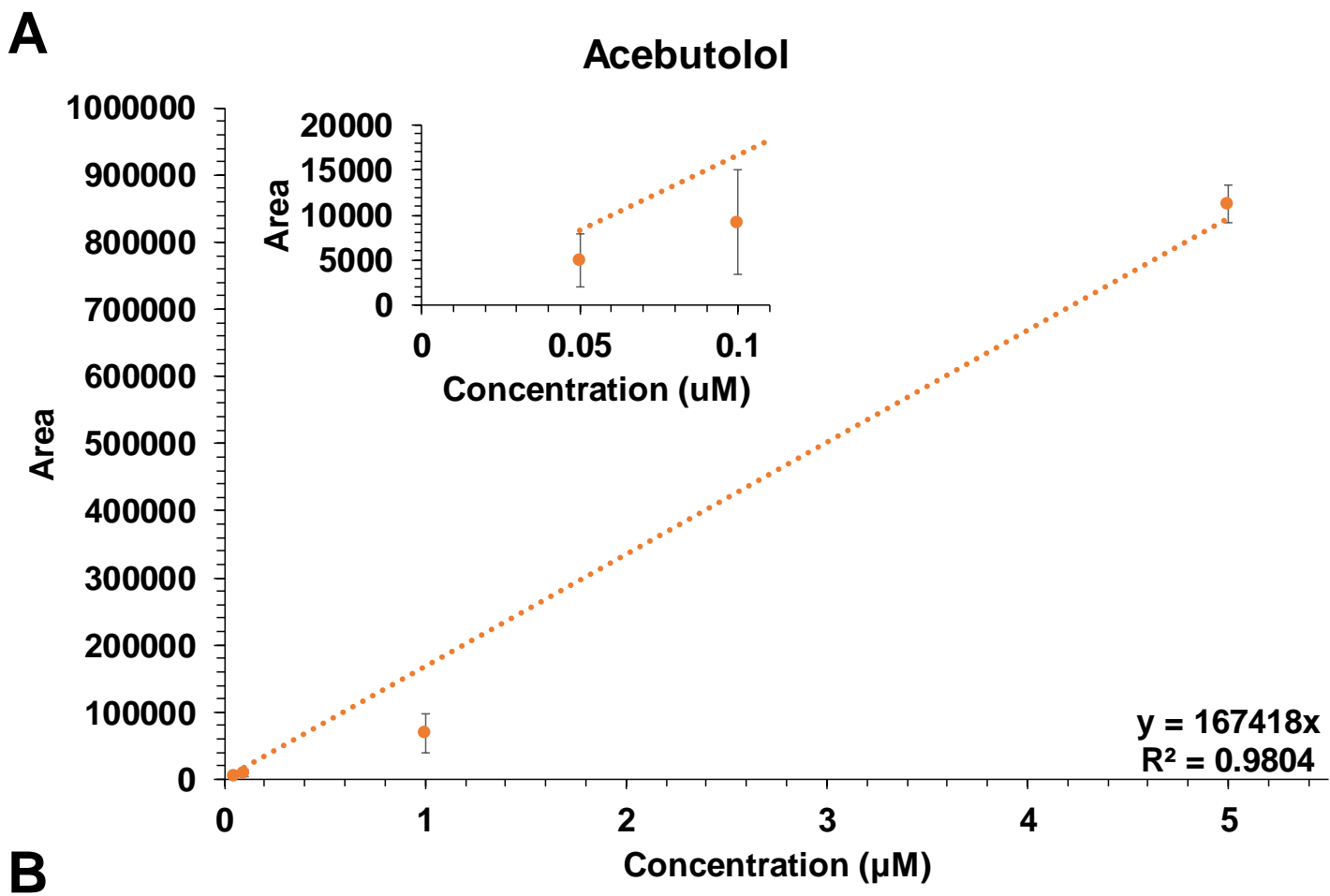

\begin{tabular}{lcc} 
Concentration & Avg. area (auto) & Avg. area (manual) \\
\hline $\mathbf{0 . 0 1}$ & $\mathrm{N} / \mathrm{A}$ & $\mathrm{N} / \mathrm{A}$ \\
$\mathbf{0 . 0 5}$ & 5004 & 5004 \\
$\mathbf{0 . 1}$ & 9211.333333 & 9211 \\
$\mathbf{1}$ & 72404 & 68966 \\
$\mathbf{5}$ & 916209 & 856965 \\
$\mathbf{1 0}$ & 814706 & 772776
\end{tabular}

\begin{tabular}{lcccc} 
Concentration & auto SD & manual SD & \multicolumn{2}{c}{ auto RSD } \\
\hline $\mathbf{0 . 0 1}$ & $\mathrm{N} / \mathrm{A}$ & $\mathrm{N} / \mathrm{A}$ & $\mathrm{N} / \mathrm{A}$ & $\mathrm{N} / \mathrm{A}$ \\
$\mathbf{0 . 0 5}$ & 2977.919408 & 2977.919408 & 60 & 60 \\
$\mathbf{0 . 1}$ & 5782.525083 & 5782.525083 & 63 & 63 \\
$\mathbf{1}$ & 32220.02367 & 29291.16816 & 45 & 42 \\
$\mathbf{5}$ & 16336.99507 & 28412.96468 & 2 & 3 \\
$\mathbf{1 0}$ & 422727.8091 & 394030.5673 & 52 & 51
\end{tabular}

Figure A-14. Acebutolol calibration curve. (A) Calibration curve for acebutolol with error bars representing \pm standard deviation. (B) Raw data imported from Excel used to generate the calibration curve for acebutolol. The plotted area values are highlighted in green. Values with "auto" next to them were based off the areas that the Xcalibur software generated during integration, while values with "manual" next to them were based off the areas that were manually selected for integration. Manual values were selected to start and stop at the beginning and end of the analyte peak, respectively. The CE-VSSI-MS separation was achieved with a $40 \mathrm{~cm}$ (total and effective length), $50 \mu \mathrm{m}$ i.d. capillary at an applied voltage of $+10 \mathrm{kV}(\mathrm{i}=10 \mu \mathrm{A})$ with a background electrolyte of $25 \mathrm{mM}$ ammonium acetate, $\mathrm{pH}$ 6.5. 
Table A-7. Separation efficiency per meter $^{\mathrm{a}}$ at pH 6.5 (CE-VSSI-MS vs CE-UV)

\begin{tabular}{|c|c|c|}
\hline & CE-VSSI-MS $^{b}$ & CE-UV ${ }^{c}$ \\
\hline & Plates (RSD, $n=3)^{\mathrm{d}}$ & Plates (RSD, $n=3$ ) \\
\hline Pindolol & $70,000(40)$ & $80,000(10)$ \\
\hline Acebutolol & $80,000(20)$ & $80,000(20)$ \\
\hline Somatostatin & $11,000(90)$ & $10,000(60)$ \\
\hline Oxytocin & $30,000(40)$ & $40,000(40)$ \\
\hline Ubiquitin & $10,000(50)$ & $17,500(5)$ \\
\hline Trypsin inhibitor & $30,000(40)$ & $17,000(2)$ \\
\hline
\end{tabular}

${ }^{a}$ Distance to detector is $40 \mathrm{~cm}$.

${ }^{b}$ Values for peak width were obtained with 2 significant figures.

${ }^{c}$ Values for peak width were obtained with 4 significant figures.

${ }^{d}$ Calculated by determining the width at base $(\mathrm{w})$ as $\mathrm{N}=16 \mathrm{t}^{2} / \mathrm{w}^{2}$ 

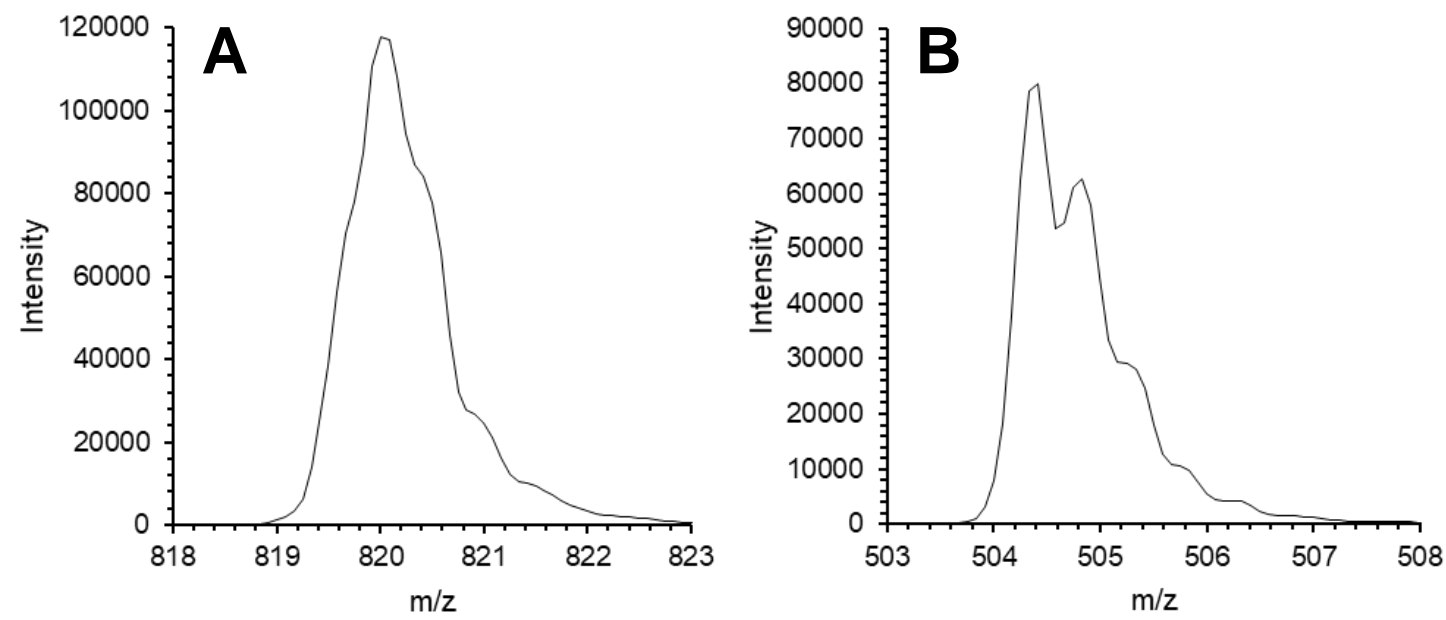

Figure A-15. Mass spectra for peptides, $\mathrm{pH}$ 6.5. The mass spectra of the isotopic envelope for the +2 charge state for $(A)$ somatostatin and (B) oxytocin is shown. Separation was achieved with a $40 \mathrm{~cm}$ (total and effective length), $50 \mu \mathrm{m}$ i.d. capillary at an applied voltage of $+10 \mathrm{kV}$ ( $\mathrm{i}$ $=10 \mu \mathrm{A}$ ) with a background electrolyte of $25 \mathrm{mM}$ ammonium acetate, $\mathrm{pH}$ 6.5. This corresponds to the data in Figure 11a. 


\section{APPENDIX B}

This section includes figures and tables that are not directly referenced in the main text

of the thesis, but were used to determine capillary conditioning, separation conditions, appropriate analytes, etc. 

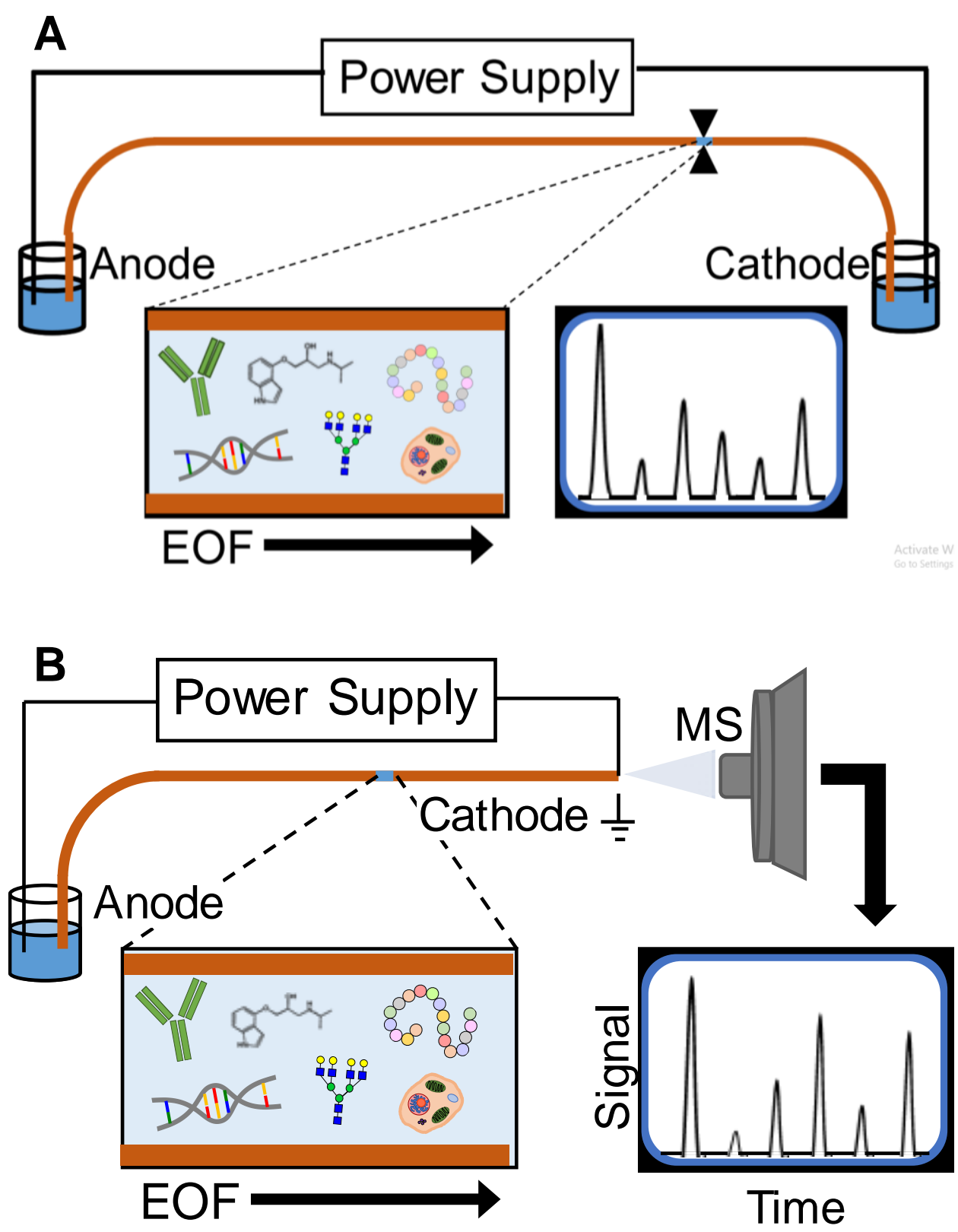

Figure B-1. Instrumental differences of CE-UV and CE-MS. Both the (A) CE-UV and (B) CEMS instrumental designs contain a high voltage power supply, anodic reservoir, and 2 electrodes (i.e. one at the anode and one at the cathode). The major difference is with the cathodic end of the capillary, which is (A) submerged in a reservoir for CE-UV and (B) open to the air for CE-MS. Because of this, the cathodic electrode is integrated into the end of the capillary for the CE-MS design. (A) Figure reproduced from: Anal. Chem. 2020, 92, 49-66. (B) Figure adapted from: Anal. Chem. 2020, 92, 49-66. 


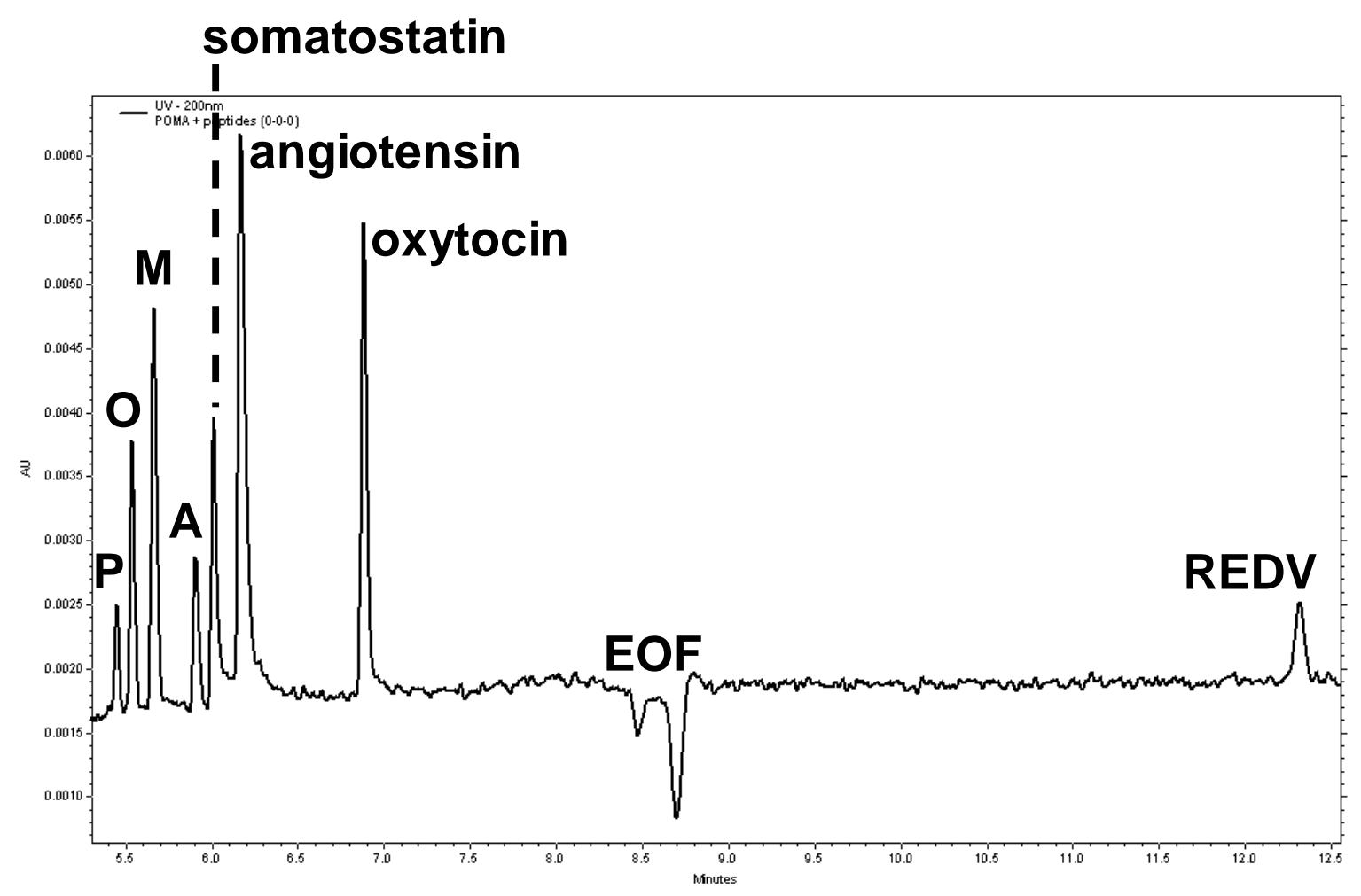

Figure B-2. Separation of $\beta$-blockers and peptides (CE-UV). CE-UV separation of $50 \mu \mathrm{M}$ pindolol, $50 \mu \mathrm{M}$ oxprenolol, $50 \mu \mathrm{M}$ metoprolol, $100 \mu \mathrm{M}$ acebutolol, $75 \mu \mathrm{M}$ somatostatin, 100 $\mu \mathrm{M}$ angiotensin, $100 \mu \mathrm{M}$ oxytocin, and $100 \mu \mathrm{M}$ REDV. Separation was achieved with a $50 \mathrm{~cm}$ (total length), $40 \mathrm{~cm}$ (effective length), $50 \mu \mathrm{m}$ i.d. capillary at an applied voltage of $+12.5 \mathrm{kV}$ (i $=10 \mu \mathrm{A}$ ) with a background electrolyte of $25 \mathrm{mM}$ ammonium acetate, $\mathrm{pH}$ 6.5.

Abbreviations: pindolol $(\mathrm{P})$, oxprenolol $(\mathrm{O})$, metoprolol $(\mathrm{M})$, acebutolol $(\mathrm{A})$, water dip/electroosmotic flow (EOF)

Finding: $\beta$-blockers and peptides fully resolve with CE-UV. 


\begin{tabular}{|c|c|}
\hline & $\begin{array}{c}\text { Time } \\
(\mathrm{RSD}, n=10)\end{array}$ \\
\hline Pindolol & $5.19(1 \%)$ \\
\hline Metoprolol & $5.38(1 \%)$ \\
\hline Acebutolol & $5.60(1 \%)$ \\
\hline Oxytocin & $6.44(2 \%)$ \\
\hline
\end{tabular}

Finding: Migration times of $\beta$-blockers vary only $2 \%$ across 10 runs with no flushes between. 


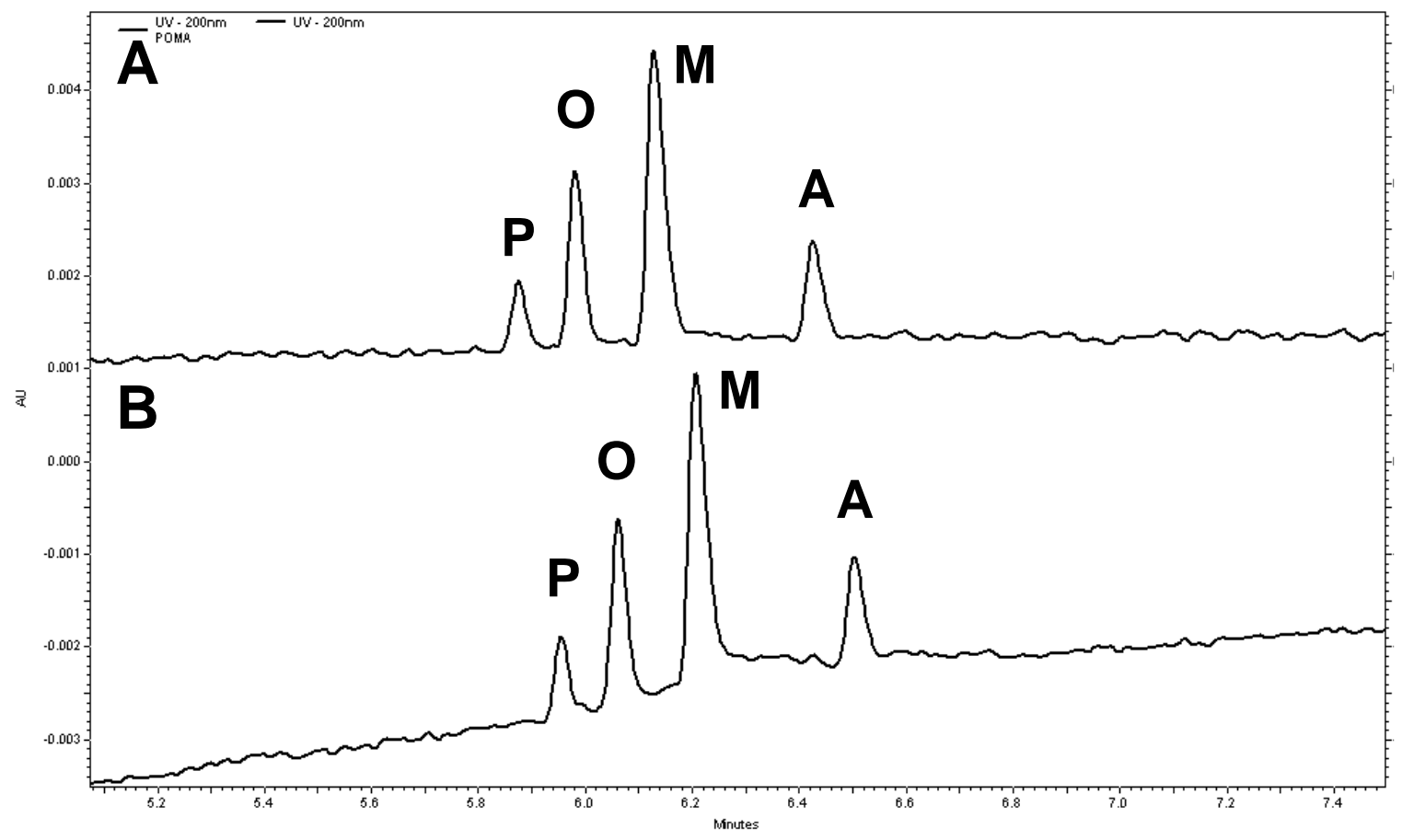

Figure B-3. Capillary stability after sitting in buffer. CE-UV separation of pindolol, oxprenolol, metoprolol, and acebutolol (A) immediately following a full flush and (B) after a full flush, sitting in buffer for 6 hours, and a 1-minute buffer flush. Separation was achieved with a $50 \mathrm{~cm}$ (total length), $40 \mathrm{~cm}$ (effective length), $50 \mu \mathrm{m}$ i.d. capillary at an applied voltage of $+12.5 \mathrm{kV}$ ( $\mathrm{i}=10$ $\mu \mathrm{A}$ ) with a background electrolyte of $25 \mathrm{mM}$ ammonium acetate, $\mathrm{pH} 6.5$.

Abbreviations: pindolol $(\mathrm{P})$, oxprenolol $(\mathrm{O})$, metoprolol $(\mathrm{M})$, acebutolol $(\mathrm{A})$

Finding: Migration times only shift by $\sim 2 \%$ after the capillary sits unused in buffer for 6 hours. 
Table B-2. Effect of an abbreviated flush at pH 6.5

\begin{tabular}{lcc}
\hline & $\begin{array}{c}\text { Abbreviated flush } \\
\text { (RSD, } \boldsymbol{n}=\mathbf{3})\end{array}$ & $\begin{array}{c}\text { Full flush }^{\text {b }} \\
\text { (RSD, } \boldsymbol{n}=\mathbf{3})\end{array}$ \\
\cline { 2 - 3 } Pindolol & $4.11(0.1)$ & $4.11(0.06)$ \\
Acebutolol & $4.37(0.1)$ & $4.36(0.09)$ \\
Somatostatin & $4.54(0.1)$ & $4.56(0.05)$ \\
Angiotensin & $4.87(0.1)$ & $5.08(0.2)$ \\
\hline
\end{tabular}

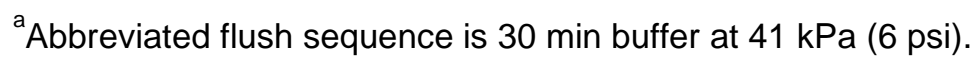

${ }^{\mathrm{b}}$ Full flush sequence is $60 \mathrm{~min} 0.1 \mathrm{~N}$ ammonium hydroxide, $10 \mathrm{~min}$ water, 30 min buffer all at $41 \mathrm{kPa}(6 \mathrm{psi})$.

Finding: Migration times are similar with an abbreviated flush and full flush on a used capillary. 
Table B-3. Effect of voltage, flow rate, and pH on ionization

\begin{tabular}{|c|c|c|c|c|}
\hline & \multicolumn{2}{|c|}{$\mathrm{pH} 6.5^{\mathrm{a}}(\mathrm{RSD}, n=3)$} & \multicolumn{2}{|c|}{$\mathrm{pH} 4^{\mathrm{b}}(\mathrm{RSD}, n=3)$} \\
\hline & Time & Intensity & Time & Intensity \\
\hline $10 \mathrm{kV}$ & $4.67(15)$ & $6.88 \mathrm{E}+06(10)$ & $2.03(6)$ & $1.32 \mathrm{E}+07(26)$ \\
\hline $10 \mathrm{kV}+0.9 \mathrm{psi}$ & $2.40(17)$ & $7.68 \mathrm{E}+06(46)$ & $3.01(6)$ & $9.57 \mathrm{E}+06(21)$ \\
\hline $0.9 \mathrm{psi}$ & $4.04(29)$ & $2.51 \mathrm{E}+04(112)$ & $1.64(4)$ & $8.63 \mathrm{E}+06(55)$ \\
\hline $1.8 \mathrm{psi}$ & $2.35(15)$ & $3.14 \mathrm{E}+03(74)$ & $2.28(4)$ & $2.05 \mathrm{E}+07(50)$ \\
\hline
\end{tabular}

${ }^{a}$ Background electrolyte was $25 \mathrm{mM}$ ammonium acetate

${ }^{\mathrm{b}}$ Background electrolyte was $25 \mathrm{mM}$ acetic acid

Finding 1: Ionization is slightly higher in $\mathrm{pH} 4$.

Finding 2: Ionization improves when a voltage is applied. 

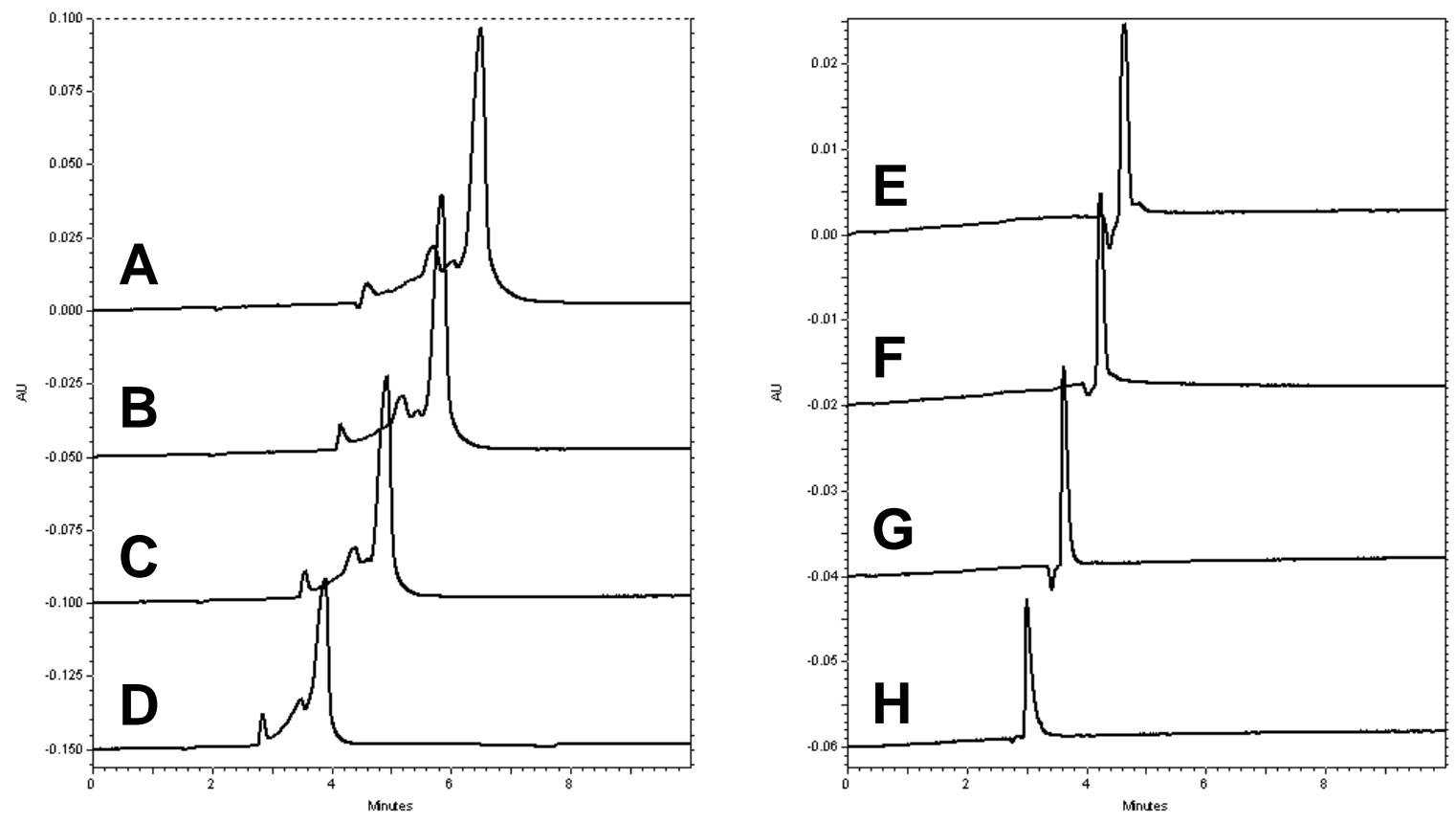

Figure B-4. Effect of ionic strength on trypsin inhibitor and ubiquitin adsorption. CE-UV separation of $(A-D)$ trypsin inhibitor and $(E-H)$ ubiquitin with background electrolytes of $(A, E)$ $100 \mathrm{mM},(\mathrm{B}, \mathrm{F}) 75 \mathrm{mM},(\mathrm{C}, \mathrm{G}) 50 \mathrm{mM}$, and (D, H) $25 \mathrm{mM}$ ammonium acetate, pH 6.5. Separations were achieved with a $50 \mathrm{~cm}$ (total length), $40 \mathrm{~cm}$ (effective length), $50 \mu \mathrm{m}$ i.d. capillary at an applied voltage of $+12.5 \mathrm{kV}$. Note: Peak shifting is caused by a difference in electroosmotic flow from changing the ionic strength (i.e. lower ionic strength $=$ faster electroosmotic flow).

Finding 1: With ammonium acetate as the background electrolyte at concentrations as low as 25 and $50 \mathrm{mM}$, there was no evidence of adsorption to capillary wall by trypsin inhibitor and ubiquitin, respectively. 


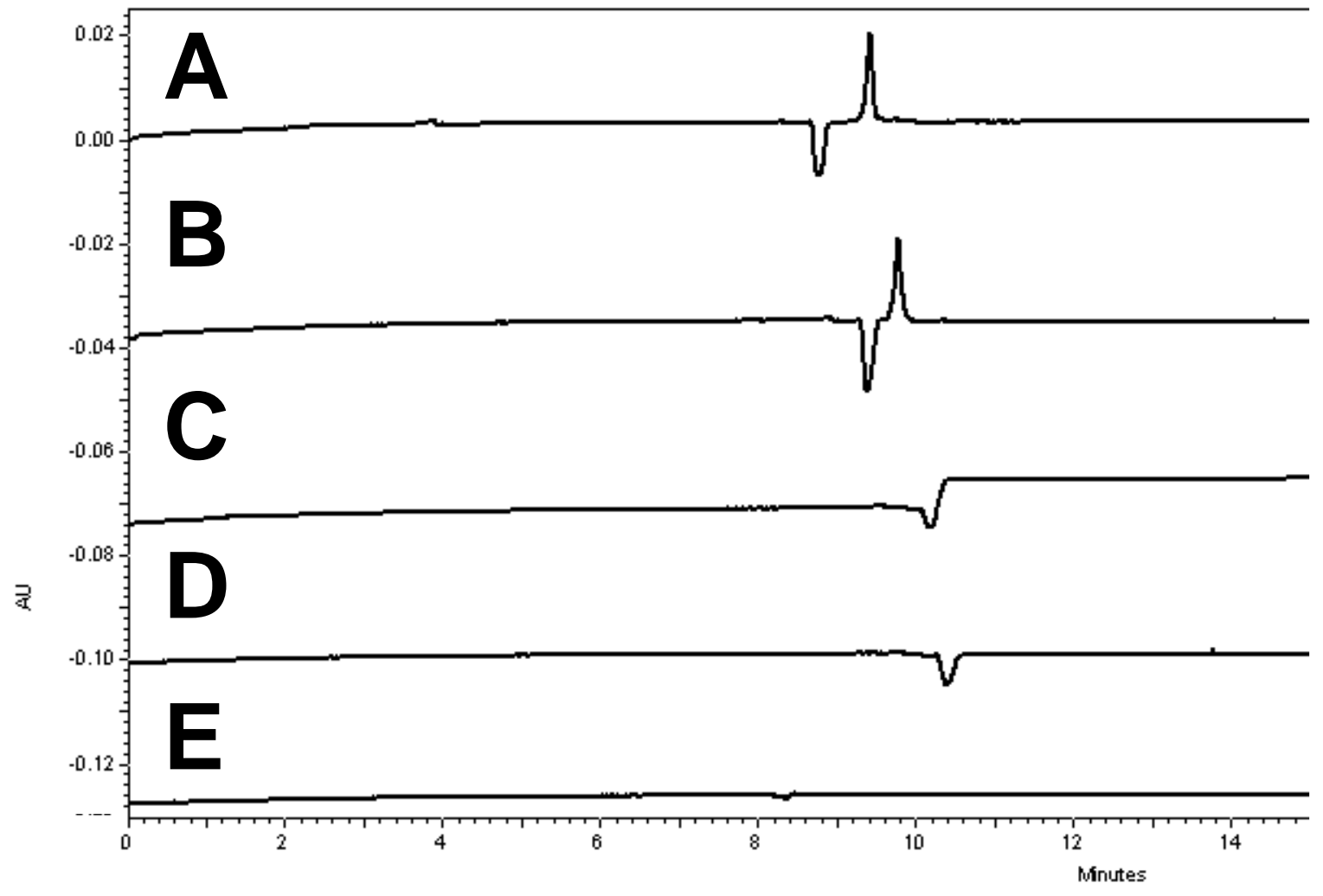

Figure B-5. Effect of ionic strength on ribonuclease $A$ adsorption. CE-UV separation ribonuclease A with background electrolytes of (A) $50 \mathrm{mM}$ phosphate acetate, $\mathrm{pH} \mathrm{7,} \mathrm{(B)} 100$ $\mathrm{mM},(C) 75 \mathrm{mM}$, (D) $50 \mathrm{mM}$, and (E) $25 \mathrm{mM}$ ammonium acetate, $\mathrm{pH}$ 6.5. The sample was 50 $\mu \mathrm{M}$ ribonuclease $A$ dissolved in $25 \mathrm{mM}$ ammonium acetate. Theoretical plate counts are $(A)$ 89,000 and (B) 82,000. Separations were achieved with a $50 \mathrm{~cm}$ (total length), $40 \mathrm{~cm}$ (effective length), $50 \mu \mathrm{m}$ i.d. capillary at an applied voltage of $+12.5 \mathrm{kV}$. Notes: Peak shifting is caused by a difference in electroosmotic flow from changing the ionic strength (i.e. lower ionic strength $=$ faster electroosmotic flow). The dip in (A-D) is due to a difference in the ionic strength of the background electrolyte and the sample.

Finding 1: Ribonuclease A requires $100 \mathrm{mM}$ ammonium acetate to not adsorb to the capillary walls. 


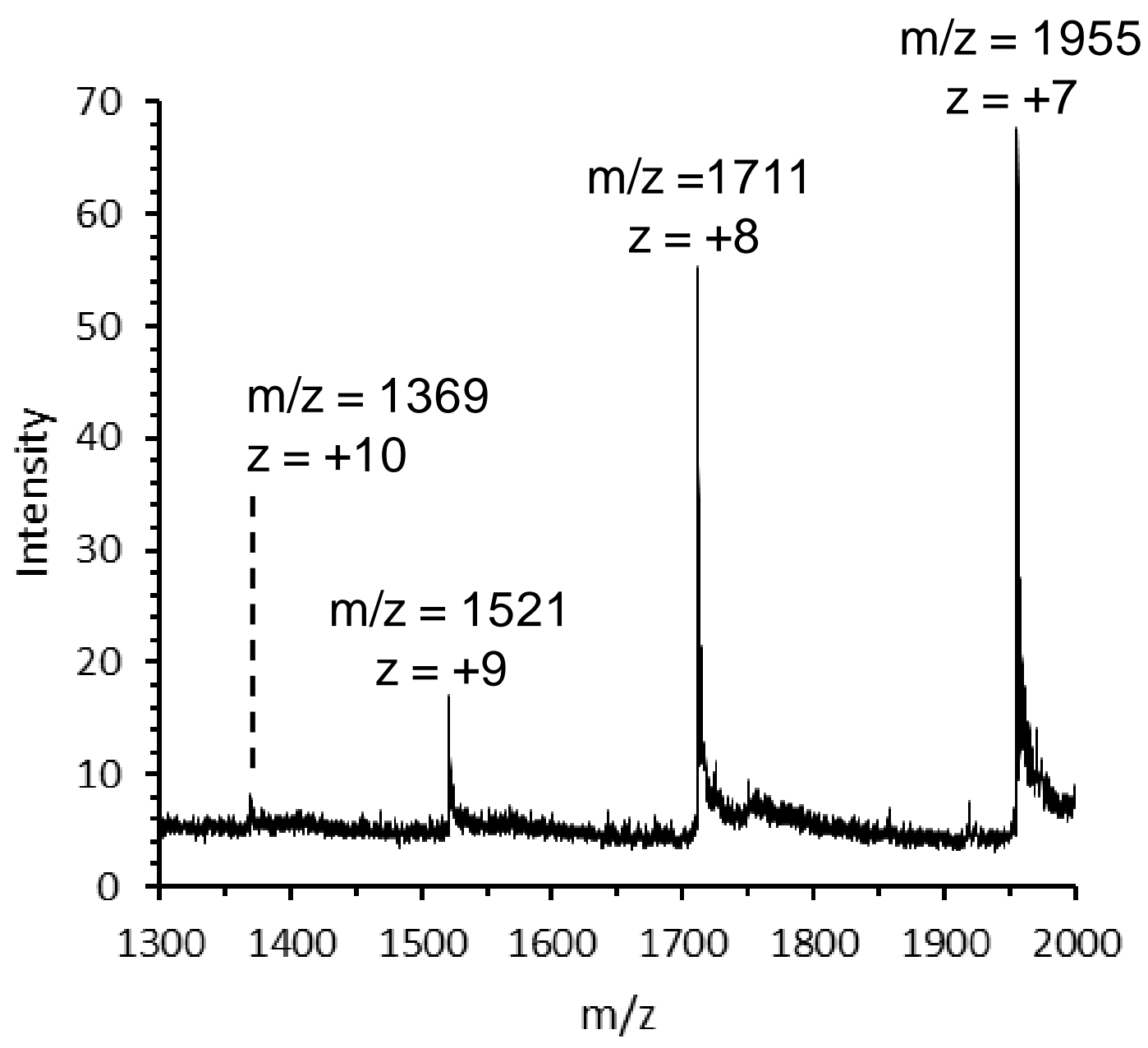

Figure B-6. Mass spectra for ribonuclease A. The mass spectra of the dominant charge states of ribonuclease $A$ is shown. Data was collected on an LTQ XL mass spectrometer. 


\section{APPENDIX C}

This section includes tables of raw data that correspond to tables and figures in Appendix A and Appendix B. 


\begin{tabular}{lcccccc}
\hline \multicolumn{2}{l}{ Table C-1. Raw data for capillary conditioning with normal flush } \\
\hline \\
\cline { 2 - 6 } Run \# & pindolol & oxprenolol & metoprolol & \multicolumn{3}{c}{ acebutolol } \\
\cline { 2 - 7 } & time & time & time & time & width & plates \\
& 5.45 & 5.537 & 5.662 & 5.904 & 0.0322 & 186247.615 \\
& 5.396 & 5.479 & 5.604 & 5.842 & 0.0306 & 201924.965 \\
average & 5.358 & 5.446 & 5.567 & 5.804 & 0.0317 & 185714.6 \\
SD & 5.401333 & 5.487333 & 5.611 & 5.85 & 0.0315 & 191295.727 \\
RSD & 0.046231 & 0.046069 & 0.047885 & 0.050478 & 0.000818535 & 9209.04782 \\
\hline
\end{tabular}

${ }^{a}$ Normal flush sequence is $60 \mathrm{~min} 1 \mathrm{~N}$ sodium hydroxide, $10 \mathrm{~min}$ water, $30 \mathrm{~min}$ buffer all at $41 \mathrm{kPa}(6 \mathrm{psi})$.

Note: Raw data for Table A-1 imported from Excel. 
Table C-2. Raw data for capillary conditioning with $0.1 \mathrm{~N} \mathrm{NH4OH}$ flush ${ }^{\mathrm{a}}$

\begin{tabular}{lcccccc}
\hline & pindolol & oxprenolol & metoprolol & \multicolumn{3}{c}{ acebutolol } \\
\cline { 2 - 6 } Run \# & time & time & time & time & width & plates \\
$\mathbf{2 6}$ & 4.696 & 4.783 & 4.875 & 5.096 & 0.0419 & 81948.4149 \\
$\mathbf{2 7}$ & 4.646 & 4.729 & 4.825 & 5.046 & 0.0423 & 78835.8079 \\
$\mathbf{2 8}$ & 4.621 & 4.708 & 4.796 & 5.017 & 0.0399 & 87589.5259 \\
& & & & & & \\
average & 4.654333 & 4.74 & 4.832 & 5.053 & 0.041366667 & 82791.2495 \\
SD & 0.038188 & 0.038691 & 0.039962 & 0.039962 & 0.00128582 & 4437.30463 \\
RSD & 0.820486 & 0.816268 & 0.827038 & 0.790866 & 3.108348352 & 5.35962998 \\
\hline
\end{tabular}

${ }^{\mathrm{a}} 0.1 \mathrm{~N}$ ammonium hydroxide flush sequence is $60 \mathrm{~min} 0.1 \mathrm{~N}$ ammonium hydroxide, $10 \mathrm{~min}$ water, $30 \mathrm{~min}$ buffer all at $41 \mathrm{kPa}(6 \mathrm{psi})$.

Note: Raw data for Table A-1 imported from Excel. 


\begin{tabular}{lcccccc}
\multicolumn{2}{l}{ Table C-3. Raw data for capillary conditioning with $\mathbf{1 ~ N ~ N H 4 O H}$ flush } \\
\hline \\
\cline { 2 - 7 } Run \# & pindolol & oxprenolol & metoprolol & \multicolumn{3}{c}{ acebutolol } \\
\cline { 2 - 7 } $\mathbf{1 5}$ & time & time & time & time & width & plates \\
$\mathbf{1 6}$ & 4.225 & 4.304 & 4.383 & 4.579 & 0.0488 & 48776.5869 \\
$\mathbf{1 7}$ & 4.237 & 4.321 & 4.4 & 4.604 & 0.0489 & 49109.1793 \\
average & 4.242 & 4.321 & 4.404 & 4.608 & 0.0427 & 64517.7117 \\
SD & 4.234667 & 4.315333 & 4.395667 & 4.597 & 0.0468 & 54134.4926 \\
RSD & 0.008737 & 0.009815 & 0.01115 & 0.015716 & 0.003551056 & 8993.66905 \\
\hline
\end{tabular}

${ }_{1} 1 \mathrm{~N}$ ammonium hydroxide flush sequence is $60 \min 1 \mathrm{~N}$ ammonium hydroxide, 10 min water, 30 min buffer all at $41 \mathrm{kPa}$ (6 psi).

Note: Raw data for Table A-1 imported from Excel. 


\section{Table C-4. Raw data for capillary conditioning with buffer flush ${ }^{\mathrm{a}}$}

\begin{tabular}{lcccccc}
\hline & pindolol & oxprenolol & metoprolol & \multicolumn{3}{c}{ acebutolol } \\
\cline { 2 - 7 } Run \# & time & time & time & time & width & plates \\
$\mathbf{1 0}$ & 8.908 & 9.217 & 9.567 & 10.367 & 0.0743 & 107854.516 \\
$\mathbf{1 1}$ & 8.558 & 8.854 & 9.183 & 9.938 & 0.0751 & 97012.54 \\
$\mathbf{1 2}$ & 8.262 & 8.546 & 8.85 & 9.571 & 0.0701 & 103273.373 \\
& & & & & & \\
average & 8.576 & 8.872333 & 9.2 & 9.958667 & 0.073166667 & 102713.476 \\
SD & 0.323376 & 0.335875 & 0.358802 & 0.398402 & 0.002685765 & 5442.63025 \\
RSD & 3.770708 & 3.78565 & 3.900024 & 4.000558 & 3.670749354 & 5.29884728 \\
\hline
\end{tabular}

${ }^{\mathrm{a}}$ Buffer flush sequence is $30 \mathrm{~min}$ buffer at $41 \mathrm{kPa}(6 \mathrm{psi})$.

Note: Raw data for Table A-1 imported from Excel. 


\section{Table C-5. Raw data for capillary conditioning with $\mathrm{HCl}$ flush ${ }^{\mathrm{a}}$}

\begin{tabular}{lcccccc}
\hline & pindolol & oxprenolol & metoprolol & \multicolumn{3}{c}{ acebutolol } \\
\cline { 2 - 6 } Run \# & time & time & time & time & width & plates \\
$\mathbf{2 0}$ & 8.787 & 9.075 & 9.412 & 10.175 & 0.0636 & 141796.127 \\
$\mathbf{2 1}$ & 8.338 & 8.608 & 8.917 & 9.621 & 0.0711 & 101440.409 \\
$\mathbf{2 2}$ & 7.987 & 8.233 & 8.517 & 9.167 & 0.086 & 62945.8822 \\
& & & & & & \\
average & 8.370667 & 8.638667 & 8.948667 & 9.654333 & 0.073566667 & 102060.806 \\
SD & 0.400999 & 0.421837 & 0.44834 & 0.504826 & 0.0114019 & 39428.7833 \\
RSD & 4.790528 & 4.883125 & 5.010127 & 5.22901 & 15.49873189 & 38.6326394 \\
\hline
\end{tabular}

${ }^{\mathrm{a}}$ Hydrochloric acid flush sequence is $60 \min 1 \mathrm{M} \mathrm{HCl}, 10$ min water, 30 min buffer all at $41 \mathrm{kPa}$ (6 psi).

Note: Raw data for Table A-1 imported from Excel. 


\section{Table C-6. Raw data for migration times and efficiencies with abbreviated flush ${ }^{\text {a }}$}

\begin{tabular}{|c|c|c|c|c|c|c|c|c|c|c|c|c|}
\hline \multirow[b]{2}{*}{ Run \# } & \multicolumn{3}{|c|}{ pindolol } & \multicolumn{3}{|c|}{ acebutolol } & \multicolumn{3}{|c|}{ somatostatin } & \multicolumn{3}{|c|}{ angiotensin } \\
\hline & time & width & plates & time & width & plates & time & width & plates & time & width & plates \\
\hline & 4.117 & 0.0257 & 142169.11 & 4.371 & 0.0292 & 124138.266 & 4.533 & 0.0368 & 84059.26 & 4.867 & 0.0347 & 108986.701 \\
\hline & 4.108 & 0.0249 & 150789.79 & 4.362 & 0.0287 & 127972.688 & 4.542 & 0.0362 & 87214.14 & 4.875 & 0.0344 & 111260.785 \\
\hline & 4.108 & 0.0242 & 159639.33 & 4.362 & 0.0293 & 122785.15 & 4.546 & 0.0362 & 87367.82 & 4.879 & 0.0353 & 105833.215 \\
\hline average & 4.111 & & 150866.08 & 4.365 & & 124965.37 & 4.540333 & & 86213.74 & 4.873667 & & 108693.57 \\
\hline SD & 0.005196 & & 8735.35977 & 0.005196 & & 2690.85701 & 0.006658 & & 1867.4138 & 0.00611 & & 2725.63278 \\
\hline RSD & 0.126396 & & 5.79014173 & 0.119041 & & 2.15328218 & 0.146648 & & 2.16602811 & 0.12537 & & 2.50763026 \\
\hline
\end{tabular}

${ }^{a}$ Abbreviated flush sequence is $30 \mathrm{~min}$ buffer at $41 \mathrm{kPa}$ (6 psi).

Note: Raw data for Table B-2 imported from Excel. 


\begin{tabular}{|c|c|c|c|c|c|c|c|c|c|c|c|c|}
\hline \multirow{5}{*}{ Run \# } & \multicolumn{3}{|c|}{ pindolol } & \multicolumn{3}{|c|}{ acebutolol } & \multicolumn{3}{|c|}{ somatostatin } & \multicolumn{3}{|c|}{ angiotensin } \\
\hline & time & width & plates & time & width & plates & time & width & plates & time & width & plates \\
\hline & 4.104 & 0.0252 & 146934.37 & 4.354 & 0.0286 & 128396.903 & 4.563 & 0.0389 & 76227.47 & 5.083 & 0.1859 & 4141.81984 \\
\hline & 4.104 & 0.0251 & 148107.49 & 4.358 & 0.0287 & 127738.091 & 4.563 & 0.039 & 75837.06 & 5.071 & 0.164 & 5296.74774 \\
\hline & 4.108 & 0.0255 & 143777.28 & 4.362 & 0.029 & 125338.673 & 4.567 & 0.0383 & 78772.43 & 5.096 & 0.1809 & 4396.342 \\
\hline average & 4.105333 & & 146273.05 & 4.358 & & 127157.89 & 4.564333 & & 76945.65 & 5.083333 & & 4611.64 \\
\hline SD & 0.002309 & & 2239.57211 & 0.004 & & 1609.55553 & 0.002309 & & 1594.03247 & 0.012503 & & 606.818267 \\
\hline RSD & 0.056254 & & 1.53109008 & 0.091785 & & 1.2657929 & 0.050597 & & 2.07163422 & 0.245967 & & 13.1584149 \\
\hline
\end{tabular}

${ }^{\mathrm{a}}$ Full flush sequence is $0.1 \mathrm{~N}$ ammonium hydroxide flush sequence is $60 \min 0.1 \mathrm{~N}$ ammonium hydroxide, $10 \mathrm{~min}$ water, $30 \mathrm{~min}$ buffer all at $41 \mathrm{kPa}$ (6 psi).

Note: Raw data for Table B-2 imported from Excel. 